PACS numbers: 62.20.Fe, 64.70.Kb, 65.70.+y, 81.30. Hd, 81.30.Kf, 81.30.Mh

\title{
Shape Memory Effect Driven by Diffusionless and Diffusional Transformations at Elevated Temperatures
}

\author{
G. S. Firstov, Yu. N. Koval, and J. Van Humbeeck ${ }^{*}$ \\ G. V. Kurdyumov Institute for Metal Physics, N.A.S.U., \\ 36 Academician Vernadsky Blvd., \\ UA-03680 Kyyiv-142, Ukraine \\ *K.U.Leuven-MTM, \\ Kasteelpark Arenberg 44, \\ B-3001 Leuven (Heverlee), Belgium
}

Several alloy systems can be selected for high-temperature shape-memory alloys, defined as alloys with stable reverse martensitic-transformation temperatures above $100^{\circ} \mathrm{C}$. However, due to the lack of minimum quality standards for stability, ductility, functional behaviour, and reliability, no successful applications have been realised so far. Nevertheless, research on high-temperature shapememory alloys (HTSMA) is an important topic not only for scientific reasons but also due to the market pull. This paper reviews some novel HTSMA systems showing shape-memory effect at elevated temperatures driven by martensitic (diffusionless) and diffusional transformations.

Можна навести певну кількість систем сплавів, що можуть бути визначені, як високотемпературні сплави з ефектом пам'яті фрорми, що в свою чергу визначаються як сплави зі стабільними температурами зворотного мартенситного перетворення, вищими за $100^{\circ} \mathrm{C}$. На жаль, невідомо жодного випадку успішного застосування високотемпературних сплавів 3 ефектом пам'яті форми, завдяки відсутності вимог щодо їх стабільності, пластичності, фрункціональної поведінки та надійності. Не зважаючи на це, дослідження високотемпературних сплавів з ефектом пам'яті форми є важливим не тільки з точки зору фундаментальної науки, але й завдяки вимогам ринку. Дана робота присвячена розглядові деяких новітніх систем високотемпературних сплавів з ефектом пам'яті форми, що зумовлений мартенситним (бездифузійним) та дифузійним перетвореннями.

Можно привести достаточное количество систем сплавов, которые подпадают под определение высокотемпературных сплавов с эффректом памяти формы - сплавов, в которых стабильное обратное мартенситное превращение протекает при температурах выше $100^{\circ} \mathrm{C}$. К сожалению, до сих пор 
не известно ни одного случая успешного применения высокотемпературных сплавов с эффектом памяти формы в силу отсутствия требований к их стабильности, пластичности, функциональному поведению и надежности. Тем не менее, исследования высокотемпературных сплавов с эффректом памяти формы являются важными не только с точки зрения фундаментальной науки, но и благодаря требованиям рынка. Настоящая работа посвящена рассмотрению некоторых новейших систем высокотемпературных сплавов с эфффектом памяти фрормы, который определяется как мартенситным (бездиффузионным), так и диффузионными превращениями.

Key words: shape memory effect, high-temperature martensitic and diffusional transformations.

(Received July 24, 2002)

\section{MARTENSITIC TRANSFORMATION AND SHAPE MEMORY EFFECT IN Zr-BASED INTERMETALLIC COMPOUNDS}

\subsection{Introduction}

It is known that the $B 2$ equiatomic intermetallic compounds of $\mathrm{Zr}$ ( $\mathrm{ZrCo}$ based [1], ZrCu [2], ZrRh [3]) undergo a martensitic transformation (MT) with wide temperature hysteresis. The first reports about the results of the investigations of the MT in Zr-based equiatomic intermetallics belong to Wang [4,5]. It was shown that the high-temperature $B 2$ phase of $\mathrm{ZrPd}$ and ZrRh compounds undergo on cooling the MT very close to the case of TiNi. However, the lack of systematic investigations of MT in $\mathrm{Zr}$-based intermetallics (in contrast to TiNi and related compounds) existed until the series of works of Harris with co-authors [1,6-11]. They have investigated the constitution of $\mathrm{ZrCo}, \mathrm{ZrFe}, \mathrm{ZrNi}, \mathrm{ZrCo}_{(1-x)} \mathrm{Ni}_{x}, \mathrm{ZrCu}$ alloys, their mechanical properties $[7,8]$, crystal structure (Table 1), martensitic transition temperatures $[1,8,10,11]$ and carried out the magnetic susceptibility measurements [9]. Then, the crystal structure for ZrRh martensite was defined as FeB-type [12]. Later, Semenova and Kudryavtsev [13] detected the complete SME for ZrRh alloy. The structure of martensites of ZrRh and Zrlr alloys was redefined as B19'-type (Table 5) [3,13]. Koval, Firstov and Kotko have found the nearly complete SME for $\mathrm{ZrCu}$ [2]. Alloying and thermal cycling result in the changes of thermal and hysteretic properties and in the increase of shape recovery ratio up to $100 \%$ for $\mathrm{ZrCu}$-based alloys $[2,14,15]$. Crystal structure of $\mathrm{ZrCu}$ martensites was determined as $B 19^{\prime}$-type $[16,17]$ similar to TiNi $[18,19]$ and ZrRh, ZrIr [13] (Table 1). For $\mathrm{ZrRu}_{(1-x)} \mathrm{Pd}_{x}$ martensites, the authors of [20] claimed that its crystal structure belongs to the CrB-type (Table 5). The description of the crystal structure of the crystallized from amorphous state $\mathrm{ZrCu}_{25} \mathrm{Ni}_{25}$ alloy [21] includes a mixture of two different combinations of cubic NiZr and $\mathrm{CuZr}$ units (one is like the cubic $\mathrm{Cu}_{2} \mathrm{MnAl}$ Heusler phase (obviously austenitic) 
TABLE 1. Anisotropic temperature factors $(\beta)$ and equivalent isotropic factors $(B)$ for the $C m$ superstructure. Scale factor $s=1.04 \cdot 10^{-5}$.

\begin{tabular}{c|c|c|c|c|c|c|c}
\hline Atom & $\beta_{11}$ & $\beta_{22}$ & $\beta_{33}$ & $\beta_{12}$ & $\beta_{13}$ & $\beta_{23}$ & $B\left(\AA^{2}\right)$ \\
\hline $\mathrm{Zr}$ & 0.09851 & 0.02423 & 0.07383 & 0.00000 & -0.04203 & 0.00000 & 1.01 \\
$\mathrm{Cu}$ & 0.04378 & 0.03796 & -0.02738 & 0.00000 & -0.05496 & 0.00000 & 0.96 \\
\hline
\end{tabular}

TABLE 2. Atomic positions in the unit cell for the $\mathrm{Cm}$ superstructure. Lattice parameters: $a=0.63374 \mathrm{~nm} ; b=0.85636 \mathrm{~nm} ; c=0.53453 \mathrm{~nm} ; \beta=105.58^{\circ}$.

\begin{tabular}{lcccc|c|c|c|c|c|c}
\hline & position & $x$ & $y$ & $z$ & & position & $x$ & $y$ & $z$ \\
\hline $\mathrm{Zr}$ & $2 \mathrm{a}$ & 0.0 & 0.0 & 0.0 & $\mathrm{Cu}$ & $2 \mathrm{a}$ & 0.69309 & 0.0 & 0.67810 \\
$\mathrm{Zr}$ & $2 \mathrm{a}$ & 0.56362 & 0.0 & 0.09805 & $\mathrm{Cu}$ & $2 \mathrm{a}$ & 0.20635 & 0.0 & 0.63303 \\
$\mathrm{Zr}$ & $4 \mathrm{~b}$ & 0.45808 & 0.25 & 0.72281 & $\mathrm{Cu}$ & $2 \mathrm{a}$ & 0.29125 & 0.25 & 0.17479 \\
\hline
\end{tabular}

TABLE 3. Anisotropic temperature factors $(\beta)$ and equivalent isotropic factors $(B)$ for the $\mathrm{Cm}$ superstructure. Scale factor: $s=5.57 \cdot 10^{-4}$.

\begin{tabular}{ccc|c|c|c|c|c|c}
\hline Atom & $\beta_{11}$ & $\beta_{22}$ & $\beta_{33}$ & $\beta_{12}$ & $\beta_{13}$ & $\beta_{23}$ & $B\left(\AA^{2}\right)$ \\
\hline $\mathrm{Zr}$ & 0.58029 & 0.02100 & 0.03022 & 0.00000 & -0.01541 & 0.00000 & 0.66 \\
$\mathrm{Cu}$ & -0.04882 & 0.00370 & 0.02199 & 0.00000 & 0.05117 & 0.00000 & 0.55 \\
\hline
\end{tabular}

TABLE 4. Atomic positions in the unit cell for the $P 2_{1} / m$ martensite. Lattice parameters: $a=0.32823 \mathrm{~nm} ; b=0.41484 \mathrm{~nm} ; c=0.52495 \mathrm{~nm} ; \beta=103.75^{\circ}$.

\begin{tabular}{c|c|c|c|c|c|c|c|c|c}
\hline & position & $x$ & $y$ & $z$ & & position & $x$ & $y$ & $z$ \\
\hline $\mathrm{Zr}$ & $2 \mathrm{e}$ & 0.38273 & 0.25 & 0.20251 & $\mathrm{Cu}$ & $2 \mathrm{e}$ & 0.11754 & 0.0 & 0.63921 \\
\hline
\end{tabular}

and the other is tetragonal). So, there are several definitions of the martensitic crystal structures of Zr-based equiatomic intermetallics. Our aim is to show the important differences of $\mathrm{Zr}$-based equiatomic intermetallics as a novel high temperature shape memory alloys from existing shape memory alloys (SMA), especially TiNi and related compounds.

The Zr-base alloys used in this investigation were arc-melted from iodide zirconium, electrolytic copper, nickel and cobalt in a pregettered argon atmosphere. Good chemical homogeneity was confirmed by X-ray microanalysis (JCXA-733 (Superprobe)). The changes of the hysteresis loops and the characteristic temperatures of the MT were determined by ac electrical resistivity measurements. SME was examined by a bending technique which is described in [22]. Heats of MT were detected with the 
help of Du Pont 910 and Netzcsh 404 differential scanning calorimeters in the $-150^{\circ} \mathrm{C} \leftrightarrow+600^{\circ} \mathrm{C}$ and $20^{\circ} \mathrm{C} \leftrightarrow 1000^{\circ} \mathrm{C}$ temperature ranges respectively. Volume changes during MT were determined using Du Pont TMA 934 and THETA DILATRONIC-III dilatometers. Analysis of crystal structure was performed using the X-ray diffractometry (DRON-1.0, CuK $K_{\alpha}$ ) at room temperature and Rietveld refinement (DBWS 9006PC computer program-new version [23]). The transmission electron microscopy (TEM) investigations were performed in a CM20 Twin instrument with a $\mathrm{LaB}_{6}$ filament and allowing for $\pm 60^{\circ}$ and $\pm 30^{\circ}$ tilt ranges around the primary and secondary tilt axes.

\subsection{Crystal Structure and Martensite Transformation Mechanism}

We are starting with the description of the structure of the $\mathrm{ZrCu}$ martensites.

As cast as well as homogenised samples indeed reveal extremely small product plates or variants as shown in Fig. 1a, including the smallest available selected area aperture. Most of the observed SAED patterns in these samples are relatively dense and have rather short first order reciprocal vectors, indicating that they originate from plates with the largest unit cell. Twinned patterns are also often observed. In Fig. 1 some examples of such SAED patterns, obtained from several extensive tilting experiments and combined from different plates, are shown. Keeping the monoclinic symmetry in mind and making the conventional choice for the monoclinic angle between axes $a$ and $c$, these diffraction patterns and their relative orientations, shown in the upper right corner of each pattern, yield the following unit cell dimensions for the large structure:

$$
a=0.64 \mathrm{~nm}, \quad b=0.79 \mathrm{~nm}, c=0.52 \mathrm{~nm} \text {, and } \beta=105.8^{\circ} \text {. }
$$

The choice of $c$-axis was taken in reference to the twin planes inside a given plate, the streaking in Figs. $1 \mathrm{c}$ and 1d corresponding with the aperiodic nature of these twins. This result is clearly different form the existing suggestion for the large martensite structure [17]. All reflections follow the conditions $h+k=2 n$ irrespective of I which corresponds with the monoclinic space groups $\mathrm{C} 2, \mathrm{Cm}$ and $\mathrm{C} 2 / \mathrm{m}$. The present interpretation allows for the indexing of all reflections and zones as given in Fig. 1. The pattern in Fig. 1c is now [110] zone whereas in the earlier description it was taken as an [010] zone.

As mentioned above, most of the basic SAED patterns reveal short reciprocal vectors. Nevertheless, in some cases some of the low intensity reflections disappear when the sample or selected area aperture is slightly shifted, indicating the existence of a small basic and a large superstructure based on the same lattice. This is shown for the [101], [111] and [112] zones (large cell indexation) in Fig. 2 where the reflections with 

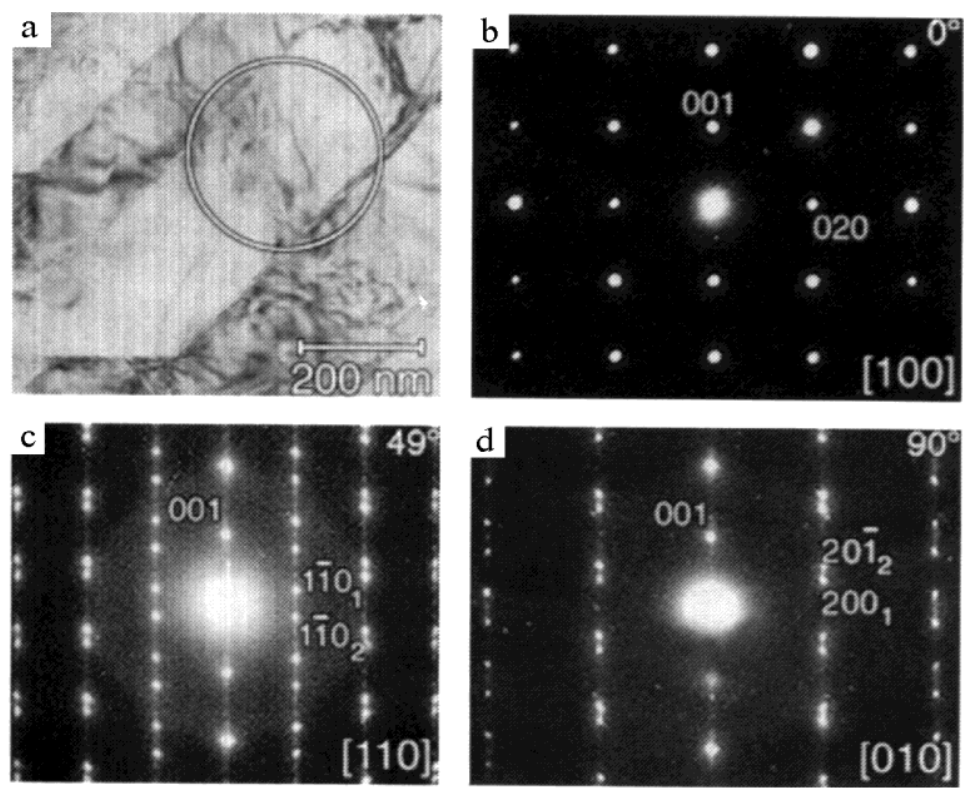

Figure 1. TEM image revealing the small martensite variant (a); different SAED patterns belonging to CM structure and indexed according to the new choice of unit cell (b), (c) and (d); Tilt angles in respect to (b) are also given in the upper right corners.

$h=2 n+1$ and $k=2 n+1$ exist in the patterns of the basic structure (upper row). [100] and [010] zones are the same for both structures. Based on this observation a basic unit cell can be constructed which is again monoclinic but with a $P 2_{1} / m$ space group and lattice parameters,
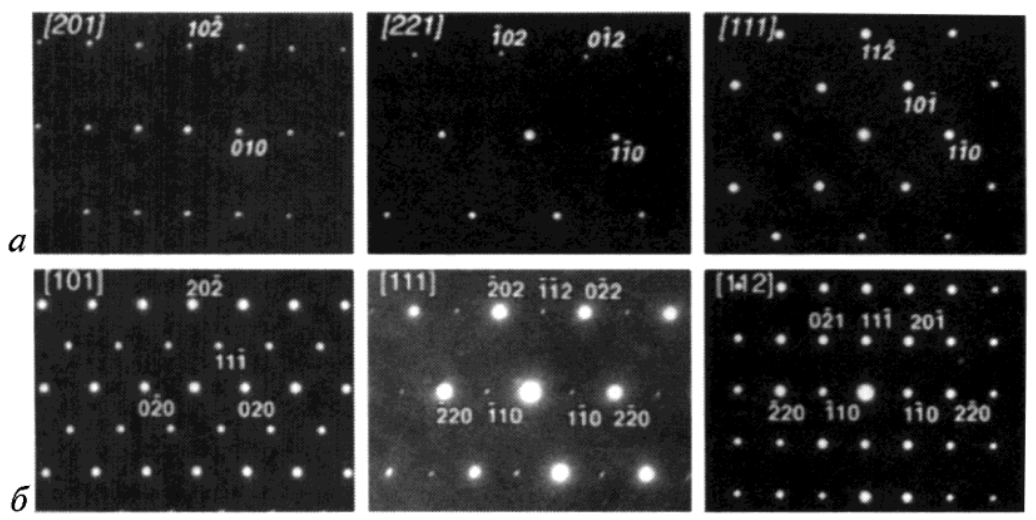

Figure 2. [201], [221] and [111] zones of the basic cells (italics) (a) and corresponding [101], [111] and [112] of the CM supercell (b). The $h k /$ reflections of the latter with $h, k=2 n+1$ are clearly extinct in the former. 


$$
a=0.32 \mathrm{~nm}, \quad b=0.39 \mathrm{~nm}, c=0.52 \mathrm{~nm} \text { and } \beta=106^{\circ} \text {, }
$$

which are similar to those of the small martensite structure as suggested before [17]. Comparing both basic and superstructures it is concluded that the latter consists of two cells of the former in the $a$ and $b$ directions. The type of distortions occurring during the MT are expected to be the same for both structures although the actual values of the shear angles can differ somewhat.

As the extensive SAED tilt experiments result in alternative unit cell parameters for the large cell, new Rietveld refinement procedure of the old Xray data, taken at room temperature and including peaks belonging to both product structures, was performed [23, 35, 36]. The lattice parameters and symmetry obtained from the SAED results discussed above were used as starting values for the iteration procedure. After the first step the Rwpfactor was approximately $35 \%$. Refinement with an isotropic temperature factor yielded $R w p=8.8 \%$ while changing the latter into an anisotropic one resulted in convergence with $R w p=6.3 \%$. The final refinement data as well as the atomic parameters for both product phases are shown in Tables 1 to 4 . The corresponding X-ray diffraction profile including the fit

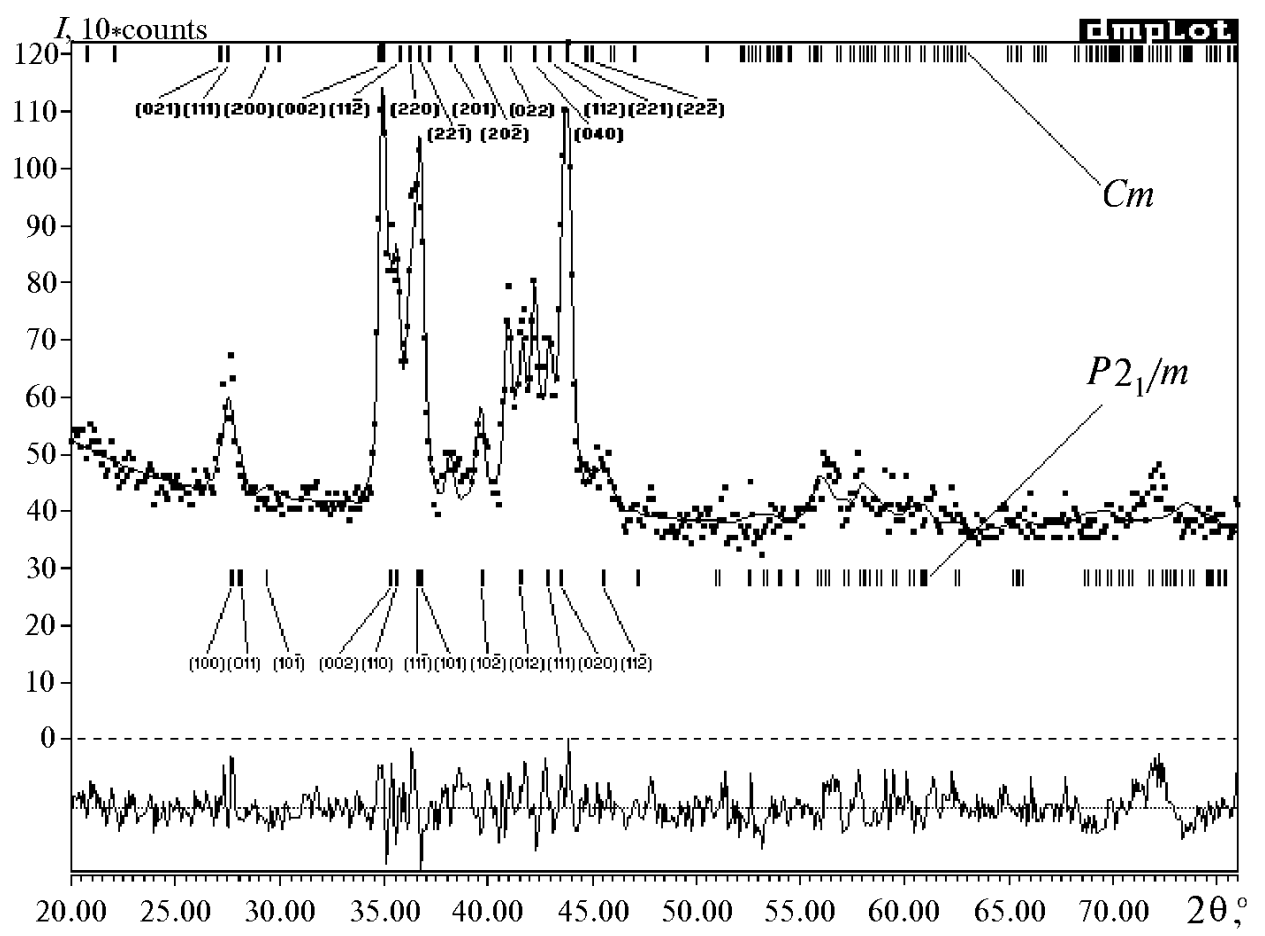

Figure 3. X-ray diffraction pattern for $\mathrm{ZrCu}$ (points-experiment; calculated curve is from the final Rietveld refinement cycle). A difference curve is also shown. 
is shown in Fig. 3.

According to Hill and Howard [36] we estimated the volume fractions for both martensites using scale factors (Tables 2, 4) and obtained $23 \%$ for twinned $\mathrm{Cm}$ and $77 \%$ for twinless $P 2_{1} / \mathrm{m}$ martensitic phases. If we take into account the lattice parameter of austenite $0.3262 \mathrm{~nm}$ and experimental volume change during forward MT $0.147 \%$ measured in [17] we also can calculate the volume change using refined lattice parameters. For the twinned martensite it equal to $0.6 \%$ and for the twinless $-0.01 \%$. Using the volume fractions we obtain general volume change $0.146 \%$ that is very close to experimental value. Reasonability of the proposed new model for the twinned martensite also confirmed by much lower anisotropic temperature factors in comparison with the results obtained in [17].

Using the smaller dimensions of the basic structure, a possible crystallographic relationship with the austenite can now be suggested. Indeed, when comparing the obtained values with those of other martensite structures formed out of $B 2$ austenite material, an apparent similarity with the monoclinic NiTi $B 19^{\prime}$ structure is found $[18,19]$. It was suggested before that this structure can be obtained from the cubic $B 2$ by shearing the (011)B2 planes, thus forming the monoclinic angle, elongating the [011] $B 2$ direction and shortening the [100]B2 and [011]B2 ones. This is drawn schematically in Fig. 4. The lattice correspondence then becomes

$$
\text { [100]B2\|[100]M, (011)B2\|(001)M, (011)B2\|(010)M. }
$$

Based on the present lattice parameters, no shortening of the [100]B2 axis is observed in CuZr. On top of these distortions, some reshuffling of the atoms in NiTi was found after refinement of neutron and X-ray data $[7,8]$ yielding a $P 2_{1} / m$ space group.

In addition to these distortions the atoms are shuffled within each unit cell. In Fig. 4 the [010] planes of both martensite structures are shown in comparison to the [011] planes of the parent $B 2$ phase. The distortions are clear from the outlines of the unit cells and the relative shifts are indicated by arrows. From this it is seen that no shuffles exist in the $[01 \overline{1}]_{B 2}$ direction, i.e. every atom remains in its respective $[01 \overline{1}]_{B 2}$ or $(010)_{M}$ plane. For the supercell the largest displacements are found in the $y=1 / 4$ or $3 / 4$ planes. The doubled lattice parameters for the supercell are primarily caused by the difference in shuffles of the internal Cu atoms on the $y=\square 0$ and $1 / 2$ planes.

The results of our further structural analysis are shown in Table 5 with the previously reported parameters of crystal structure for some other $B 2$ equiatomic intermetallics given for comparison. The remarkable resemblance in martensitic structures for $B 2 \mathrm{Zr}$-based equiatomic intermetallics with $\mathrm{NiTi}$ and even AuCd (B19' and $B 19$ respectively) is clearly seen excluding the results reported in $[10,20]$. The $B_{\mathrm{f}}(\mathrm{CrB})$ structural type defini- 


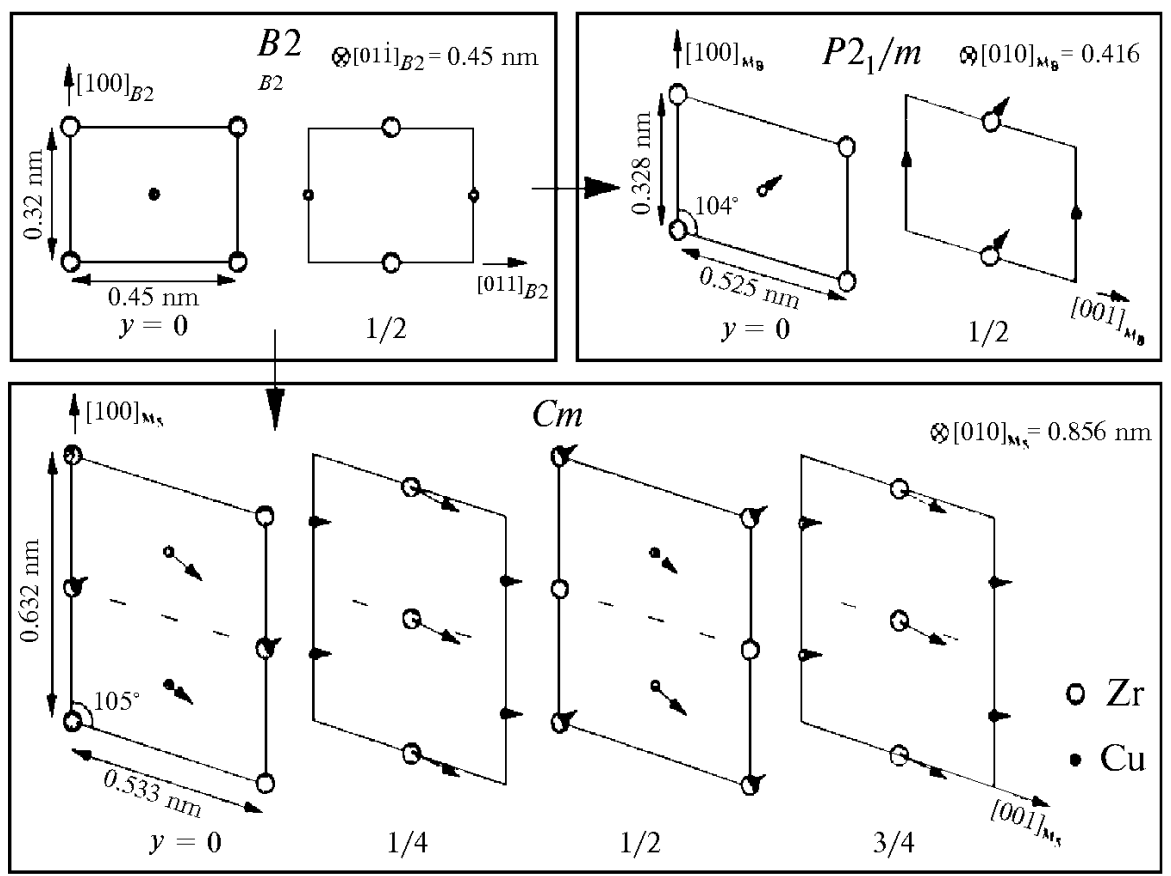

Figure 4. Schematic of the distortions and shuffles bringing the $B 2$ austenite into the two martensitic structures.

tion given for $\mathrm{ZrCo}_{36} \mathrm{Ni}_{14}$ and $\mathrm{Zr}\left(\mathrm{Ru}_{0.3} \mathrm{Pd}_{0.7}\right)$ martensites (Table 5) is unclear because the structural model proposed in $[10,20]$ depends only on the X-ray powder diffraction [10], limited electron microscopic (EM) studies [20] and possible isomorphism with ZrPt phase without any analysis of the reflections intensities.

In the present work the crystal structure of $\mathrm{Zr}_{2} \mathrm{CuCo}, \mathrm{Zr}_{2} \mathrm{CuNi}$ and $\mathrm{Zr}_{2} \mathrm{CoNi}$ compounds was refined using the Rietveld procedure [23] similar to the case of $\mathrm{ZrCu}$ [24] and a good agreement between experimental and calculated X-ray patterns was obtained ( $R$ wp factor was in the range $5-8 \%$ ). Reasonability of the refined structural parameters for $\mathrm{Zr}_{2} \mathrm{CuCo}$ compound (Table 5) reflects also in a good agreement of the sign and amount of the MT volume effect obtained in dilatometric measurements and calculated using the refined lattice parameters. Unfortunately, the crystal structure of the observed martensitic phase obviously belonging to the first type was not confirmed for $\mathrm{Zr}_{2} \mathrm{CoNi}$ compound because of very small volume fraction (Table 5) and needs additional investigation.

Formation of the two martensitic phases during forward MT significantly differs in $\mathrm{B} 2$ intermetallics of $\mathrm{Zr}$ (excluding $\mathrm{Zr}_{2} \mathrm{CuCo}$ compound) from isomorphous compounds of $\mathrm{Ti}$. The origin of this is will be explained later. 
TABLE 5. Structural parameters of Zr-based and some another intermetallic compounds.

\begin{tabular}{|c|c|c|c|c|c|c|c|c|c|c|c|}
\hline \multirow{2}{*}{$\begin{array}{c}\text { State } \\
\text { Parameters }\end{array}$} & \multicolumn{2}{|c|}{ Austenitic } & \multicolumn{6}{|c|}{ Martensitic } & \multirow{2}{*}{\begin{tabular}{|c|}
$\Delta v / v$, \\
$\mathrm{A} \rightarrow \mathrm{M}$ \\
$\%$
\end{tabular}} & \multirow{2}{*}{\begin{tabular}{|c}
$\begin{array}{c}\text { Volume } \\
\text { fraction } \\
\text { of } \\
\text { martens. }\end{array}$ \\
$\%$ \\
\end{tabular}} & \multirow{2}{*}{ Ref. } \\
\hline & $a, \AA$ & $\begin{array}{c}\text { St. } \\
\text { type }\end{array}$ & $a, \AA$ & $b, \AA$ & $c, \AA$ & $\beta,{ }^{\circ}$ & Sp.gr. & $\begin{array}{c}\text { St. } \\
\text { type }\end{array}$ & & & \\
\hline TiNi & 3.015 & $B 2$ & 2.898 & 4.108 & 4.646 & 97.78 & $P 2_{1} / m$ & $B 19^{\prime}$ & -0.02 & - & [19] \\
\hline $\mathrm{uCd}$ & 3.322 & $B 2$ & 3.154 & 4.764 & 4.864 & - & Pmma & $B 19$ & -0.41 & - & [28] \\
\hline $\mathrm{ZrCo}_{36} \mathrm{Ni}_{14}$ & 3.197 & $B 2$ & 3.253 & 9.707 & 4.186 & - & $\mathrm{Cmcm}$ & $B_{\mathrm{f}}$ & +0.28 & - & [10] \\
\hline $\mathrm{Zr}\left(\mathrm{Ru}_{0.3} \mathrm{Pd}_{0.7}\right)$ & $?$ & $B 2$ & 3.32 & 10.22 & 4.48 & - & $\mathrm{Cmcm}$ & $B_{f}$ & $?$ & - & [20] \\
\hline $\mathrm{ZrRh}$ & 3.295 & $B 2$ & 3.31 & 4.32 & 5.31 & 100.4 & $P 2_{1} / m$ & $B 19^{\prime}$ & $?$ & 100 & [13] \\
\hline Zrlr & 3.318 & $B 2$ & 3.33 & 4.38 & 5.35 & 99.9 & $P 2_{1} / m$ & $B 19^{\prime}$ & $?$ & 100 & [13] \\
\hline \multirow[t]{2}{*}{$\mathrm{ZrCu}$} & $3.262_{4}$ & $B 2$ & 1)6.337 & 8.563 & 5.345 & 105.6 & $\mathrm{Cm}$ & & +0.14 & 23 & {$[16$, } \\
\hline & & & 2)3.282 & & 5.249 & 103.7 & $P 2_{1} / m$ & $B 19^{\prime}$ & & 77 & 17] \\
\hline \multirow[t]{2}{*}{$\mathrm{Zr}_{2} \mathrm{CuNi}$} & $6.45^{@}$ & $L 2_{1}$ & 1)6.234 & 8.973 & 5.301 & 103.8 & $\mathrm{Cm}$ & & +0.16 & 12 & [32] \\
\hline & $@$ @_21] & & 2)3.336 & 4.193 & 5.235 & 103.1 & $\mathrm{P}_{1} / \mathrm{m}$ & $B 19^{\prime}$ & & 88 & \\
\hline $\mathrm{Zr}_{2} \mathrm{CuCo}$ & $3.245_{0}$ & $B 2$ & 3.275 & 4.186 & 5.203 & 106.2 & $\mathrm{P}_{1} / \mathrm{m}$ & $B 19^{\prime}$ & +0.20 & 100 & [32] \\
\hline \multirow[t]{2}{*}{$\mathrm{Zr}_{2} \mathrm{CoNi}$} & $?$ & $?$ & 1)6.439 & 8.461 & 5.362 & 105.8 & $\mathrm{Cm}$ & & +0.07 & 10 & [32] \\
\hline & & & 2)3.274 & 4.050 & 5.340 & 106.1 & $P 2_{1} / m$ & $B 19^{\prime}$ & & 90 & \\
\hline
\end{tabular}

The results of the dynamic mechanical response measurements (DMA) on the second complete MT cycle in $\mathrm{ZrCu}$ are presented in Fig. 5. The plate specimen was loaded in parent phase in a way that strain amplitude was equal to about $10^{-3}$. It is seen that the low frequency elastic modulus increases linearly on cooling from $300^{\circ} \mathrm{C}$ until $160^{\circ} \mathrm{C}$. Then it starts to decrease and after passing a minimum around $80^{\circ} \mathrm{C}$ increases again until $-50^{\circ} \mathrm{C}$. Internal friction (IF) dependence during this cooling shows a broad maximum clearly containing at least two peaks and correlates with a modulus decrease. Further cooling to $-50^{\circ} \mathrm{C}$ reveals a small peak around $0^{\circ} \mathrm{C}$. Subsequent heating results in a decrease of the low frequency modulus with a minimum at $310^{\circ} \mathrm{C}$ with further two step increase that finishes at $370^{\circ} \mathrm{C}$. The correspondent IF dependence shows a weak maximum at $50^{\circ} \mathrm{C}$ and a maximum at $310^{\circ} \mathrm{C}$ with a prolonged completion.

The elastic modulus and the internal friction on the second complete MT cycle in $\mathrm{ZrCu}$ measured by the impulse excitation technique (IET) are shown in Fig. 6. Both properties are showing approximately the same behaviour as for the dynamic mechanical response measurements presented in Fig. 5. High frequency elastic modulus behaviour has almost 


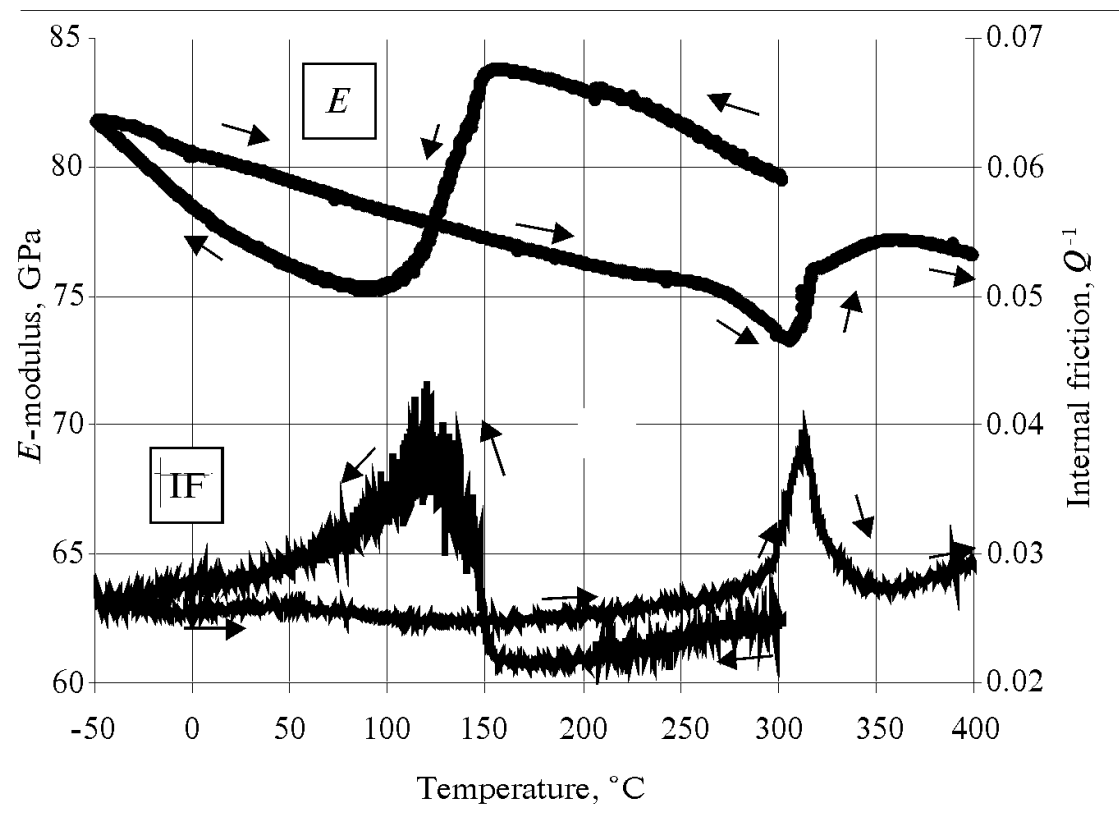

Figure 5. Evolution of the internal friction (IF) and modulus $(E)$ during the second complete MT cycle in $\mathrm{ZrCu}\left(5^{\circ} \mathrm{C} / \mathrm{min}\right.$, DMA-fixed frequency $4 \mathrm{~Hz}, \approx 10^{-3}$ strain amplitude).

the same magnitude and differs only in a slope of its general increase on cooling. IF is significantly lower in this case, especially above $200^{\circ} \mathrm{C}$. IF peak on cooling (Fig. 6, closed triangles) correlates well with the DMA one (Fig. 5) but starts higher at $220^{\circ} \mathrm{C}$. Then the small peak slightly above $50^{\circ} \mathrm{C}$ can be seen also. On subsequent heating the high frequency elastic modulus (Fig. 6, open circles) shows a minimum around $280^{\circ} \mathrm{C}$ that is lower in temperature and smaller in magnitude than the DMA one (Fig. 5). Correspondent IF peak on heating (Fig. 6, open triangles) is very weak. The difference in absolute values in results of DMA and IET measurements is related to the large difference in strain amplitude $\left(10^{-7}\right.$ for IET that is $10^{4}$ times smaller than for DMA).

The results of the differential scanning calorimetry (DSC) measurements are presented in Fig. 7. The second forward MT exothermic reaction starts at $170^{\circ} \mathrm{C}$ and finishes around $30^{\circ} \mathrm{C}$ after passing two maximums. The second reverse MT endothermic reaction starts at $280^{\circ} \mathrm{C}$ and finishes at $420^{\circ} \mathrm{C}$ after passing two maximums as well. The general amount of the released heat on the forward MT was equal to $Q^{A>M}=977$ $\mathrm{J} / \mathrm{mol}(12.63 \mathrm{~J} / \mathrm{g})$ and for the reverse MT it was equal to $Q^{\mathrm{M}>\mathrm{A}}=1345$ $\mathrm{J} / \mathrm{mol}(17.38 \mathrm{~J} / \mathrm{g})$. These general two step peaks were fitted with the help of the two distorted Pearson peak functions each and as a result we were 


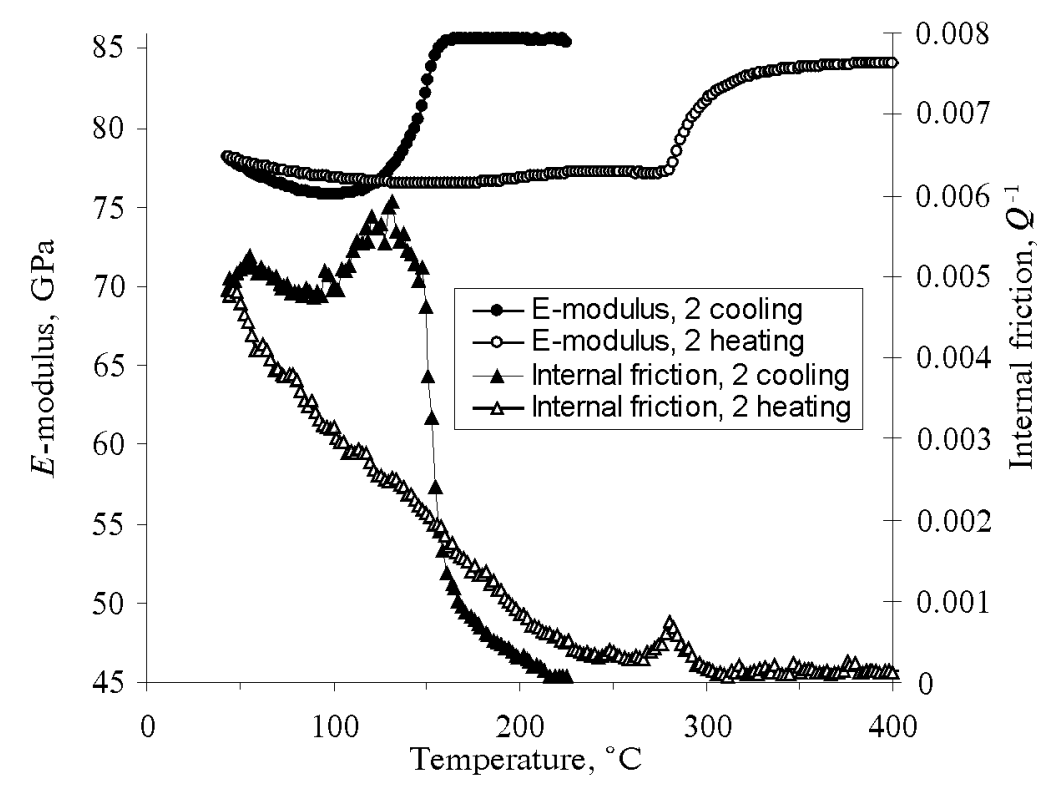

Figure 6. Evolution of the internal friction and $E$-modulus during the second complete MT cycle in $\mathrm{ZrCu}\left(5^{\circ} \mathrm{C} / \mathrm{min}, \mathrm{IET}, f r \approx 4.2-4.4 \mathrm{kHz}, \approx 10^{-7}\right.$ strain amplitude).

able to obtain the transformation heats and temperatures for each step as it is shown in Fig. 7.

Knowing already a presence of two martensitic phases ( $\mathrm{Cm}$ and $\left.\mathrm{B19}^{\prime}\right)$ as a result of MT in $\mathrm{ZrCu}$ [34] it was obvious to perform in situ high temperature X-ray diffraction measurements in order to bring into correlation structural parameters of all the present phases and there order of appearance with the obtained heats and temperatures of the extracted intrinsic MT steps.

In particular, the Rietveld refinement of X-ray diffraction patterns obtained on cooling and heating during complete MT cycle in $\mathrm{ZrCu}$ allowed us to obtain the temperature dependencies of the volume fractions for all phases present as well as changes in there lattice parameters. The results of this analysis are shown in Figs. 8 and 9. It is seen how $B 2$ volume fraction (Fig. 8, open boxes) starts to decrease on cooling at $170^{\circ} \mathrm{C}$ up to around room temperature correspondingly to the overall exothermic reaction (Fig. 7). At the same time, the volume fractions of the $B 19^{\prime}$ martensite (Fig. 8, closed triangles) and of the martensite belonging to the $\mathrm{Cm}$ space group (Fig. 8, open circles) increase in amount. It is impossible to recognize which type of martensite forms first but it is clearly seen that $B 19^{\prime}$ martensite finishes its appearance around $100^{\circ} \mathrm{C}$, while martensite belonging to the $\mathrm{Cm}$ space group proceeds to form until about $30^{\circ} \mathrm{C}$, replacing austenite completely. It means that the first sharp intrinsic exo- 


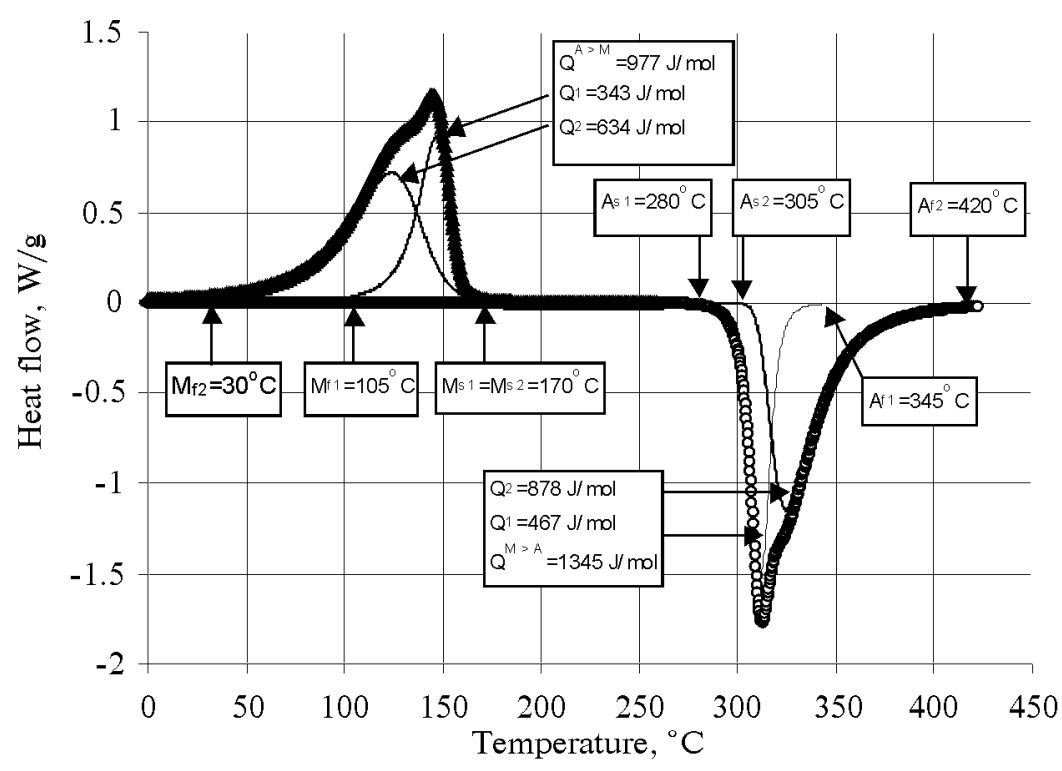

Figure 7. DSC measurement results of the second complete MT cycle in $\mathrm{ZrCu}$ $\left(10^{\circ} \mathrm{C} / \mathrm{min}\right)$.

thermic peak was caused by the formation of the $B 19^{\prime}$ martensite (Fig. 7). Taking into account its volume fraction (23\%) and the amount of heat of the first sharp exothermic peak extracted after fitting $(343 \mathrm{~J} / \mathrm{mol})$ we are able to find the heat of the imaginary separate forward $B 2>B 19^{\prime} M T$ in $\mathrm{ZrCu} Q^{B 2>B 19^{\prime}}=1490 \mathrm{~J} / \mathrm{mol}$.

The same can be done for the prolonged intrinsic exothermic peak that is attributed to the imaginary separate forward $B 2>C_{m}$ MT in $\mathrm{ZrCu}-$ $Q^{B 2>C m}=823 \mathrm{~J} / \mathrm{mol}$. Further heating leads to the appearance of the $B 2$ austenite around $250^{\circ} \mathrm{C}$ which starts to replace $B 19^{\prime}$ martensite first and corresponds to the sharp peak of the first intrinsic endothermic reaction that finishes around $350^{\circ} \mathrm{C}$. The volume fraction of the $\mathrm{Cm}$ martensite starts to decrease at $300^{\circ} \mathrm{C}$ that correlates well with the beginning of the second intrinsic endothermic reaction which is prolonged until approximately $420^{\circ} \mathrm{C}$. Again, we are able to obtain MT heats for both reverse intrinsic MT's. So, $Q^{B 19^{\prime}>B 2}=2030 \mathrm{~J} / \mathrm{mol}$ and $Q^{C m>B 2}=1140 \mathrm{~J} / \mathrm{mol}$. According to Ortin and Planes [26], the difference between reverse and forward MT heats represents the amount of energy dissipated during the complete MT cycle $E_{d}=Q^{M>A}-Q^{A>M}$. For the second cycle of MT for $\mathrm{ZrCu}$ in general this dissipated energy will be $E^{\mathrm{ZrCu}, \mathrm{d}}=1345-977=368 \mathrm{~J} / \mathrm{mol}$. For the imaginary distinct $B 2<>B 19^{\prime}$ and $B 2<>C_{m}$ MT's those dissipated energies will be $E^{B 2 \leftrightarrow B 19^{\prime}, \mathrm{d}}=2030-1491=539 \mathrm{~J} / \mathrm{mol}$ and $E^{B 2 \leftrightarrow C m, \mathrm{~d}}=1140$ $-823=317 \mathrm{~J} / \mathrm{mol}$. It is seen that the actual dissipated energy is almost 


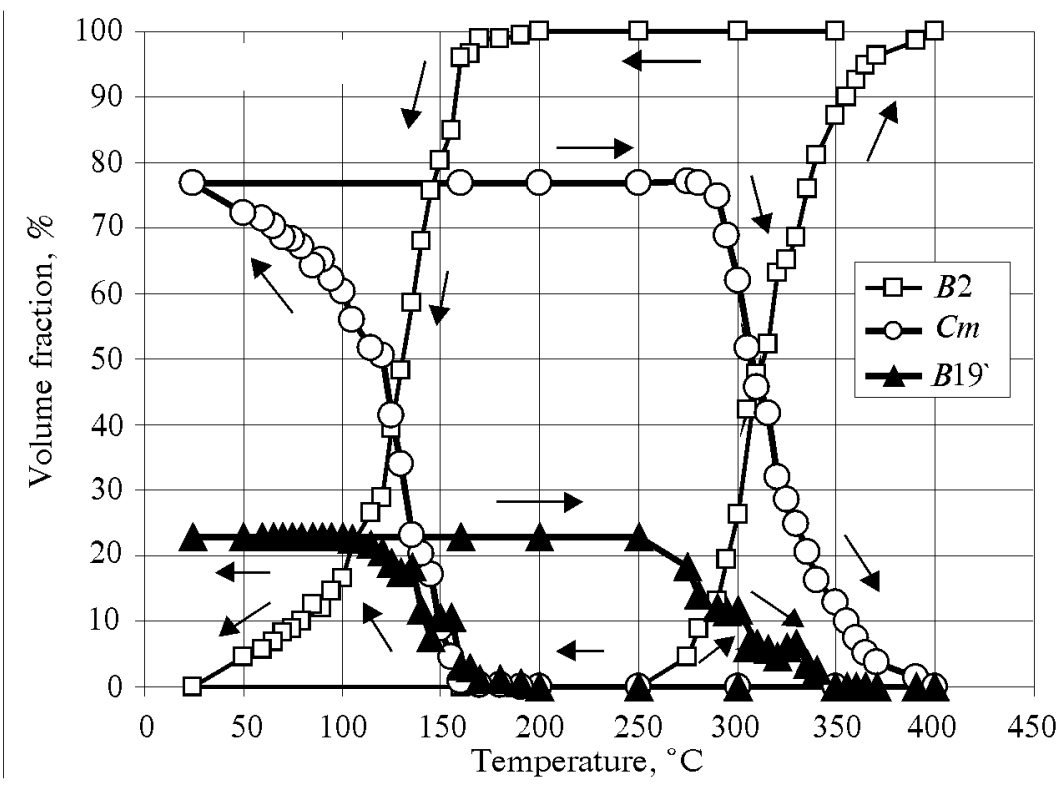

Figure 8. Changes in the volume fractions for $B 2, C m$ and $B 19^{\prime}$ phases derived from the results of the Rietveld refinement of the X-ray diffraction patterns taken on cooling-heating cycle during the second MT in $\mathrm{ZrCu}$.

the same in amount as the possible energy loss for the imaginary distinct $B 2<>C_{m}$ MT.

The Rietveld refinement helped us to retrieve the lattice parameters for all the observed phases, also. Temperature dependencies of those lattice parameters are represented in Fig. 9. B2 phase lattice parameter decreases on cooling (and increases on heating) can be simply approximated by the following linear function: $a_{B 2}=3.2618+T \cdot 5 \cdot 10^{-5} \AA$ (Fig. 9a, $T$-temperature, ${ }^{\circ} \mathrm{C}$ ). Parameter $a_{B 19^{\prime}}$ increases on cooling (decreases on heating) $-a_{B 19^{\prime}}=3.2836-T \cdot 6 \cdot 10^{-5} \AA$. It should be noted that their temperature dependencies cross each other around $200^{\circ} \mathrm{C}$ that is slightly above $M_{\mathrm{s}}$ for this complete MT cycle in ZrCu (Fig. 9a). Parameter $b_{B 19^{\prime}}$ increases almost linearly on heating $\left(b_{B 19^{\prime}}=4.1787+T \cdot 10^{-4} \AA\right)$, while $c_{B 19^{\prime}}$ has a maximum at a $350^{\circ} \mathrm{C}$ as well as monoclinic angle $\beta_{B 19^{\prime}}$ which decreases on heating (Fig. 9b). This maximum corresponds to $A_{\mathrm{f} 1}=A^{B 19^{\prime} \rightarrow B 2, \mathrm{f}}$ temperature. Lattice parameters $C_{C m}$ and $\beta_{C m}$ behaviour is very similar to that in $B 19^{\prime}$ martensite, only the peak on heating can be observed around $300^{\circ} \mathrm{C}$ (Fig. 9b, c). As for the $a_{C m}$ and $b_{C m}$, they show the same behaviour on heating (slight increase; Fig. 9c) but on cooling $b_{C m}$ undergoes a decrease, while $a_{c m}$ increases.

Then, the lattice parameters of the austenite and both martensites were used to calculate the volume per atom changes during $B 2<>B 19^{\prime}$ 


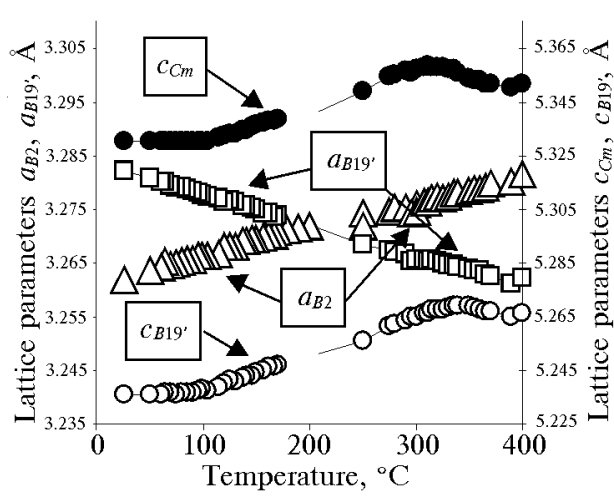

a

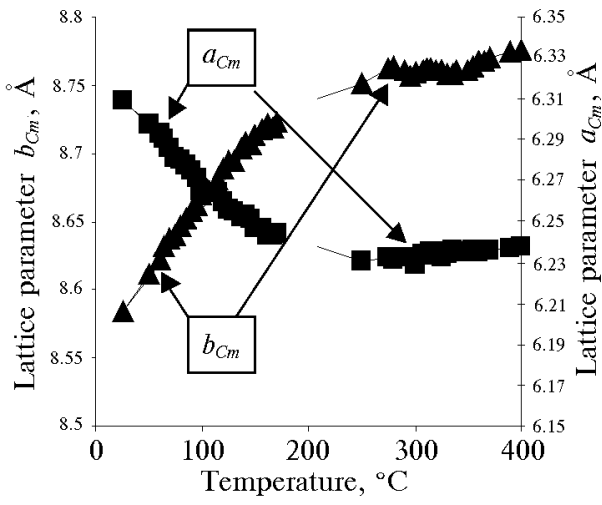

C

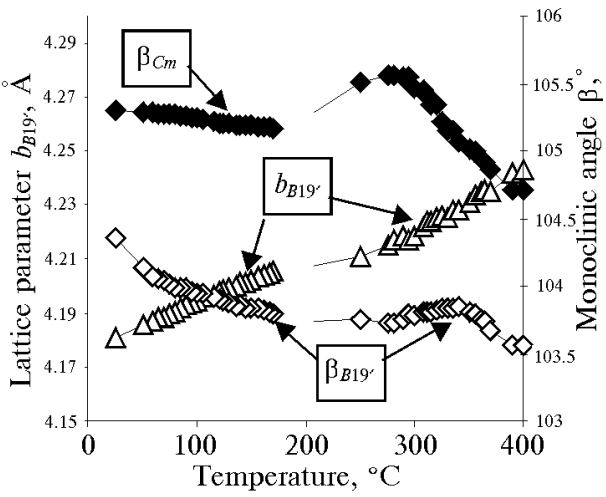

b

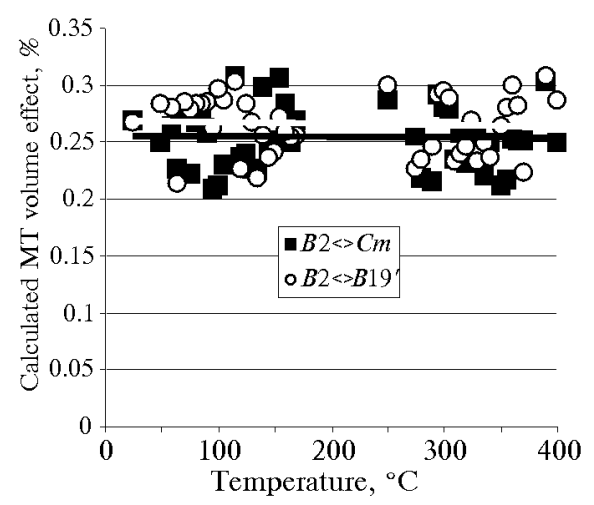

d

Figure 9. Lattice parameters changes for $B 2(c), C m(a, b, c)$ and $B 19^{\prime}(b, c)$ phases derived from the results of the Rietveld refinement of the X-ray diffraction patterns taken on cooling-heating cycle during second MT in $\mathrm{ZrCu}$ and MT volume effect calculated from relation between the lattice parameters of the austenite and both martensites (d).

and $B 2<>C m$ MT's (Fig. 9d). Calculated volume effect for both forward MT's is positive and in the $0.2-0.3 \%$ range. Linear approximations of such volume effect temperature dependencies tell us that the $B 2>B 19^{\prime}$ forward MT volume effect is bigger than for $B 2>C m M T$ in $\mathrm{ZrCu}$. It can be also clearly seen that calculated (Fig. 9d) and observed volume changes during second MT (Fig. 10) are very close to each other.

The results stated above give us the possibility to explain the martensites' formation mechanism in $\mathrm{ZrCu}$. According to the martensites' volume fraction change (Fig. 8) and DSC measurements (Fig. 7) it seems like the $B 19^{\prime}$ martensite forms first preferentially. On the other hand, the structural analysis shows that the positive volume effect on forward MT 


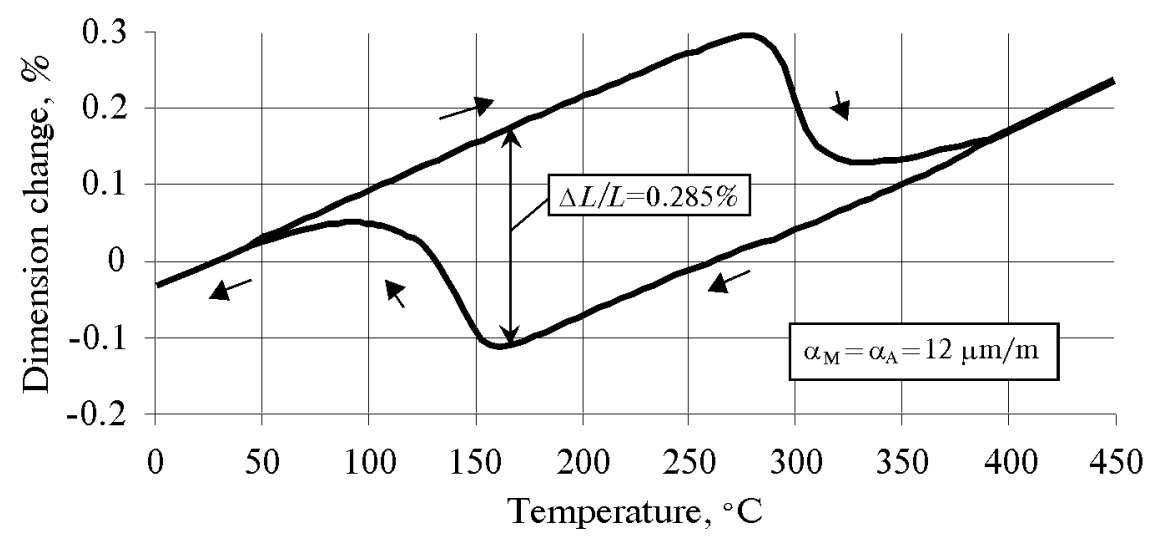

Figure 10. Dilatometric measurements of the second complete MT cycle in $\mathrm{ZrCu}$.

for $B 19^{\prime}$ is bigger than for $\mathrm{Cm}$ martensite (Fig. 9d). Taking into account the results of Seo and Schryvers [42] that show alternate $B 19^{\prime} \rightarrow C m \rightarrow B 19^{\prime} \rightarrow \ldots$ 'sandwich'-type of microstructure, it is logical to suppose that the formation of $B 19^{\prime}$ martensite at first induces considerable stresses in surrounding matrix and the $\mathrm{Cm}$ martensite then forms as a relaxation of such stresses. Such forward MT can prevent the plastic deformation and can be the reason for the nearly perfect shape memory effect during MT in $\mathrm{ZrCu}$ that is taking place with wide temperature hysteresis [2]. The reverse MT shows that B19' martensite disappears first (Fig. 7, 8). It indicates that $\mathrm{MT}$ in $\mathrm{ZrCu}$ is non-thermoelastic.

The thermoelasticity concept that was confirmed experimentally [33] includes such requirement that the last portions of martensite phase on forward MT must be transformed to austenite in a first order. In ZrCu we have a completely opposite situation. Such an order of appearance $\leftrightarrow$ disappearance for the martensites in $\mathrm{ZrCu}$ can be also the reason for the more intensive energy dissipation as a result of serious overheating through $B 19$ ' martensite 'barrier' for $B 2 \leftrightarrow C_{m} \mathrm{MT}$.

The most important question in this case, why $B 19^{\prime}$ martensite forms first in spite of its bigger MT volume effect, twinless substructure etc.? In [24] the lattice correspondence between $B 2$ and $B 19^{\prime}$ for $\mathrm{ZrCu}$ was supposed as $[100]_{B 2}||[100]_{M},(011)_{B 2}\left\|(001)_{M},(011)_{B 2}\right\|(010)_{M}$. Lattice parameters $a_{B 19^{\prime}}$, and $a_{B 2}$ behaviour (Fig. 9a) shows that their perfect match close to $M_{\mathrm{s}}$ can favour the formation of $B 19^{\prime}$ at first on cooling.

It can be concluded that:

MT in $\mathrm{ZrCu}$ is of non-thermoelastic type;

The relaxation of internal elastic stresses during forward $B 2>B 19^{\prime}$ MT in $\mathrm{ZrCu}$ takes place by means of the formation of additional $\mathrm{Cm}$ martensite instead of twinning or plastic deformation; 
The perfect match of the interplanar spacings of the (100) parallel planes for $B 2$ and $B 19^{\prime}$ phases can be the reason for the initial formation of the $B 19^{\prime}$ martensite.

\subsection{Thermodynamic and SME Behaviour}

Electrical resistivity and calorimetric measurements show ([2], Table 6) that the hysteresis of $\mathrm{MT}$ in $\mathrm{ZrCu}, \mathrm{Zr}_{2} \mathrm{CuNi}$ and $\mathrm{Zr}_{2} \mathrm{CoNi}$ compounds is larger in comparison with the case of $\mathrm{MT}$ in $\mathrm{AuCd}$, TiNi and even $\mathrm{Zr}_{2} \mathrm{CuCo}$. The difference in the heats of the reverse and forward MT $E_{d}=$ $Q^{\mathbb{M} \rightarrow A}-Q^{A \rightarrow M}$ listed in Table 6 (according to Ortin and Planes [26]) represents the energy lost in the complete MT cycle. Comparison of the values of thermal hysteresis and $E_{d}$ for MT in $B 2 \mathrm{Zr}$ intermetallics and AuCd, $\mathrm{NiTi}$ and $\mathrm{TiPd}$ shows that the irreversible contributions to the nonchemical free energy change in energy balance [26] (friction stresses required to move the interfaces; free energy changes related to defects induced by MT; partial plastic accommodation of the transformational shape and volume changes, mainly accomplished by slip) are higher for $\mathrm{Zr}$-based intermetallics. The temperature intervals of MT $\left(M_{\mathrm{s}}-M_{\mathrm{f}}, A_{\mathrm{s}}-A_{\mathrm{f}}\right)$ that reflect the value of the friction forces are also higher for these compounds ( $100 \mathrm{~K}$, Table 6$)$.

The very interesting behaviour of the hysteresis loops was observed on partial cycling during electrical resistivity and confirmed by dilatometric measurements. After stabilisation of the full hysteresis loop (20 thermal cycles) partial reverse MT's result in much lower temperatures of the forward MT on subsequent cooling in $\mathrm{Zr}_{2} \mathrm{CuNi}$ compound (Fig. $5 \mathrm{f}$, the same behaviour was observed for $\mathrm{Zr}_{2} \mathrm{CoNi}$ alloy).

When the reverse partial cycles became more complete the shape of the partial hysteresis loops came nearer to original (full) hysteresis loop. Repeated full cycle exhibited original shape of the hysteresis loop. So, this process is quite reversible in spite of the large width of hysteresis even for the full cycle. Usually, in the case of thermoelastic MT all partial hysteresis loops are internal in respect to the full one (see [27] for example). The same behaviour can be seen for $\mathrm{Zr}_{2} \mathrm{CuCo}$ compound (Fig. 13a).

SME for $\mathrm{Zr}_{2} \mathrm{CuNi}$ (the same as the SME behaviour in $\mathrm{Zr}_{2} \mathrm{CoNi}$ ) and $\mathrm{Zr}_{2} \mathrm{CuCo}$ compounds are shown in Fig. 11 and Fig. 12 respectively. Shape recovery ratio $\left(K_{\mathrm{SME}}\right)$ for $\mathrm{Zr}_{2} \mathrm{CuNi}$ is nearly complete $(\sim 90 \%)$ similar to $\mathrm{ZrCu}$ ([2], Table 6) contrary to wide temperature hysteresis, large amount of $E_{d}$ and high temperatures of shape recovery. Decrease of the hysteresis size and $E_{d}$ reflect in complete SME for $\mathrm{Zr}_{2} \mathrm{CuCo}$ compound (Table 6, Fig. 12).

High reversibility of MT in Zr-based intermetallics was confirmed by the stabilization of the hysteresis loops on thermal cycling and perfect SME. This reversibility was observed simultaneously with the high level of the irreversible processes during MT in this compounds. This unusual situation 
TABLE 6. Thermodynamical parameters of MT and shape recovery ratio for $\mathrm{Zr}$ based and some another intermetallics.

\begin{tabular}{|c|c|c|c|c|c|c|c|c|c|c|c|}
\hline Compound & $\begin{array}{l}M_{\mathrm{s}}, \\
{ }^{\circ} \mathrm{C}\end{array}$ & $\begin{array}{l}M_{\mathrm{i}}, \\
{ }^{\circ} \mathrm{C}\end{array}$ & $\begin{array}{l}A_{s}, \\
{ }^{\circ} \mathrm{C}\end{array}$ & $\begin{array}{l}A_{\mathrm{f}}, \\
{ }^{\circ} \mathrm{C}\end{array}$ & $\begin{array}{l}T_{0}, \\
{ }^{\circ} \mathrm{C}\end{array}$ & $\begin{array}{l}\Delta T, \\
{ }^{\circ} \mathrm{C}\end{array}$ & $\begin{array}{c}Q^{\mathrm{A} \rightarrow \mathrm{M}}, \\
\mathrm{J} / \mathrm{g}\end{array}$ & $\begin{array}{c}Q^{\mathrm{M} \rightarrow \mathrm{A}}, \\
\mathrm{J} / \mathrm{g}\end{array}$ & $\begin{array}{l}E_{\mathrm{d}} \\
\mathrm{J} / \mathrm{g}\end{array}$ & $\begin{array}{c}K_{\text {sme }} \\
\%\end{array}$ & Ref. \\
\hline AuCd & 60 & 55 & 75 & 80 & 70 & 20 & 1.87 & 2.22 & 0.35 & 100 & [29] \\
\hline $\mathrm{TiNi}$ & 50 & 20 & 60 & 90 & 55 & 40 & 27.3 & 29.9 & 2.6 & 100 & [30] \\
\hline TiPd & 560 & 550 & 580 & 590 & 570 & 40 & 33.2 & 33.7 & 0.5 & 100 & [31] \\
\hline $\mathrm{Zr}_{2} \mathrm{CuC}$ & -25 & -125 & -65 & 25 & -42 & 55 & 14.2 & 15.8 & 1.6 & 100 & $\begin{array}{l}\text { this } \\
\text { work }\end{array}$ \\
\hline $\mathrm{ZrCu}$ & 140 & 40 & 230 & 330 & 185 & 175 & 13.9 & 19.1 & 5.2 & $\sim 90$ & $\begin{array}{l}\text { [2], } \\
\text { this } \\
\text { work }\end{array}$ \\
\hline ZrRh & 450 & 350 & 550 & 650 & 500 & 200 & - & - & - & 100 & [13] \\
\hline $\mathrm{Zr}_{2} \mathrm{CuNi}$ & 610 & 510 & 690 & 790 & 650 & 180 & 35.2 & 40.1 & 5.3 & $\sim 90$ & $\begin{array}{l}\text { this } \\
\text { work }\end{array}$ \\
\hline $\mathrm{Zr}_{2} \mathrm{CoNi}$ & 620 & 480 & 700 & 950 & 710 & 225 & 29.3 & 35.7 & 6.4 & $\sim 90$ & $\begin{array}{l}\text { this } \\
\text { work }\end{array}$ \\
\hline Zrlr & 750 & 700 & 890 & 990 & 830 & 215 & - & - & - & - & [13] \\
\hline
\end{tabular}

may be explained as follows. High values of the friction forces in $\mathrm{Zr}_{2} \mathrm{CuCo}$ alloy (wide temperature intervals of MT, Table 6) may be attributed to the influence of the even small but positive volume effect of the forward MT. In the cases of MT in $\mathrm{ZrCu}, \mathrm{Zr}_{2} \mathrm{CuNi}$ and $\mathrm{Zr}_{2} \mathrm{CoNi}$ compounds additional irreversible contribution to the non-chemical free energy change in energy balance becomes important - interaction of the martensitic crystals belonging to the different kinds of martensites that can be also the source of the unrecoverable plastic deformation resulted in nearly complete $\mathrm{SME}\left(K_{\mathrm{SME}} \cong 90 \%\right.$, Table 6). It was indirectly confirmed by the unusual behaviour of partial hysteresis loops in the cases of $\mathrm{Zr}_{2} \mathrm{CuNi}$ and $\mathrm{Zr}_{2} \mathrm{CoNi}$ compounds when the two martensitic phases were formed (Table 5, Fig. 13f). On partial MT cycles in $\mathrm{Zr}_{2} \mathrm{CuCo}$ alloy the situation is very close to the thermoelastic case (Fig. 13a) due to the formation of only one kind of martensite (Table $5)$.

As for the case of ZrRh alloy having complete SME and wide hysteresis [13] when the presence of only one martensite was reported it should be mentioned that we can find the similar situation in [10]. The authors of this paper also reported about the one martensite with the results of dilatometric measurements with two stages of reverse MT. It can be supposed that the more detailed structural analysis will show the presence of two martensites in these alloys.

Drastic change of MT behaviour from thermoelastic in $\mathrm{Zr}_{2} \mathrm{CuCo}$ to non- 


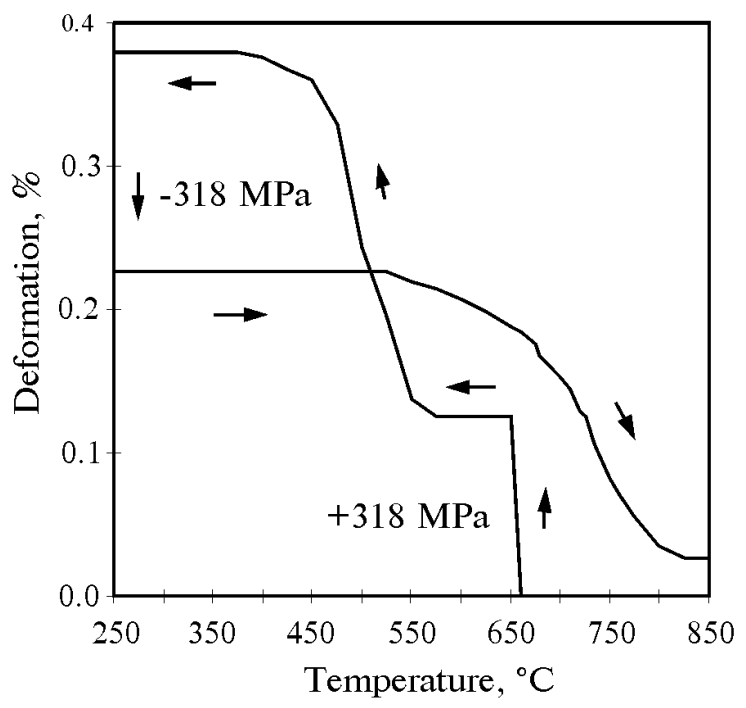

Figure 11. SME in $\mathrm{Zr}_{2} \mathrm{CuNi}$ compound.

thermoelastic in $\mathrm{Zr}_{2} \mathrm{CuNi}$ initiated our interest to the changes along the $\mathrm{Zr}_{2} \mathrm{CuNi}-\mathrm{Zr}_{2} \mathrm{CuCo}$ quasi-binary cross-section.

The results of electrical resistivity measurements are shown in Figs. $13,14,17$. It is seen that the MT in the $\mathrm{Zr}_{2} \mathrm{CuNi}$ compound takes place

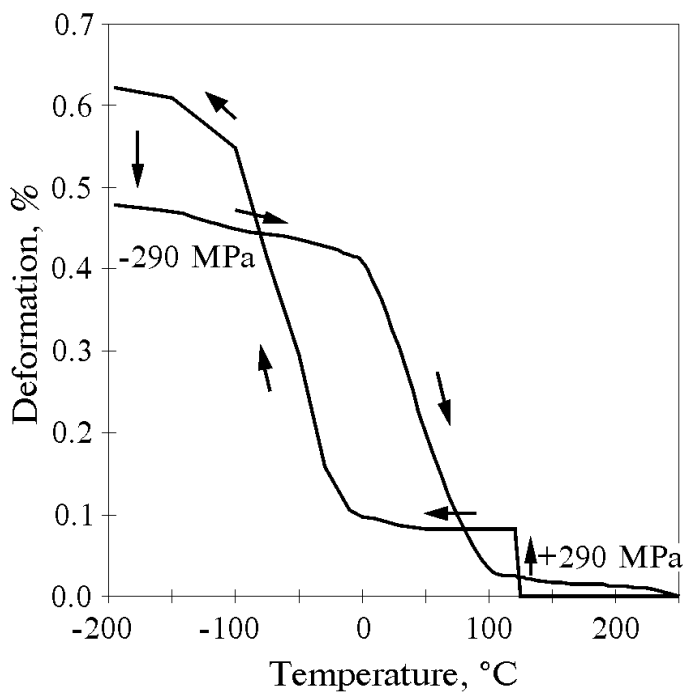

Figure 12. SME in $\mathrm{Zr}_{2} \mathrm{CuCo}$ compound. 
with a wide hysteresis $(180 \mathrm{~K})$ and $\mathrm{MT}$ intervals $(100 \mathrm{~K})$. Co for Ni substitution results in a linear decrease of MT temperatures by $\approx 600 \mathrm{~K}$ (Fig. 14) and general hysteresis decrease to $50 \mathrm{~K}$ for $\mathrm{Zr}_{2} \mathrm{CuCo}$ with a maximum at 15-20 at.\% of $\mathrm{Ni}$ (Fig. 17). The $A_{\mathrm{s}}$ temperature, higher than $M_{\mathrm{s}}$ at high $\mathrm{Ni}$ content, becomes lower than $M_{\mathrm{s}}$ on Co additions (Fig. 14). After stabilization of the full hysteresis loop (20 thermal cycles) partial reverse MT's in $\mathrm{Zr}_{2} \mathrm{CuNi}$ result in much lower $M_{\mathrm{s}}, M_{\mathrm{f}}$ temperatures on subsequent cooling as it was mentioned above (Fig. 13f). When the reverse partial cycles became more complete the shape of the partial hysteresis loops came nearer to the original (complete) hysteresis loop. A new full cycle showed again the original shape of the hysteresis loop. Addition of 4.42 at.\% of Co weakens the effect mentioned above with the simultaneous appearance of the effect of the reverse MT temperatures increase on partial cycling (Fig. 13e, thin dashed line-1st partial cycle, thin solid lines-subsequent cycles). It is clearly seen from Fig. 13d that partial cycling results in disappearing of the forward MT lowering effect for the alloy with 9.6 at.\% Co. The starting partial reverse path (Fig 13d, thin dashed line) shows usual behaviour but the subsequent partial reverse paths are outside of the stabilized complete hysteresis loop. The same behaviour was observed for the alloys containing 14.8 (Fig. 13c) and 19.9 (Fig. 13b) at.\% of Co. It can also be seen (Fig. 13b, c, d, e) that every subsequent partial path is outside of (higher in temperature than) the previous one. Moreover, after the finishing of partial cycling the subsequent first complete reverse path is much higher in temperature even compared to the previous partial paths (Fig. 13b, c, d, bold dashed line). A final complete cycle has the same shape as the original stabilized one (Fig. 13b, c, d, e) similar to $\mathrm{Zr}_{2} \mathrm{CuNi}$ (Fig. 13f).

$X$-ray diffraction measurements confirm the presence of only one B19' type martensite in $\mathrm{Zr}_{2} \mathrm{CuCo}$ and simultaneous formation of two martensitic phases in $\mathrm{Zr}_{2} \mathrm{CuNi}$ belonging to the $P 2_{1} / m$ (B19' type) and $\mathrm{Cm}$ space groups similar to $\mathrm{ZrCu}$ [24]. The lattice parameters are not changed significantly along the $\mathrm{Zr}_{2} \mathrm{CuCo}-\mathrm{Zr}_{2} \mathrm{CuNi}$ cross-section because the atomic radii of $\mathrm{Co}$ and $\mathrm{Ni}$ are nearly identical. Considerable changes can be seen for $\mathrm{Cm}$ and $P 2_{1} / \mathrm{m}$ martensite volume fractions (Fig. 15) that were obtained according to [6]. The amount of the $B 19^{\prime}$ type martensite volume fraction increases from $\approx 15 \%$ in $\mathrm{Zr}_{2} \mathrm{CuNi}$ to $\approx 95 \%$ in the alloy with 9.6 at.\% of Co. The exact structural parameters for the studied cross-section will be published elsewhere.

SME for the $\mathrm{Zr}_{2} \mathrm{CuNi}-\mathrm{Zr}_{2} \mathrm{CuCo}$ quasi-binary cross-section was studied under the $120 \mathrm{MPa}$ static load applied before cooling below the $M_{\mathrm{s}}$ temperature. Then the specimens were released at $77 \mathrm{~K}$ after storing of $0.2-0.5 \%$ martensitic deformation for subsequent free shape recovery on heating. The composition dependence of the shape recovery ratio $K_{\mathrm{SME}}=$ $=\left(\varepsilon_{\mathrm{M}} / \varepsilon_{\mathrm{R}}\right) \cdot 100 \%$ is shown in Fig. 16 . It can be seen that the shape recovery 


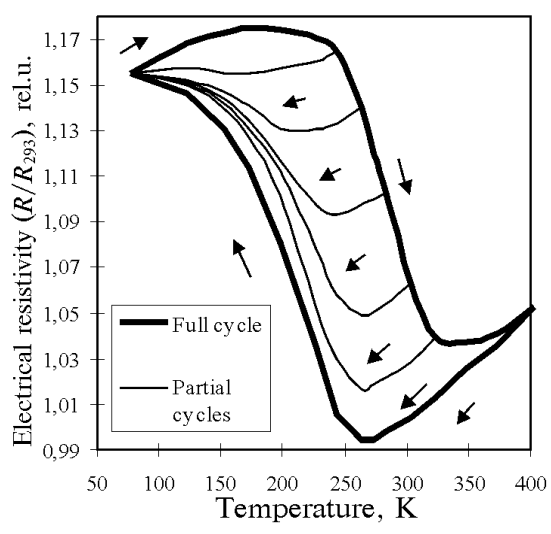

(a) $\mathrm{Zr}_{2} \mathrm{CuCo}$

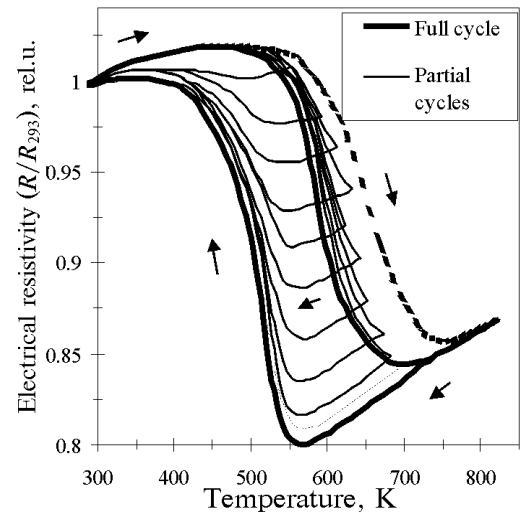

(c) $(14.8$ at.\% Co +10.22 at.\% $\mathrm{Ni})$

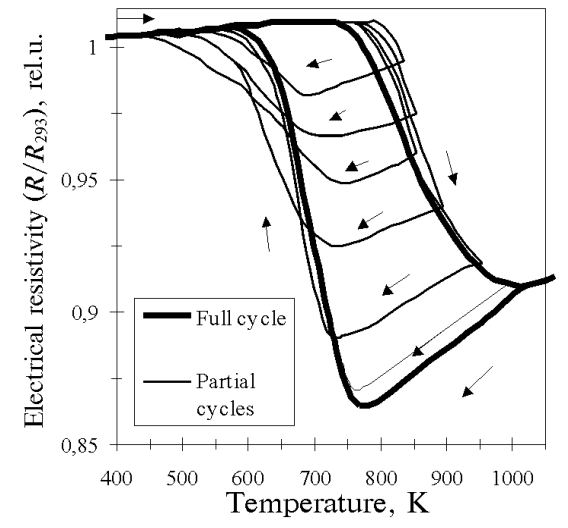

(e) (4.42 at.\% Co +20.31 at.\% Ni)

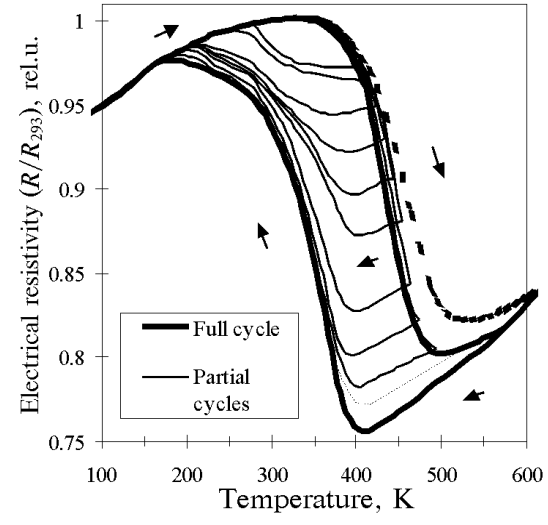

(b) (19.9 at.\% $\mathrm{Co}+4.4$ at. $\% \mathrm{Ni})$

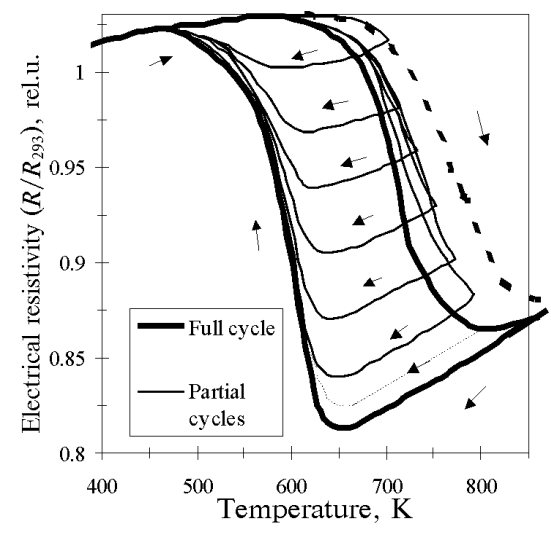

(d) $(9.6$ at. $\%$ Co +15.51 at. $\% \mathrm{Ni})$

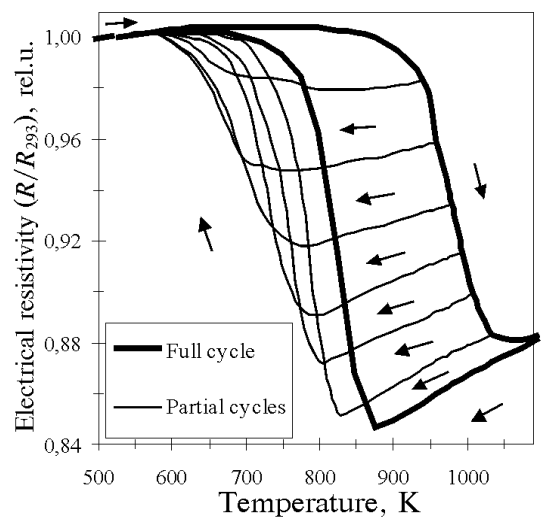

(f) $\mathrm{Zr}_{2} \mathrm{CuNi}$

Figure 13. Evolution of the MT hysteresis loops during full and partial thermal cycling along the $\mathrm{Zr}_{2} \mathrm{CuCo}-\mathrm{Zr}_{2} \mathrm{CuNi}$ quasibinary cross-section (Ni for Co substitution). 


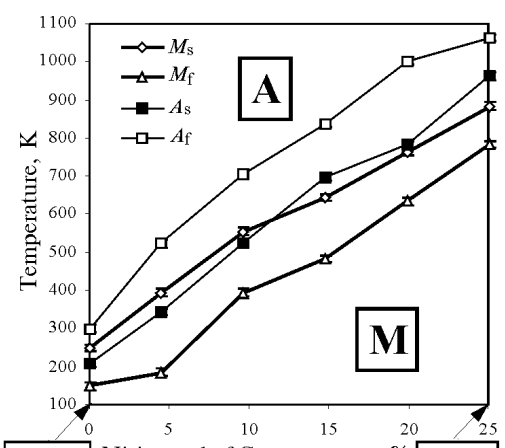

$\mathrm{Zr}_{2} \mathrm{CuCO} \mathrm{Ni}$ instead of Co content, at. $\% \mathrm{Zr}_{2} \mathrm{CuN}$

Figure 14. MT temperatures as a function of $\mathrm{Ni}$ content for the $\mathrm{Zr}_{2} \mathrm{CuNi}-$ $\mathrm{Zr}_{2} \mathrm{CuCo}$ quasibinary cross-section.

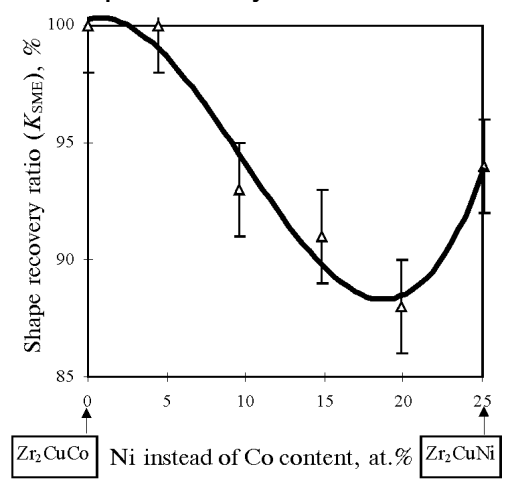

Figure 16. Shape recovery ratio $v s \mathrm{Ni}$ for Co substitution for the $\mathrm{Zr}_{2} \mathrm{CuCo}-$ $\mathrm{Zr}_{2} \mathrm{CuNi}$ quasibinary cross-section.

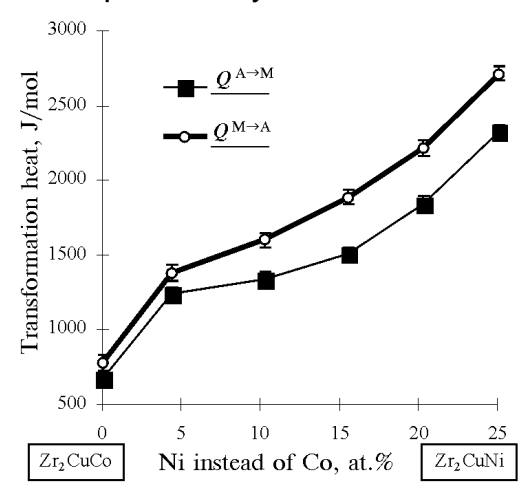

Figure 18. Martensite transformation heats as a function of $\mathrm{Ni}$ content for the $\mathrm{Zr}_{2} \mathrm{CuNi}-\mathrm{Zr}_{2} \mathrm{CuCo}$ cross-section.

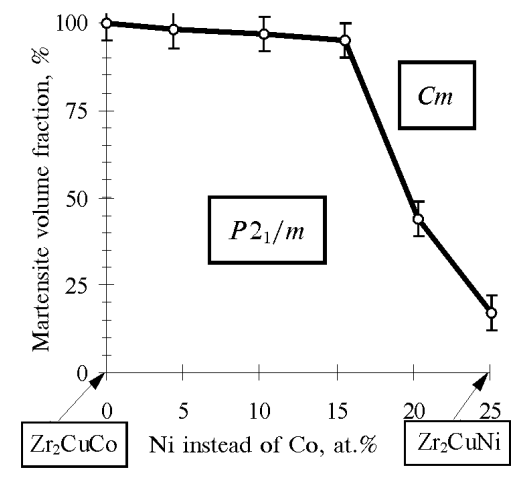

Figure 15. $\mathrm{Cm}$ and $P 2_{1} / m$ martensite volume fractions changes vs $\mathrm{Ni}$ for Co substitution.

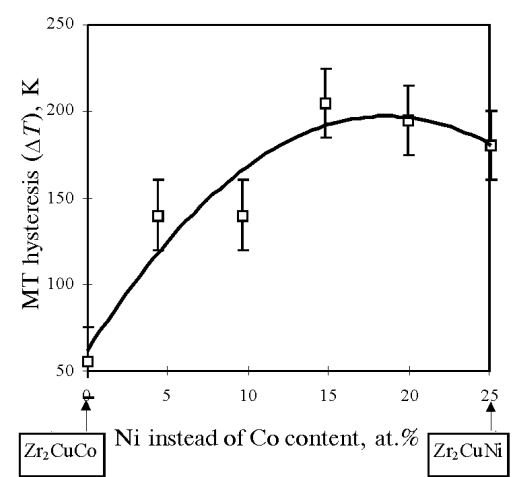

Figure 17. MT hysteresis changes vs $\mathrm{Ni}$ for Co substitution for the $\mathrm{Zr}_{2} \mathrm{CuCo}-\mathrm{Zr}_{2} \mathrm{CuNi}$ cross-section.

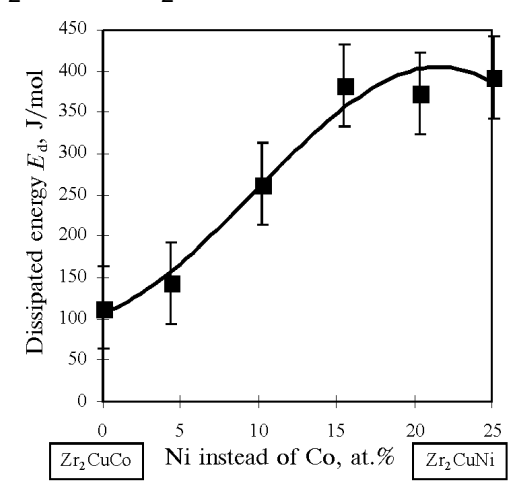

Figure 19. The energy dissipated on MT complete cycle $\left(E_{d}=Q^{\mathrm{M} \rightarrow \mathrm{A}}-\right.$ $\left.-Q^{A \rightarrow M}\right)$ vs Ni for Co substitution. 
becomes complete on Co additions through a minimum at 15-20 at.\% of $\mathrm{Ni}\left(K_{\mathrm{SME}} \geq 85 \%\right)$.

The results of the compression tests with subsequent SME testing in a dilatometer are shown in Figs. 20 and 21 respectively. It is seen that with $\mathrm{Ni}$ additions the strengthening during deformation increases that resulted in a cracking of alloy with 20.31 at.\% of $\mathrm{Ni}$ content when the deformation exceeds $5 \%$ (Fig. 20). Shape recovery for most alloys studied is not smaller than $1 \%$ excepting $\mathrm{Zr}_{2} \mathrm{CuNi}$ (Fig. 21).

The results of calorimetric measurements are shown in Figs. 18, 19, 22,23 . Considerable values of MT heats for the alloys with high Ni content (Fig. 18) are noticed. Co additions significantly decrease the transformation heats by $\approx 2 \mathrm{~kJ} / \mathrm{mol}$. The difference in the reverse and forward MT heats that represents the energy lost in the complete MT cycle $E_{d}=Q^{\mathrm{M} \rightarrow \mathrm{A}}-Q^{\mathrm{A} \rightarrow \mathrm{M}}$ (according to [26]) is shown in Fig. 19. $E_{\mathrm{d}}$ values also decrease with increasing Co content through the maximum at $\approx 20$ at.\% of $\mathrm{Ni}$ and correlate well with the thermal MT hysteresis behaviour (Fig. 17) and the minimum in shape recovery (Fig. 16). Exo- and endothermic reaction peaks during MT along $\mathrm{Zr}_{2} \mathrm{CuCo}-\mathrm{Zr}_{2} \mathrm{CuNi}$ quasi-binary crosssection are shown in Fig. 22 and 23 respectively. Prolonged forward MT intervals for the alloys with higher $\mathrm{Ni}$ content are clearly divided into two overlapped stages (Fig. 22) as well as the reverse MT's (Fig. 23). The difference exists only in the actual temperature positions of the major and minor peaks. In $\mathrm{Zr}_{2} \mathrm{CuNi}$ and alloys with 20.31 and 15.51 at.\% $\mathrm{Ni}$, the second minor stage of the forward MT is lower in temperature than for the major stage (Fig. 22) in contrast with the reverse MT when the temperature position of the minor peak is higher (Fig. 23). The situation is changed drastically for the case of MT in the alloy containing 10.22 at.\% $\mathrm{Ni}$. The minor stage of the reverse MT appears at temperatures lower than the major stage (Fig. 23) similar to the forward MT (Fig. 22). Further Co additions result in one stage behaviour for forward and reverse MT's.

Such correspondence between the different stages of forward and reverse MT's gives an opportunity to conclude that the MT in alloys with high $\mathrm{Ni}$ content is non-thermoelastic. The thermoelasticity concept that was confirmed experimentally [33] includes such requirement that the last portions of martensite phase on forward MT must be transformed to austenite in a first order. The minor peaks observed due to the formation of two different interacting martensite phases are lower in temperature than the major peaks (Fig. 22) and consequently they must be also lower than the major peaks on the reverse MT in the thermoelastic case. In reality, we have the opposite situation as was mentioned above (Fig. 23). Thus, a very high level of dissipative processes in a latter case can be influenced only by the elastic interaction between martensitic crystals of different type. Internal stresses produced by the major kind of martensitic crystals suppress the reverse MT for another kind of martensite. 


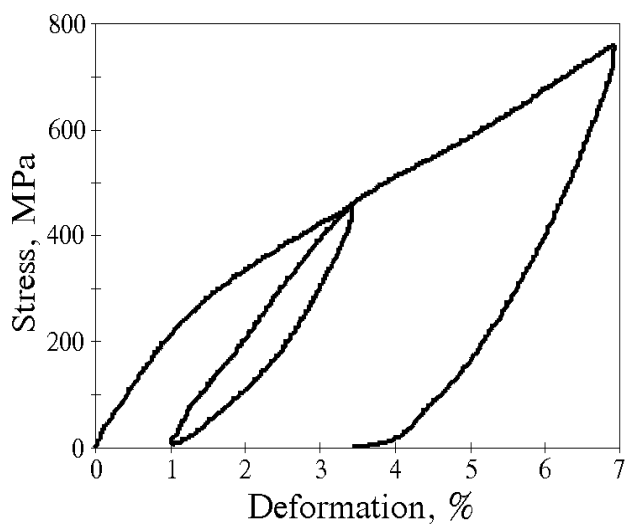

(a)

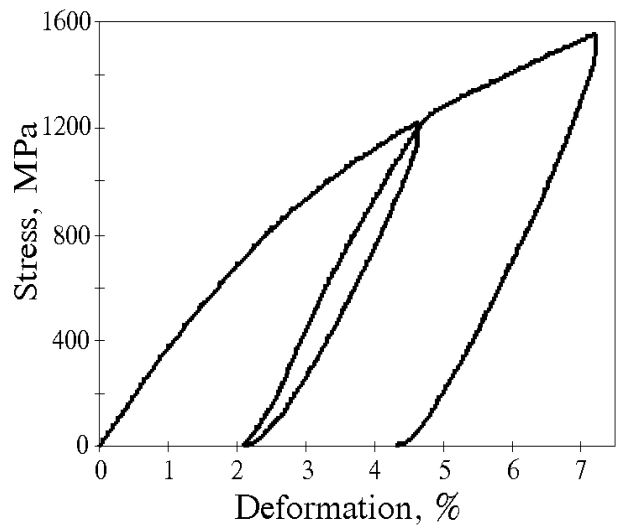

(c)

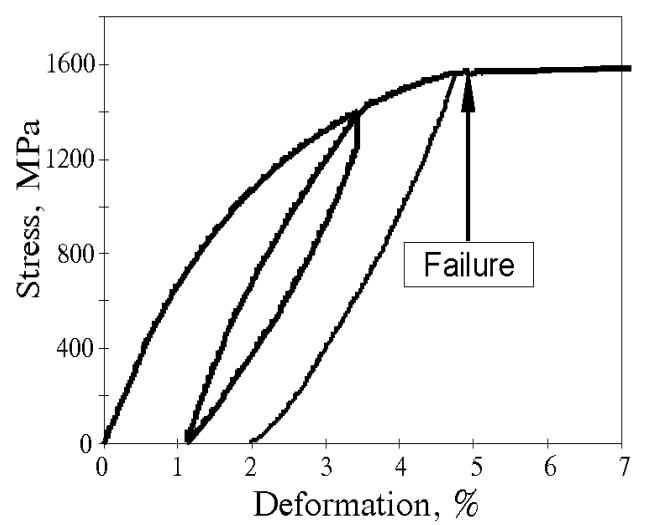

(e)

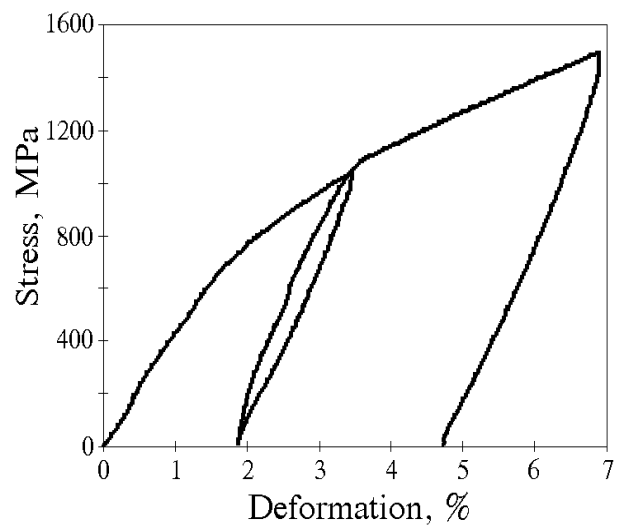

(b)

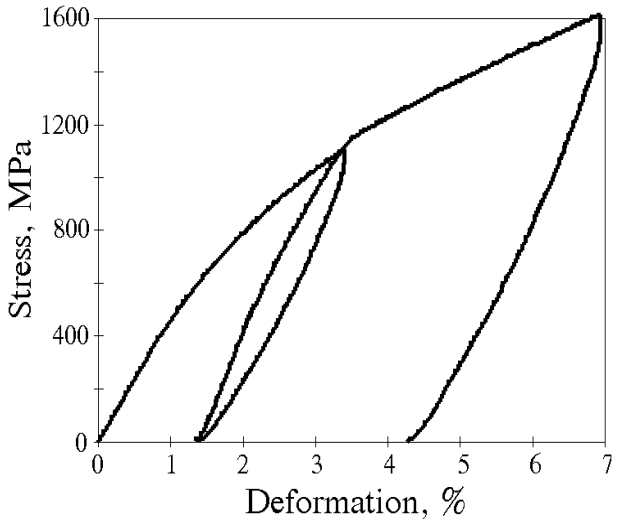

(d)

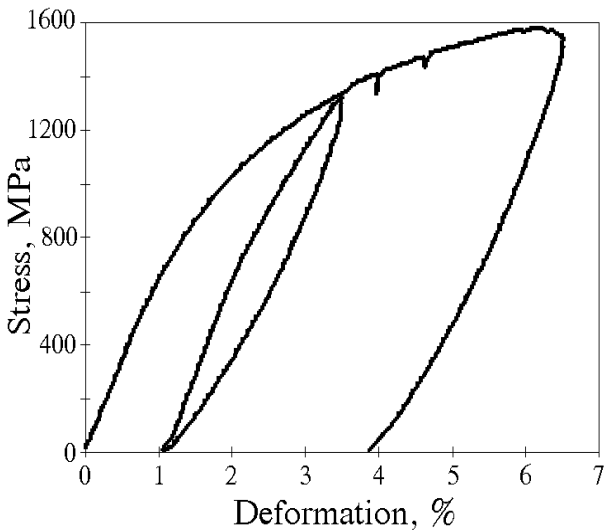

(f)

Figure 20. Compression tests for alloys along the $\mathrm{Zr}_{2} \mathrm{CuCo}-\mathrm{Zr}_{2} \mathrm{CuNi}$ quasibinary cross-section (Ni for Co substitution) before the SME testing in the dilatometer. 


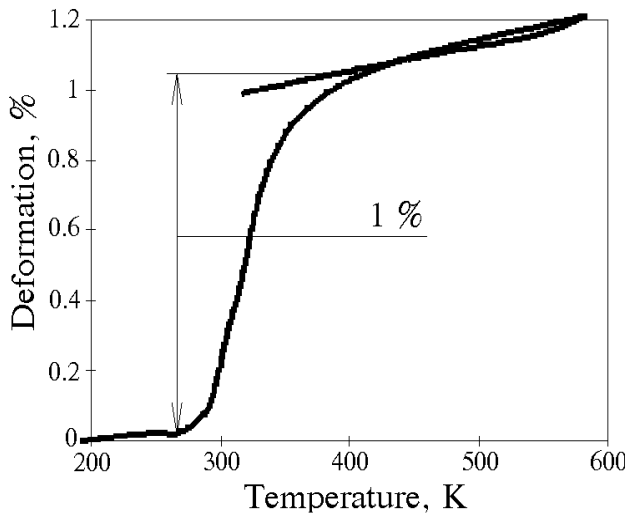

(a)

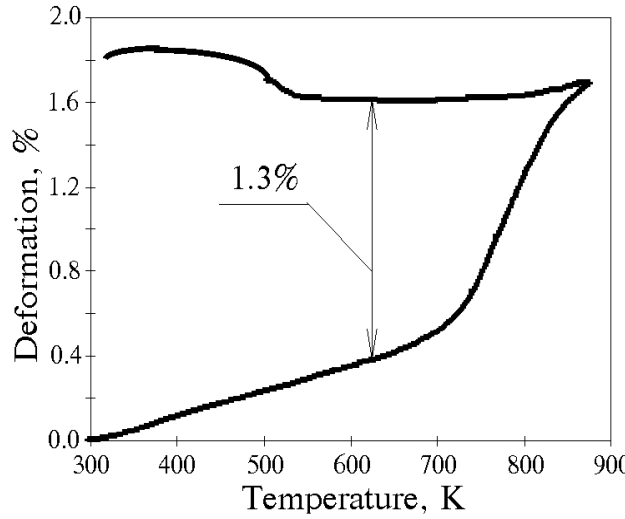

(c)

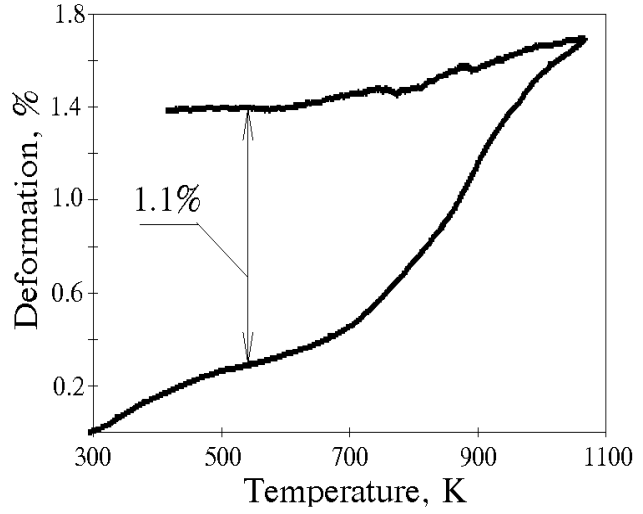

(e)

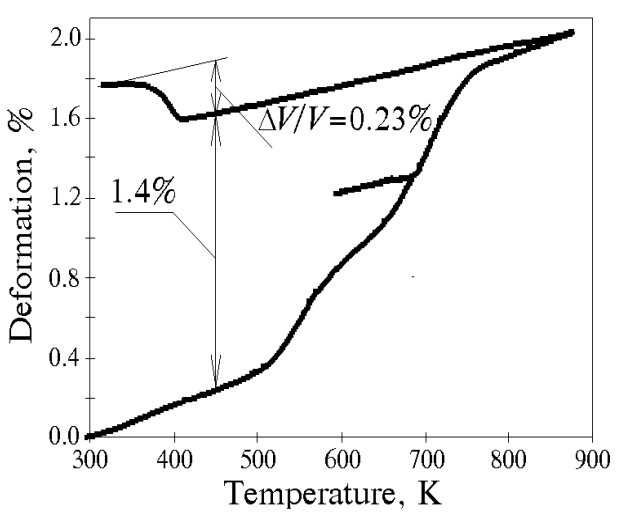

(b)

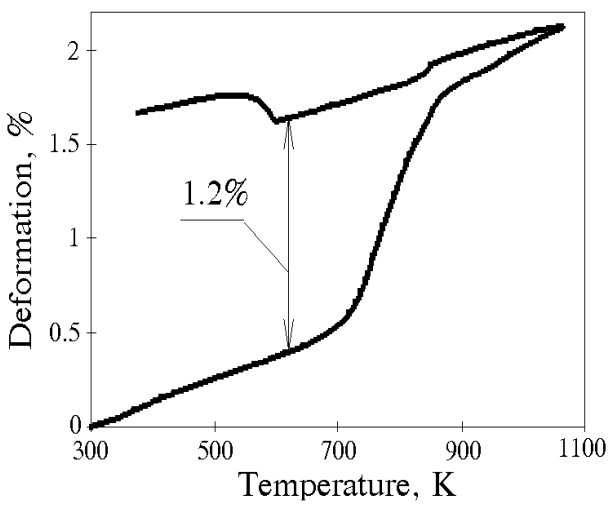

(d)

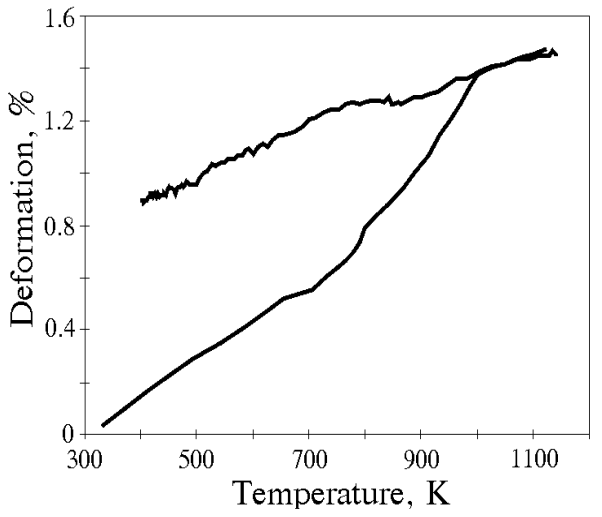

(f)

Figure 21. SME testing of the alloys along the $\mathrm{Zr}_{2} \mathrm{CuCo}-\mathrm{Zr}_{2} \mathrm{CuNi}$ quasibinary cross-section (Ni for Co substitution) in a dilatometer. 


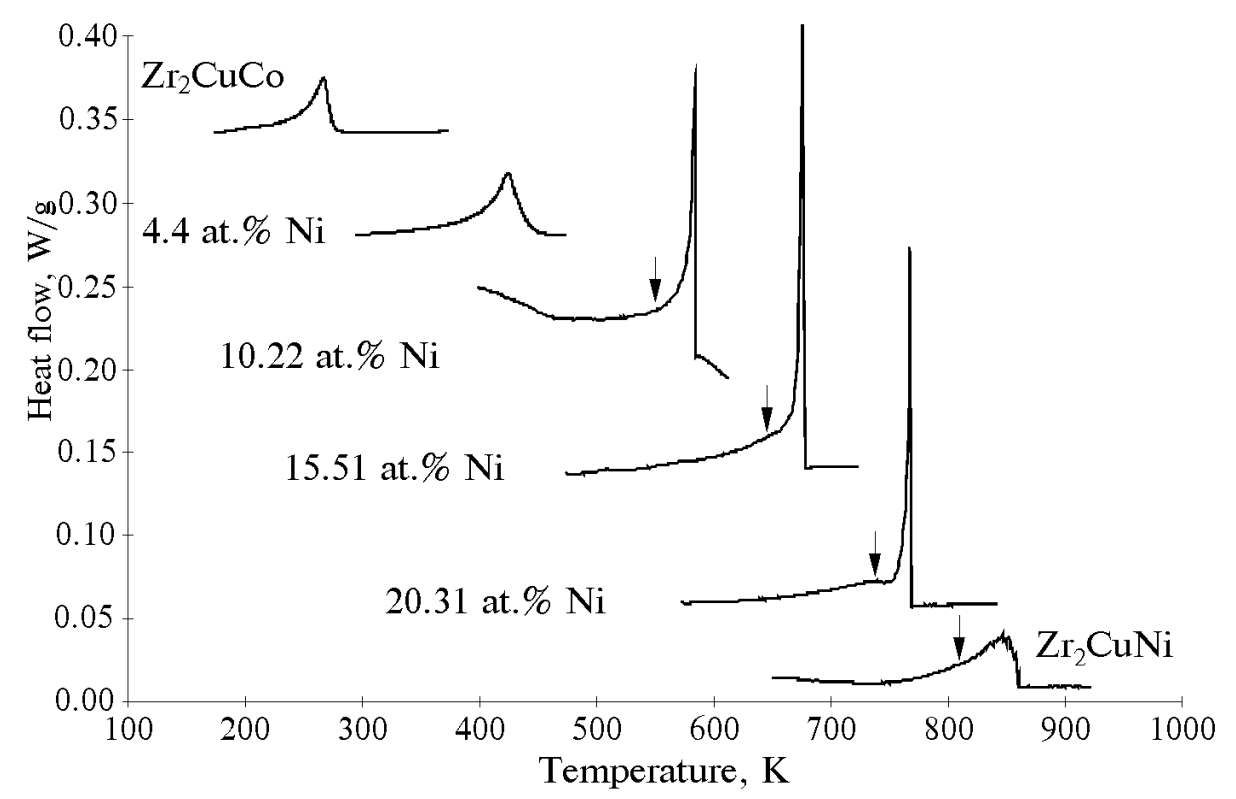

Figure 22. Evolution of exothermic reaction peaks during forward MT along the $\mathrm{Zr}_{2} \mathrm{CuCo}-\mathrm{Zr}_{2} \mathrm{CuNi}$ quasi-binary cross-section (Ni for Co substitution); arrows indicate the position of the second stage of the forward MT.

This explanation is valid for the case of $\mathrm{Cm}$ phase majority in $\mathrm{Zr}_{2} \mathrm{CuNi}$ where the major forward MT is prolonged as for an alloy with 15.51 at. $\% \mathrm{Ni}$ with the major $B 19^{\prime}$ type phase having the sharp forward MT exothermic peak (Fig. 22). Only at 14.8 at.\% Co, the situation becomes very close to the thermoelastic case. This can be concluded based on the observed sequence of the major and minor MT stages (last portions of martensite (minor kind) are transformed first into austenite).

The value of the internal shear stresses that can decrease the partial forward MT by $100 \mathrm{~K}$ can be estimated (Fig. 13f, upper partial path). The Clausius-Clapeyron like equation can be rewritten as follows

$$
d \tau=d T \cdot d Q /\left(T_{0} \cdot V_{\mathrm{mol}} \cdot \gamma\right),
$$

where $d \tau$ is the internal shear stress change associated with the martensite crystals, $d T=100 \mathrm{~K}$ is the partial forward MT temperature change, $d Q=M Q^{A \rightarrow M}=0.2 \times 2320 \mathrm{~J} / \mathrm{mol}=464 \mathrm{~J} / \mathrm{mol}(M$ is the volume fraction of the martensite that will be formed on partial forward $\mathrm{MT} ; Q^{\mathrm{A} \rightarrow \mathrm{M}}$ transformation heat of the complete forward MT), $T_{0} \approx 925 \mathrm{~K}$ is the phase equilibrium temperature, $V_{\mathrm{mol}}=10.25 \cdot 10^{-6} \mathrm{~m} / \mathrm{mol}$ is the molar volume of $\mathrm{Zr}_{2} \mathrm{CuNi}$ and $\gamma=0.1 \mathrm{a} / \mathrm{b}=0.01$ is the shear strain $(a / b$-martensitecrystals aspect ratio) and, finally, $d \tau=0.489 \mathrm{GPa}$. Then, the shear stresses that can be produced by martensitic crystal in surrounding aus- 


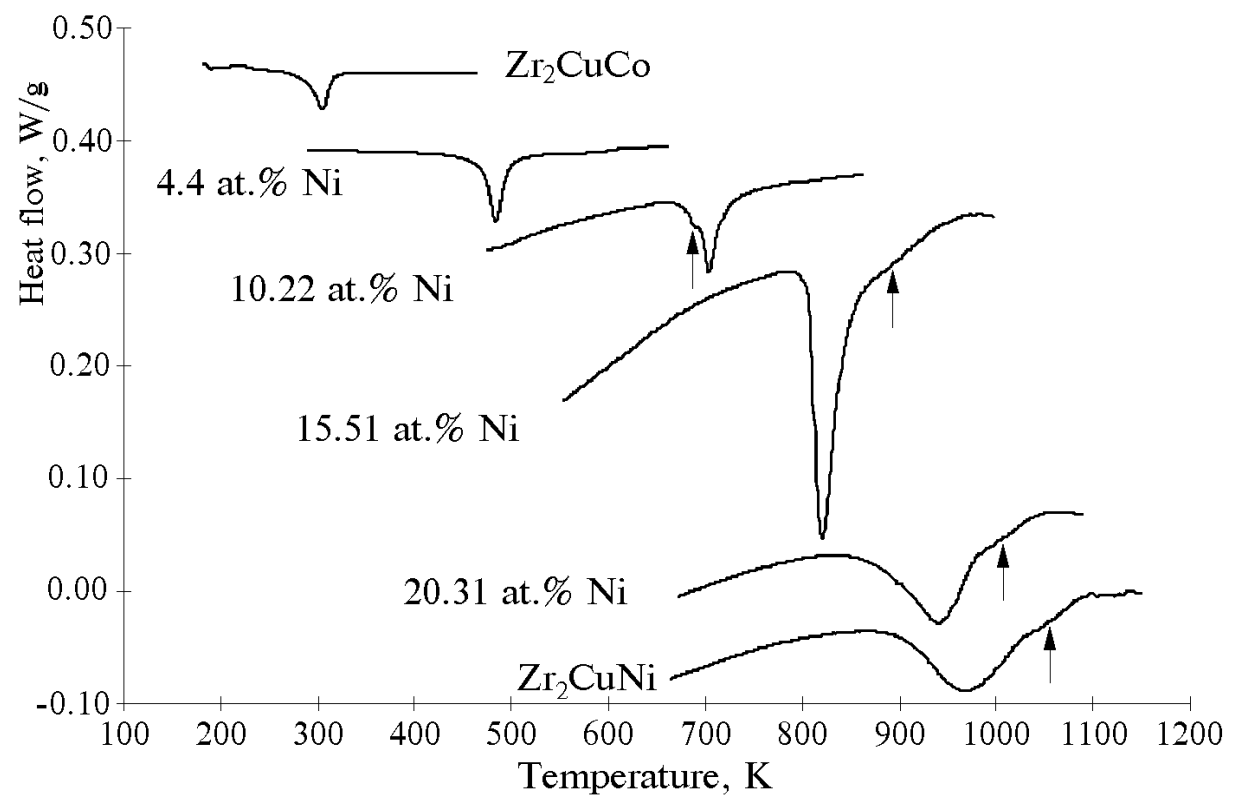

Figure 23. Evolution of endothermic reaction peaks during reverse MT along the $\mathrm{Zr}_{2} \mathrm{CuCo}-\mathrm{Zr}_{2} \mathrm{CuNi}$ quasi-binary cross-section (Ni for Co substitution); arrows indicate the position of the reverse MT stage that can be put into the correspondence with the second stage of the forward MT.

tenite can be estimated from the following expression: $\tau=G \gamma=0.5 E \gamma$, where $G$ and $E \approx 100 \mathrm{GPa}$ [34] are the shear and Young's moduli and we achieve $\tau \approx 0.5 \mathrm{GPa}$. So, it means that after partial reverse cycle small austenitic 'islands' are imposed by elastic stresses produced by the neighbouring martensitic crystals and their influence is enough to suppress the subsequent forward partial MT in a way that we have observed (Fig. 13f). Naturally, the martensite crystals produce short range stresses in a matrix. That is why the maximal effect of partial forward MT decrease was achieved at smaller degrees of partial reverse MT. The shape of partial hysteresis loop came nearer to the shape of complete cycle at higher degrees of partial reverse MT because the austenite becomes more free from the influence of internal stresses. Thus, it can be concluded that the unusual behaviour on partial thermal cycling in $\mathrm{Zr}_{2} \mathrm{CuNi}$ compound may be attributed to the elastic interaction between martensitic crystals of different type and austenite due to the observed effect of the restoration of the original shape of the complete hysteresis loop after partial cycles.

Disappearance of the effect described above on Co additions is combined with the reverse partial paths of temperature increase that can be attributed to the significant changes in martensites volume fractions (Fig. 15). 
It should be fairly noted that all the estimations can be applied even for the thermoelastic MT in $\mathrm{Zr}_{2} \mathrm{CuCo}$ or in another known SMA where such effects are absent or very weak. It means that one has to take into account not only the volume fractions of two different martensites but also their configurations in respect to each other. This task needs quantitative metallographic measurements that are now in progress.

\subsection{Influence of Alloying and Thermal Cycling on the Martensitic Transformation and Shape Memory Effect in ZrCu Intermetallic Com- pound}

Figures $24 \mathrm{a}, 26 \mathrm{a}$ and $28 \mathrm{a}$ show the results of the electrical resistivity vs temperature measurements during alloying by $\mathrm{Ni}, \mathrm{Ti}$ and $\mathrm{NiTi}$ respectively. Additions of the Ni lead to the general increase of the Ms temperature up to $510^{\circ} \mathrm{C}(19.85$ at.\% of $\mathrm{Ni})$ with a small minimum at 2.1 at.\% of $\mathrm{Ni}$ (Fig. 24a, solid line). Titanium and NiTi additions, on the other hand, decrease the Ms (Figs. 26a, 28a, solid line). The hysteresis of the MT in all cases passes through a maximum (Figs. 24a, 26a, 28a, dashed line).

At higher concentrations of $\mathrm{Ni}$ hysteresis decreases to the approximately initial value, $\sim 200^{\circ} \mathrm{C}$, whereas for $\mathrm{Ti}$ and $\mathrm{NiTi}$ additions, the hysteresis drops to even lower values, $\sim 50^{\circ} \mathrm{C}$ (at 12.91 and 39.81 at.\%, respectively).

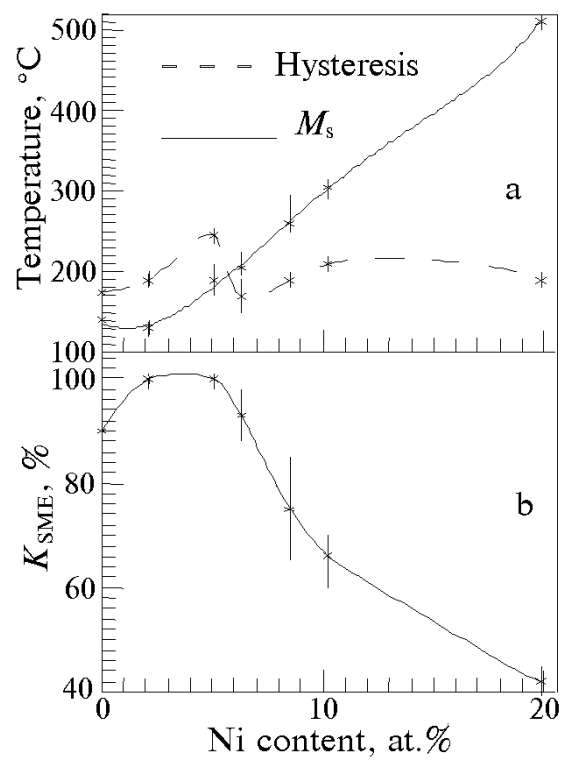

Figure 24. Hysteresis, $M_{\mathrm{s}}(\mathrm{a})$ and shape recovery ratio (b) behaviour vs $\mathrm{Ni}$ content.

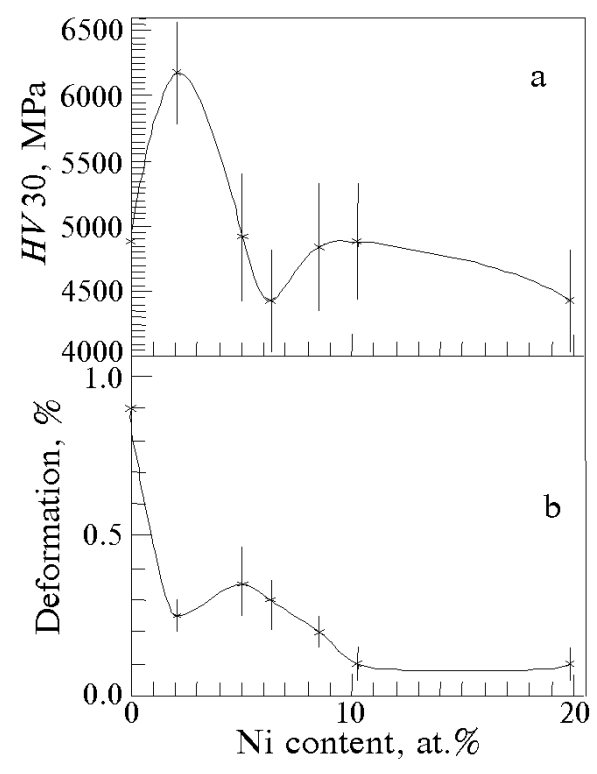

Figure 25. Vickers hardness (a) and martensitic deformation stored under $100 \mathrm{MPa}$ (b) behaviour vs Ni content. 


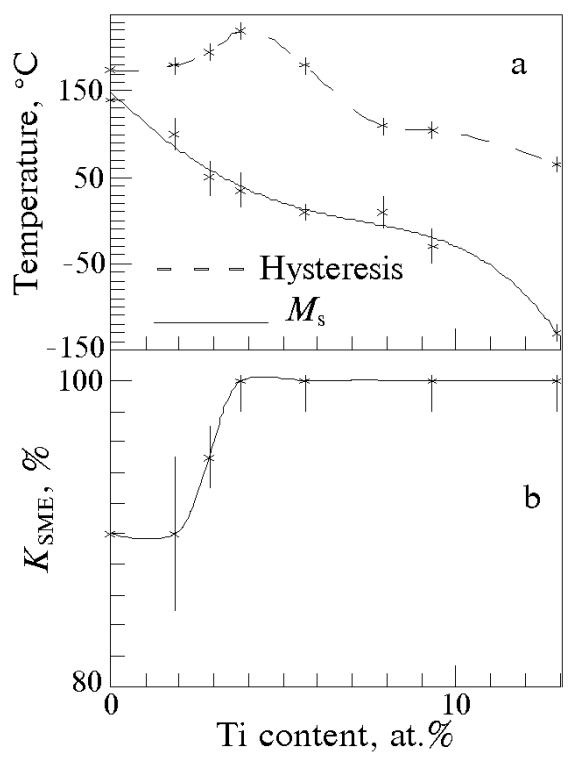

Figure 26. Hysteresis, $M_{\mathrm{s}}$ (a), and shape recovery ratio (b) behaviour $v s \mathrm{Ti}$ content.

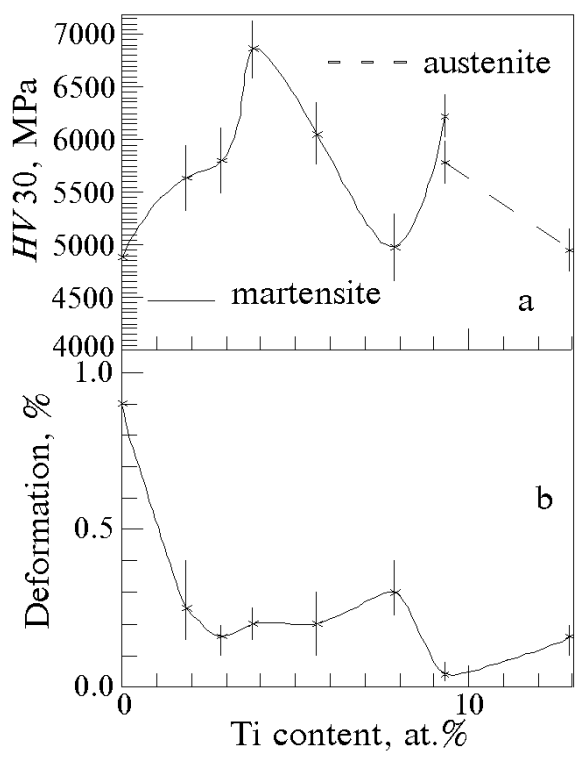

Figure 27. Vickers hardness (a) and martensitic deformation stored under $100 \mathrm{MPa}$ (b) behaviour vs Ti content.

SME examination shows the increase of the shape recovery to $100 \%$ in the case of alloying by $\mathrm{Ti}$ and $\mathrm{NiTi}$ (Figs. 26b, 28b). The influence of $\mathrm{Ni}$ is shown in Fig. 24b. It is seen that the complete SME was observed only at $\sim 2-5$ at. $\%$ of $\mathrm{Ni}$ when the curve passes through its maximum. Further alloying by $\mathrm{Ni}$ leads to the decrease of shape recovery to $\sim 40 \%$ at 19.85 at.\% of Ni. Martensitic deformation stored under the $100 \mathrm{MPa}$ load during forward MT for all alloying cases is shown in Figs. 25b, 27b and 29b. The martensitic deformation, from this figures, is seen to drop from a value of $0.9 \%$ for $\mathrm{ZrCu}$ to $0.1-0.3 \%$ when nickel and titanium are added to this alloy.

The results of the Vickers hardness measurements are shown in Figs. 25a, 27a and 29a. The HV30 of the martensite in $\mathrm{ZrCu}$ is nearly 5000 $\mathrm{MPa}$. Alloying with nickel reduces the $H V 30$ to about $4500 \mathrm{MPa}$, through a maximum of $6000 \mathrm{MPa}$ is observed for an alloy with 2.1 at.\% of $\mathrm{Ni}$. Titanium and $\mathrm{NiTi}$ additions, on the other hand, harden the $\mathrm{ZrCu}$. For NiTi additions the $H V 30$ value passes through a maximum $(\sim 7000 \mathrm{MPa})$ at 21.7 at.\% of NiTi but decreasing subsequently with further addition to the initial unalloyed value (Fig. 29a, solid line). HV30 of austenite at $\sim 30$ at.\% of $\mathrm{NiTi}$ addition is smaller than that of martensite but some increase (not more than $1000 \mathrm{MPa}$ ) with further addition is observed (Fig. 29a, dashed line). In the initial stages, changes in the HV30 of martensite with titanium additions is very similar to that of NiTi additions (Fig. 27a, solid 


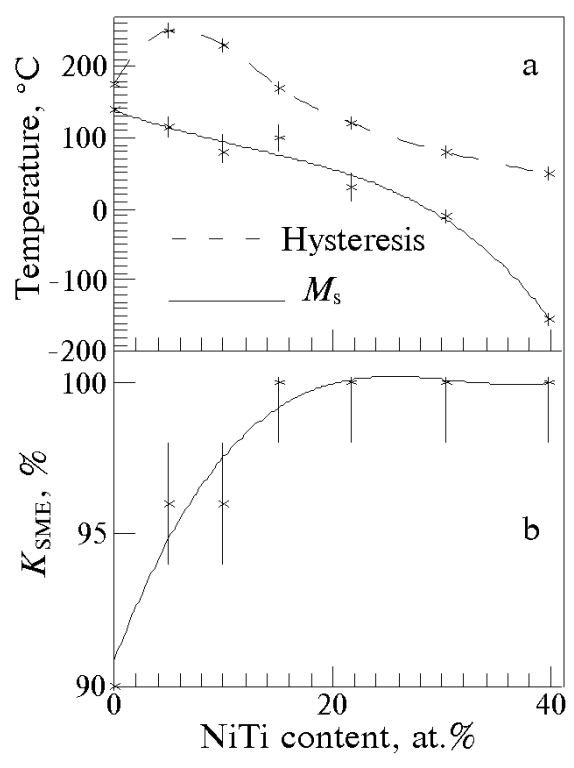

Figure 28. Hysteresis, $M_{\mathrm{s}}$ (a), and shape recovery ratio (b) behaviour vs NiTi content.

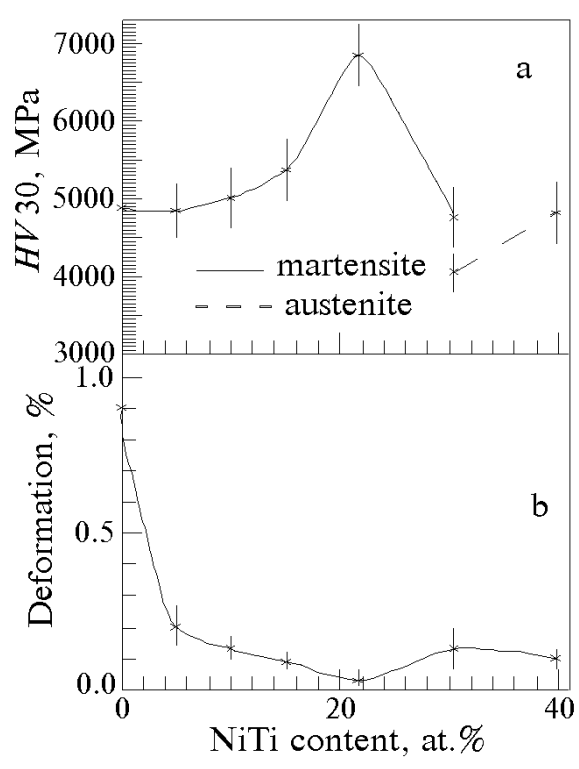

Figure 29. Vickers hardness (a) and martensitic deformation stored under $100 \mathrm{MPa}$ (b) behaviour vs NiTi content.

line). At later stages the behaviour becomes more complex.

The changes in the stored martensitic deformation and HV 30 correlate well with the changes in HV30 produced on alloying. An increase in hardness corresponds to a decrease in the martensitic deformation (Figs. $25,27,29$ ). Since the hardness is proportional to the yield stress, it is most likely that the increased yield stress affects the martensitic deformability.

As for the shape recovery decrease in the case of alloying with $\mathrm{Ni}$, it may be attributed to the negative slope of the yield stress temperature dependence, because we was obliged to load our specimens above $M_{\mathrm{s}}$, which rises with the increase of the $\mathrm{Ni}$ content.

According to the views developed in [43] the martensitic transition temperatures of the TiMe (Me: Metal) compounds depend on the ratios of the lattice parameters and the density of states $(N(E))$ at the Fermi level in TiMe and in pure Ti. The increase of the $N(E)$ at the Fermi level destabilizes $B 2$ phase in respect to martensite and vice versa. It has been shown that the similar dependence is valid for ZrMe compounds as well. Thus, the changes in the electronic concentration (e/a) must lead to changes in the values of $N(E)$ at the Fermi level resulting in the $M_{\mathrm{s}}$ shift. So, the $M_{\mathrm{s}}$ increases on alloying with $\mathrm{Ni}$ (Fig. 30, solid line), which has an atomic radius close to $\mathrm{Cu}$ and a higher e/a, implying that $\mathrm{Ni}$ additions 


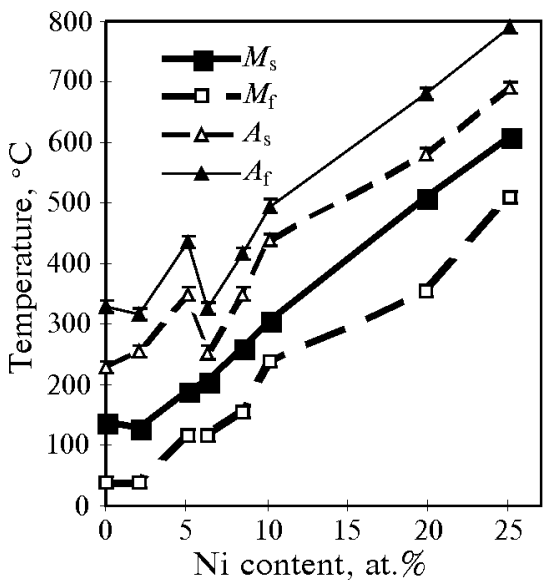

Figure 30. Characteristic temperatures of the MT vs Ni content.

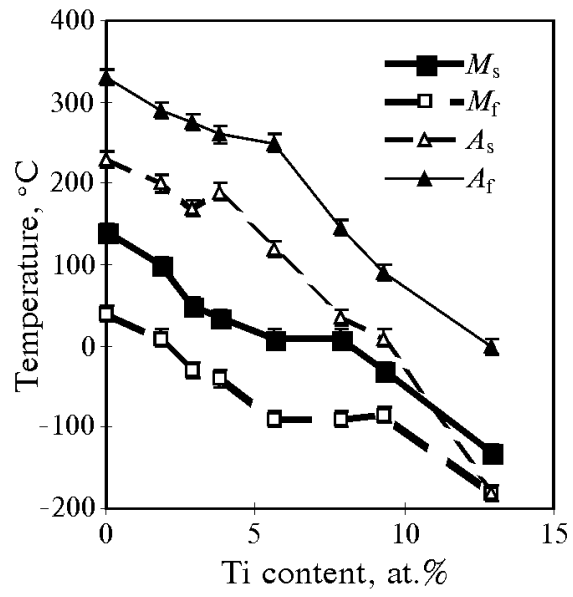

Figure 31. Characteristic temperatures of the MT vs Ti content.

must result in the increase of the $N(E)$ at the Fermi level.

Alloying with $\mathrm{Ti}$ and $\mathrm{NiTi}$ leads to an $M_{\mathrm{s}}$ drop (more intensive in the $\mathrm{Ti}$ case; see Figs. 26a, 28a, solid line). In contrary to $\mathrm{Ni}$, Ti has an identical e/ $a$ and smaller atomic radius. It has been shown [44] that the alloying with an element having the same $e / a$, is equivalent to the influence of external pressure. Describing the effect of pressure on the thermal hysteresis of

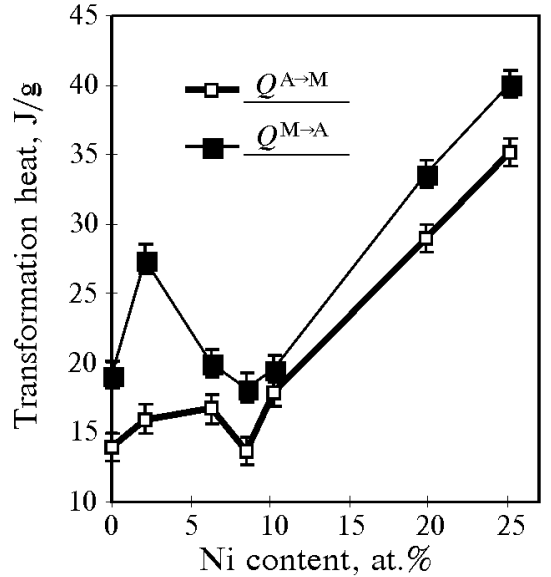

Figure 32. Transformation heats of the MT vs Ni content.

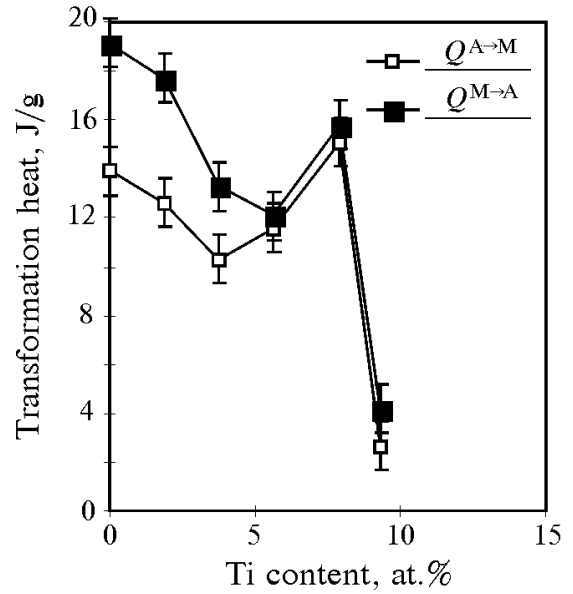

Figure 33. Transformation heats of the MT vs Ti content. 


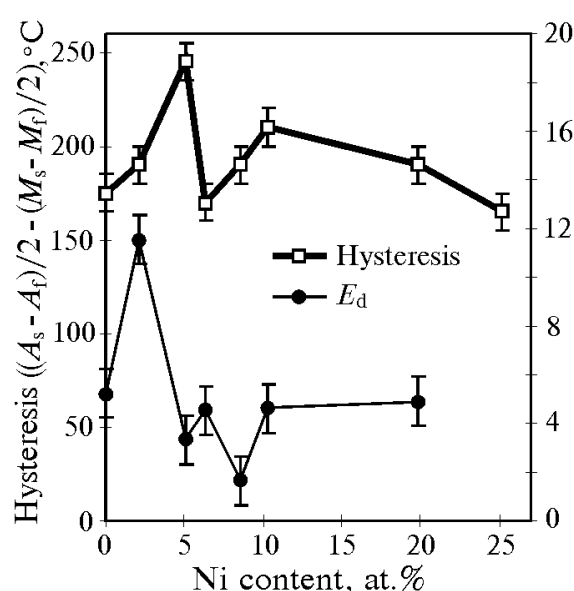

Figure 34. Comparison of the hysteresis of the MT and energy dissipated on the complete cycle vs Ni content.

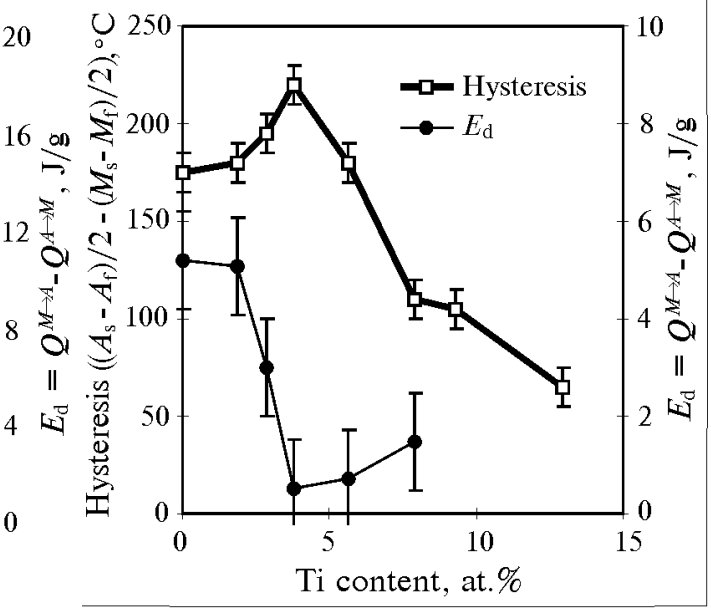

Figure 35. Comparison of the hysteresis of the MT and energy dissipated on the complete cycle vs Ti content.

a first-order transition, Das and Ghosh [45] have shown that the thermal hysteresis becomes progressively larger with increasing pressure. It may then be supposed that the substitution of $\mathrm{Zr}$ by Ti leads to a widening of the thermal hysteresis of the MT in $\mathrm{ZrCu}$ with alloying additions. On the other hand, Wang and Ernst [5] have shown that the stability of the $B 2$ phase in respect to martensite rises in $\mathrm{ZrMe} \rightarrow$ TiMe equiatomic compounds row. This fact would also explain the decrease in the martensitic temperatures as $\mathrm{Ti}$ is substituted for $\mathrm{Zr}$ in $\mathrm{ZrCu}$.

In order to check the validity of our previous assumptions, a systematic study was carried out by means of paramagnetic susceptibility measurements, X-ray diffractometry, and X-ray photoelectron spectroscopy (XPS) in order to determine crystal and electronic structure changes along with alloying additions. The experimental MT temperatures were compared with those calculated for ZrCu-based alloys with the help of Shabalovskaya semiempirical approach [43]. The results of such a comparison are discussed below.

According to [45] the ratio between the lattice parameters of the high temperature phase of the concerned TiMe compound and pure $\mathrm{Ti}$ is the term of an equation for $M_{\mathrm{s}}$ which defines TiMe $B 2$ phase stability. In our case we shall consider the ratio between lattice parameters of the $B 2$ phase of $\mathrm{ZrCu}$-based alloys and the lattice parameter of the $\beta$-phase of pure Zr. Experimental results are shown in Fig. 36. It can be seen that alloying with $\mathrm{Ni}$ replacing $\mathrm{Cu}$ does not result in any significant changes in lattice parameter of the $B 2$ phase at $1173 \mathrm{~K}$. On the contrary, Ti replacing $\mathrm{Zr}$ additions result in a linear decrease $\left(a_{B 2}=3.260_{3}-3.2 \cdot 10^{-3} C_{\mathrm{Ti}} \AA, C_{\mathrm{Ti}}-\right.$ 


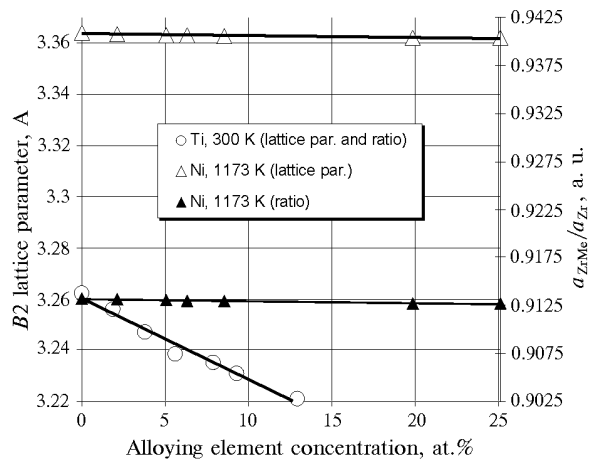

Figure 36. B2-lattice parameters and $a_{\mathrm{zrMe}} / a_{\mathrm{zr}}$ ratio $v s$ alloying of $\mathrm{ZrCu} \mathrm{com}$ pound.

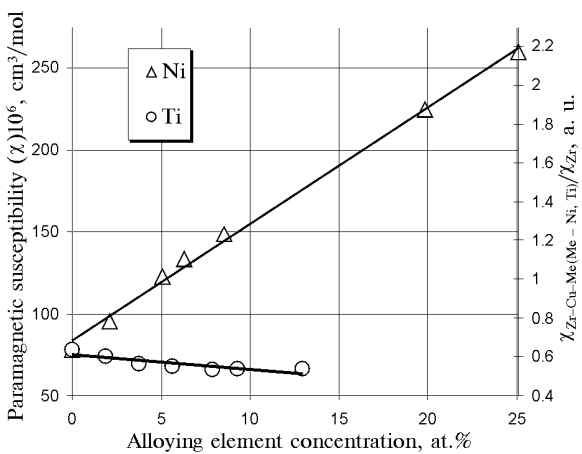

Figure 37. Paramagnetic susceptibility and $\chi_{\mathrm{ZrMe}} / \chi_{\mathrm{Zr}}$ ratio $v s$ alloying of $\mathrm{ZrCu}$ compound.

at.\% $\mathrm{Ti}$ ) of the room temperature $B 2$-phase lattice parameter. In the case of alloying by $\mathrm{Ti}$ we used room temperature lattice parameter of $\mathrm{Zr} \beta$ phase [47] $\left(a_{\beta}^{R T}=3.5658_{5} \AA\right)$ for $a_{(Z r, T i) C u} / a_{Z r}$ calculations. In the case of alloying by $\mathrm{Ni}$ we measured lattice parameter of $\mathrm{Zr} \beta$-phase at $1173 \mathrm{~K}$ $\left(a_{\beta}^{1173 \mathrm{~K}}=3.6835_{3} \AA\right)$ for $a_{\mathrm{Zr}(\mathrm{Cu}, \mathrm{Ni})} / a_{\mathrm{Zr}}$ calculations. The ratio itself is about 0.9 in magnitude (Fig. 36) and remained almost unchanged. Nevertheless, in both cases of alloying, a linear dependence of the austenite lattice parameters takes place. It means that, contrary to Shabalovskaya findings for TiMe compounds (parabolic dependence of the austenite lattice parameter on $M_{\mathrm{s}}$ ) [43], we have to make changes for the ZrMe $M_{\mathrm{s}}$ expression as follows.

$$
M_{\mathrm{s}}=M_{\mathrm{s}}(\mathrm{Zr})\left(a_{\mathrm{ZrMe}, \mathrm{B} 2} / a_{\mathrm{Zr}, \text { b.c.c. }}\right)\left(\Delta E / W_{\mathrm{Me}}\right)\left[N_{d}\left(E_{\mathrm{F}}\right)_{\mathrm{ZrMe}} / N_{d}\left(E_{\mathrm{F}}\right)_{\mathrm{Zr}}\right] \text {, }
$$

where $M_{s}(\mathrm{Zr})=1136 \mathrm{~K}$, the temperature of the $\beta>\alpha \mathrm{MT}$ in pure $\mathrm{Zr}$; $a$ is the lattice parameter of the cubic $B 2$ or $\beta$-phase; $\Delta E$ is the shift of the maximum of the electronic density of states (e-DOS) of Me (in our case $\mathrm{Cu}$ and $\mathrm{Ni}$ ) in the compound with respect to that in the elemental state; $W_{\mathrm{Me}}$ is the Me e-band width in ZrMe compound; $N_{d}\left(E_{\mathrm{F}}\right)$ 's are the $\mathrm{Zr} d$ DOS's at Fermi level $E_{\mathrm{F}}$.

Since $\mathrm{ZrCu}$ is paramagnetic [11], its magnetic susceptibility is directly proportional to $\mathrm{Zr} d$-DOS at Fermi level according to Stoner expression [48]. It means that we can use the ratio of the ZrMe and pure Zr magnetic susceptibilities instead of DOS in the equation above. The results of room temperature magnetic susceptibility measurements $(\chi)$ are shown in Fig. 37 . It can be clearly seen that alloying by Ti does not change $\chi$ too much, while $\mathrm{Ni}$ additions significantly increase the paramagnetic susceptibility of $\mathrm{ZrCu}$. Taking into account room temperature magnetic susceptibility of pure $\mathrm{Zr}\left(120 \cdot 10^{-6} \mathrm{~cm}^{3} / \mathrm{mol}\right)$ we found the ratio $\chi_{\mathrm{ZrMe}} / \chi_{\mathrm{Zr}}$ for $\mathrm{Ti}$ additions to be 


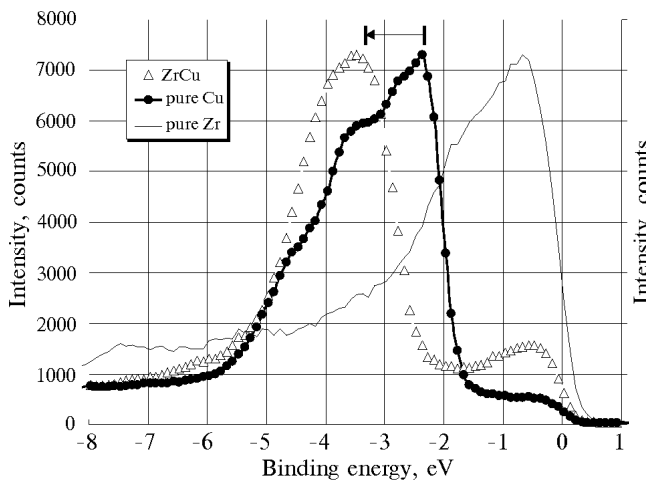

Figure 38. XPS valence band of the $\mathrm{ZrCu}$ compared with pure $\mathrm{Cu}$ and $\mathrm{Zr}$; $\Delta E$ shift is also shown.

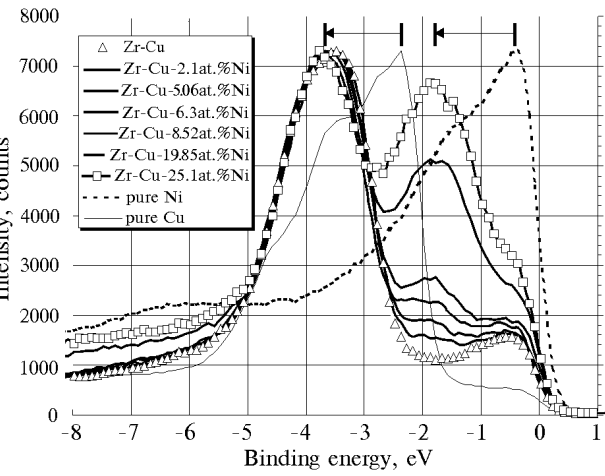

Figure 39. XPS valence band of the $\mathrm{ZrCu}$ along with $\mathrm{Ni}$ instead of $\mathrm{Cu}$ additions; $\Delta E$ shifts for $\mathrm{Zr}-\mathrm{Cu}-25.1$ at. $\% \mathrm{Ni}$ in respect with pure $\mathrm{Cu}$ and $\mathrm{Ni}$ spectra are also shown.

about $\sim 0.5$ in magnitude, while $\mathrm{Ni}$ additions result in the increase of such ratio from $\sim 0.5$ up to $\sim 2.2$.

$\Delta E$ and $W_{\text {Me }}$ were obtained using XPS measurements of the valence band of $\mathrm{ZrCu}$ quasi-binary intermetallic compounds. The results are shown in Figs. 38-41. It can be seen for the binary $\mathrm{ZrCu}$ compound (Figs. 38, 40, 41) that the electronic band shift in respect to pure $\mathrm{Cu}$ is about $0.93 \mathrm{eV}$, while the band width is about $1.6 \mathrm{eV}$. Alloying by Ti does not affect XPS valence band spectra in a very significant way though some changes were detected as a result of a peak fitting procedure (Fig.

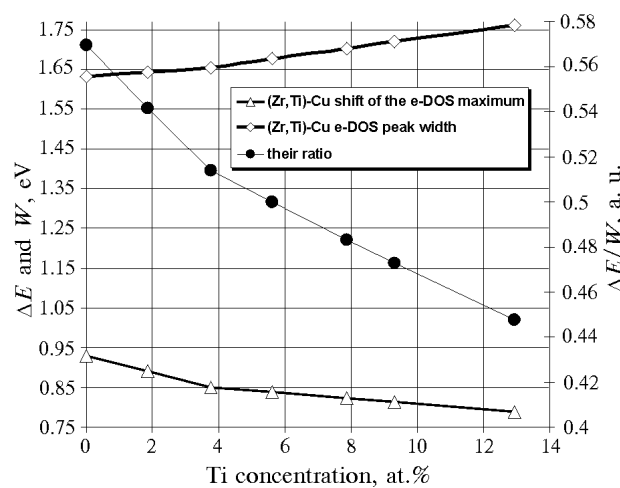

Figure 40. Valence band parameters of the $\mathrm{ZrCu}$ along with $\mathrm{Ti}$ replacing $\mathrm{Zr}$ additions.

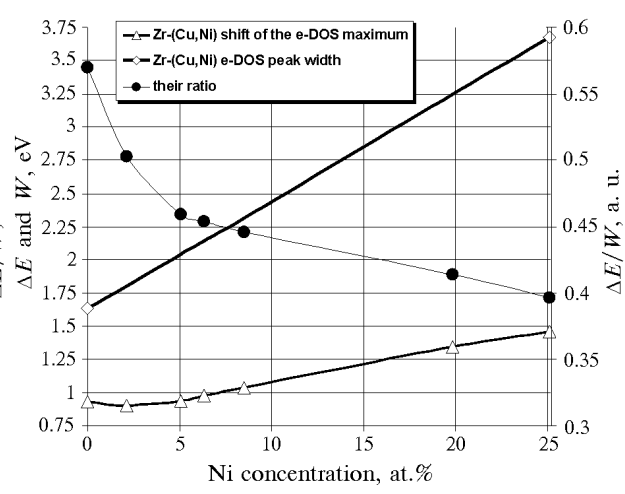

Figure 41. Valence band parameters of the $\mathrm{ZrCu}$ along with $\mathrm{Ni}$ replacing $\mathrm{Cu}$ additions. 


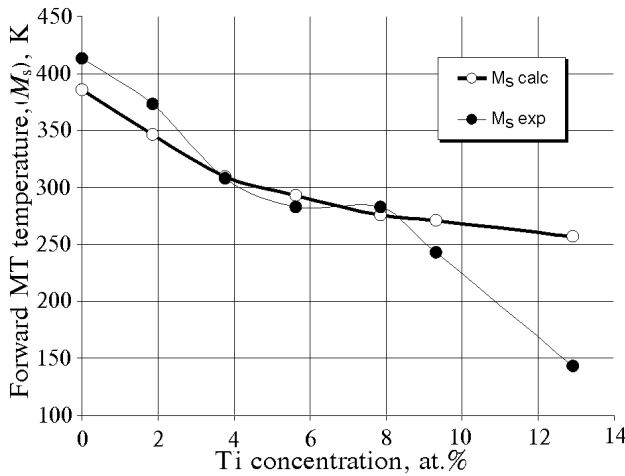

Figure 42. Experimental [4] and calculated $M_{\mathrm{s}}$ behaviour along with $\mathrm{Ti}$ replacing $\mathrm{Zr}$ additions.

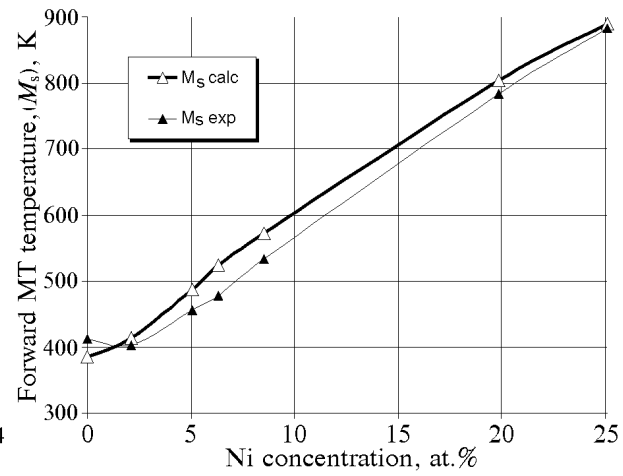

Figure 43. Experimental [4] and calculated $M_{\mathrm{s}}$ behaviour along with $\mathrm{Ni}$ replacing $\mathrm{Cu}$ additions.

40). Ni additions result in more visible alterations of the valence band (Fig. 39). In addition to the main peak in $\mathrm{ZrCu}$, located around $-3.5 \mathrm{eV}$, another peak arises closer to Fermi level (around $-1.9 \mathrm{eV}$ ) due to Ni additions. So, in this case we considered a specific value of $\Delta E$ taken as a weighed shift of the two peaks mentioned above in respect to pure $\mathrm{Cu}$ and pure Ni XPS spectra (Fig. 39). The $W_{\text {Me }}$ was assumed to increase linearly from $1.6 \mathrm{eV}$ in $\mathrm{ZrCu}$ to $3.25 \mathrm{eV}$ in $\mathrm{Zr}-(\mathrm{Cu}-25.1$ at.\% Ni) (width value was taken for both peaks together (Fig. 39)). As a result, we found that for both cases of $\mathrm{Ti}$ and $\mathrm{Ni}$ alloying the $\Delta E / W_{\mathrm{Me}}$ ratio behaves in a similar way decreasing from $\sim 0.57$ to $\sim 0.45$ (Figs. 40, 41).

Finally, we were able to calculate Ms values using the formula presented above for the binary $\mathrm{ZrCu}$ and $\mathrm{ZrCu}$-based quasi-binary intermetallic compounds containing $\mathrm{Ti}$ and $\mathrm{Ni}$. The results of such calculations compared with $M_{\mathrm{s}}$ experimental data [14] are shown in Figs. 42 and 43 respectively. It can be seen that the absolute calculated $M_{\mathrm{s}}$ values dovetail into experimental data well. In this sense, all terms of the expression for $M_{\mathrm{s}}$ of ZrMe quasi-binary compounds are of the same importance. On the other hand, in the case of Ni alloying only the term, that corresponds to an increase of $Z r d$-states at Fermi level $\left(\chi_{z r M e} / \chi_{z r}\right)$ due to their redistribution from the depth of the valence band, governs $M_{\mathrm{s}}$ increase or, in other words, instability of the high-temperature $B 2$ phase. In the case of the binary $\mathrm{ZrCu}$ and $\mathrm{Ti}$ alloying, the $\Delta E / W_{\mathrm{Me}}$ term, which is controlling interatomic interaction in compounds, determines the $M_{\mathrm{s}}$ decrease or, in other words, B2-phase stability. In this case bonding increases due to the enhancement of $s p-d$ hybridization. The quantum mixing of the orbitals results in suppression of the tendency towards shear transformation as well as it was pointed out in [45] for TiMe compounds.

In all of alloying cases the increase in shape recovery is accompanied 


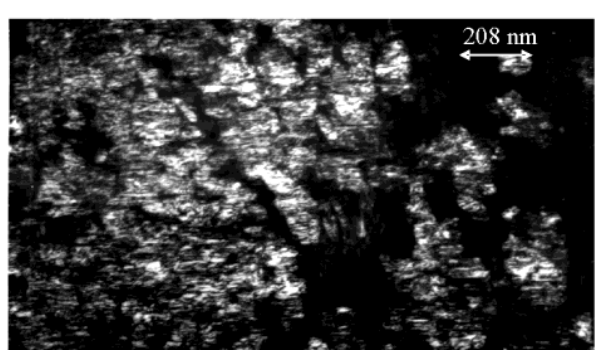

a

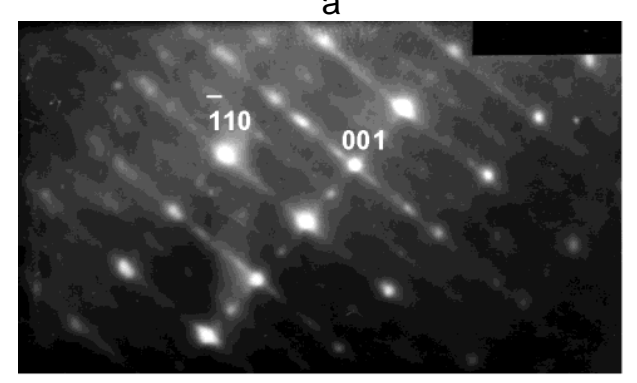

C

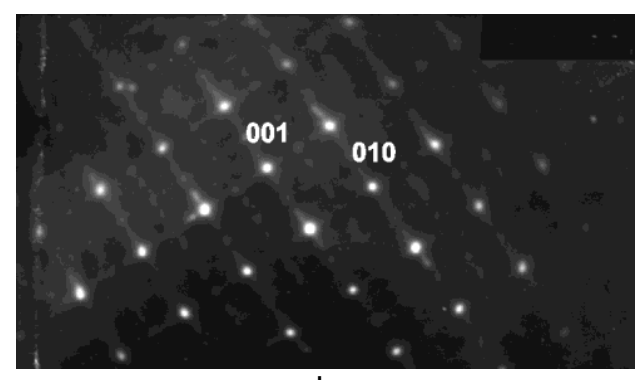

b

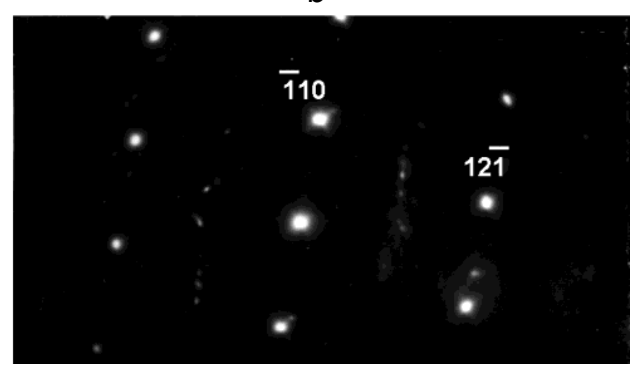

d

Figure 44. Structure of the $\mathrm{ZrCu}$ compound after the 90 cycles in $-196-400^{\circ} \mathrm{C}$ temperature range and subsequent heating to $400^{\circ} \mathrm{C}$ (B2 austenite): dark field in (100) type reflection (a); diffraction pattern, zone axis [100] (b); diffraction pattern, zone axis [110] (c); diffraction pattern, zone axis [113] (d).

by a widening of the hysteresis loop, a situation similar to that occurring upon thermal cycling of the equiatomic $\mathrm{ZrCu}$ [2]. Some structural changes are responsible for such situation in the latter case. So, let us describe these changes in comparison with MT and SME behaviour during thermal cycling of $\mathrm{ZrCu}$.

The results of electron microscopic investigation at room temperature of the $\mathrm{ZrCu}$ specimens in thermally cycled state (after 90 cycles in -196$400^{\circ} \mathrm{C}$ temperature range with the heating-cooling rate $50-100^{\circ} \mathrm{C} / \mathrm{sec}$ ) are shown in Figs. 44, 45.

In the austenitic state (after the heating to $400^{\circ} \mathrm{C}$, Fig. 44) the formation of the cellular substructure with regular dislocations ensembles of high density were revealed. The dislocations (Fig. 44a) are oriented perpendicular to the diffusive streaks running to (100) type reflections (Fig. 44b) and (110) type reflections (Fig. 44c). Appearance of the weak spots of $1 / 2(100)$ and $1 / 2(110)$ type (Fig. 44b) can be attributed to the formation of zones with lower translation symmetry than in the major $B 2$ structure.

In the martensitic state (after the cooling to $-196^{\circ} \mathrm{C}$ ) only the thin plates (10-20 nm thickness) of the B19' martensite (Fig. 45a) can be found. These thin plates are in the twinning correspondence $\left((011)_{B 19^{\prime}}\right.$ twinning plane) to each other similar to the as-cast condition [2] and filling 


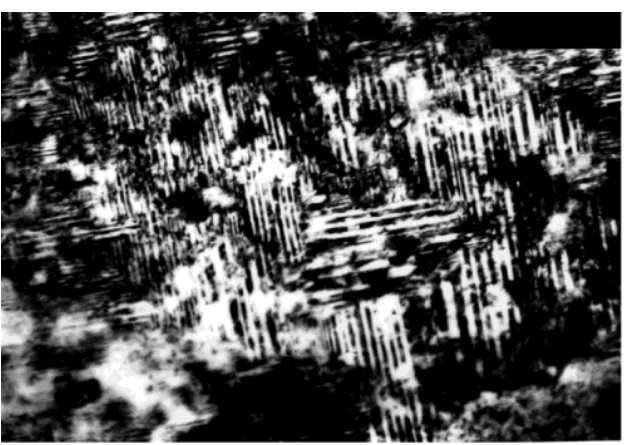

a

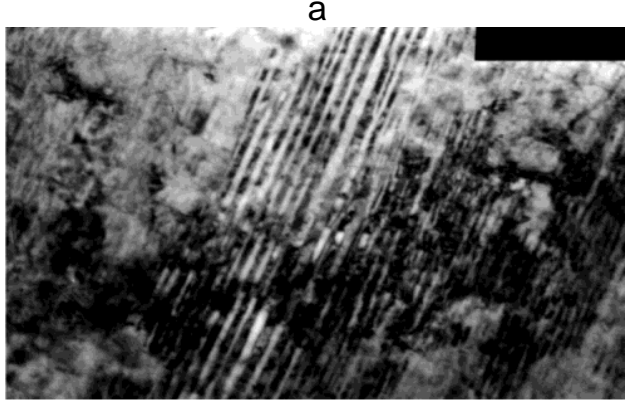

C

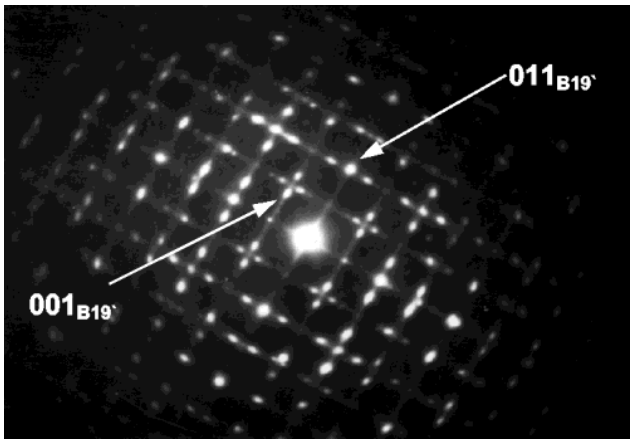

b

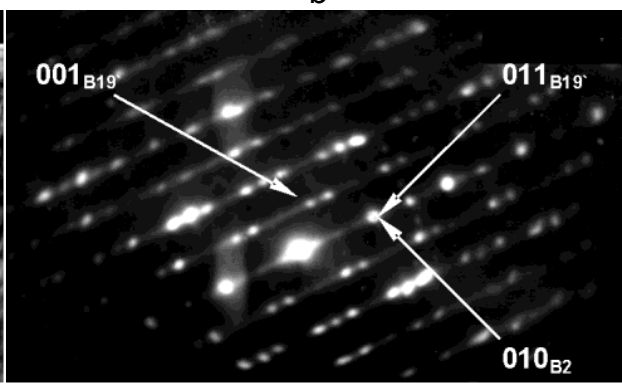

d

Figure 45. Structure of the $\mathrm{ZrCu}$ compound after the 90 cycles in $-196-400^{\circ} \mathrm{C}$ temperature range and subsequent cooling to $-196^{\circ} \mathrm{C}\left(B 19^{\prime}\right.$ martensite): bright field from the orthogonal oriented ensembles of martensite crystals (a) and corresponded diffraction pattern, zone axis [100] (b); bright field from the neighbouring martensite and retained austenite (c) and corresponded diffraction pattern, zone axis [100] (d).

the cells seen in the austenitic state (Fig. 44a). So, it can be also seen that the thickness of the $B 19^{\prime}$ martensite plates undergoes ten fold decrease during thermal cycling in comparison with the as-cast condition [2]. Figures $45 \mathrm{c}$ and $45 \mathrm{~d}$ represent the neighbouring austenite and martensite regions and corresponded diffraction pattern. Analysis of this pattern gives us the possibility to identify the orientation relationship between austenite and $B 19^{\prime}$ martensite for $\mathrm{ZrCu}$

$$
[100]_{B 2}\left\|[100]_{B 19^{\prime}}, \quad(010)_{B 2}\right\|(011)_{B 19^{\prime}}
$$

that is in good agreement with the scheme of the distortions and shuffles for $B 2 \rightarrow B 19^{\prime}$ structure change given in section 1.2 of this article (Fig. 4, [24]).

We have also studied the MT and SME behaviour in equiatomic $\mathrm{ZrCu}$ on thermal cycling by ac electrical resistivity method and bending technique [22] correspondingly. The results are shown in Figs. 46-48. Evolu- 


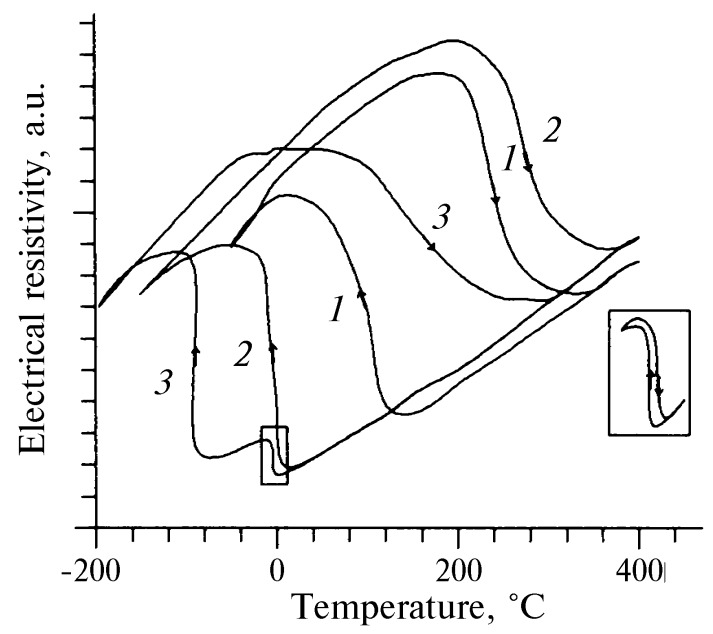

Figure 46. The changes of the MT hysteresis loop in $\mathrm{ZrCu}$ during thermal cycling: 1) 2nd cycle, 2) 45th cycle, 3) 90th cycle.

tion of the MT hysteresis loops shows (Fig. 46) that at the initial stage of thermal cycling (up to 50 cycles) the widening of the hysteresis loop takes place (from $180^{\circ} \mathrm{C}$ to $300^{\circ} \mathrm{C}$ ) without significant changes in temperature intervals of $\mathrm{MT}\left(\sim 100^{\circ} \mathrm{C}\right)$ and in the temperature position of the geometric centre of the full hysteresis loop (or $T_{0}$ position). Subsequent thermal cycling results in serious lowering of the $M_{\mathrm{s}}$ temperature with continuous widening of the hysteresis and appearance of the second stage of MT with narrow hysteresis that takes place close to the $-10^{\circ} \mathrm{C}$ (Fig 46, 90th cycle, insert).

The similar behaviour was observed (Fig. 47) during DSC measurements (performed at $10^{\circ} \mathrm{C} / \mathrm{min}$ heating-cooling rate). The splitting of the MT into two stages with the increase of the number of thermal cycles is clearly seen (Fig. 47a-e). The difference between the DSC and electrical resistivity measurements results in the number of cycles necessary for the splitting mentioned above caused by the different heating-cooling rates used. Nevertheless, the transformation temperatures of the MT with narrow hysteresis correlate well for both methods. The heats of the transformation for this transition are very close in values to the thermoelastic MT's (Table 6, Fig. $47 \mathrm{f}, \mathrm{g}$ ). So, it can be supposed that the shape recovery should be complete for this transition.

The results of SME measurements are shown in Figs. 48, 49. Samples in as-cast state demonstrate nearly complete SME (85-90\% of shape recovery ratio) (Fig. 48). The amount of martensitic deformation was equal to $0.5-1.3 \%$, which was stored under the external stress $50-150$ $\mathrm{MPa}$. It was found that the recovery stress generation takes place during reverse MT on heating (Fig. 48, dashed line). Shape recovery ratio in this 


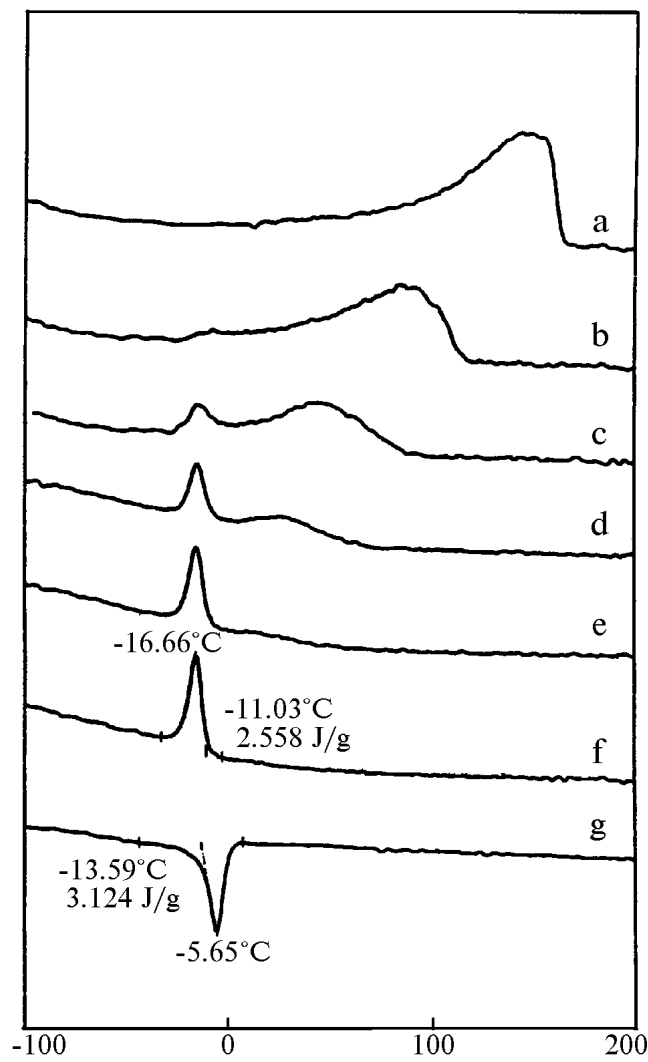

Figure 47. Evolution of $\mathrm{DSC}$ curves for $\mathrm{ZrCu}$ in $-100^{\circ} \mathrm{C}-400^{\circ} \mathrm{C}$ temperature range: a) 2nd cycle cooling, b) 4th cycle cooling, c) 6th cycle cooling, d) 8th cycle cooling, e) 10th cycle cooling, f) 12th cycle cooling, g) 12th cycle heating.

case is lowered to $60 \%$.

SME behaviour of thermally cycled specimens is shown in Fig. 49. It is seen that both of the MT stages are accompanied by complete SME excluding the situation when the sample restores its shape in the presence of external load ( $10 \%$ of shape recovery ratio only). Complete SME in the case of MT with narrow hysteresis is realized simultaneously with the generation of considerable recovery stresses (up to $300 \mathrm{MPa}$ ).

It should be remarked that the stored martensitic deformation under $150 \mathrm{MPa}$ in specimens after thermal cycling treatment is smaller than in as-cast state. MT with narrow hysteresis exhibits $0.1 \%$ and $0.4 \%$ of deformation is accumulated in the wide hysteresis case.

So, the influence of thermal cycling is expressed by an increase of shape recovery ratio (without external load) and widening of the hysteresis loop. Miyazaki, Igo, and Otsuka [50] explaining the effect of the thermal cycling in various shape memory alloys considered the following 


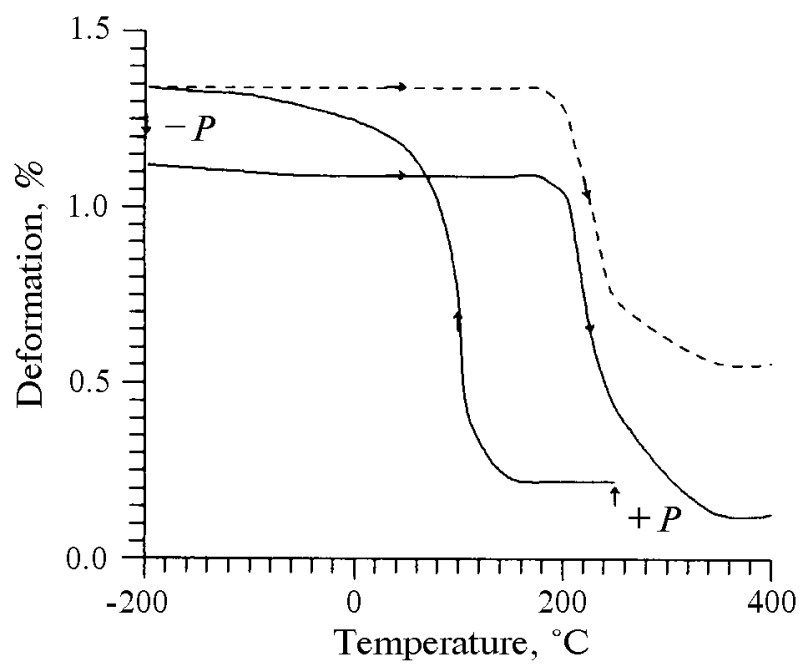

Figure 48. SME behaviour at the second thermal cycle (solid line-sample was unloaded before reverse MT, dashed line-shape recovery under external load), $P=150 \mathrm{MPa}$.

causes: a) change in the degree of order, b) ageing effect during thermal cycling, c) introduction of dislocations.

All of the causes mentioned may result in widening of the MT hysteresis loop.

On the other hand, the precipitation processes can harden the matrix and

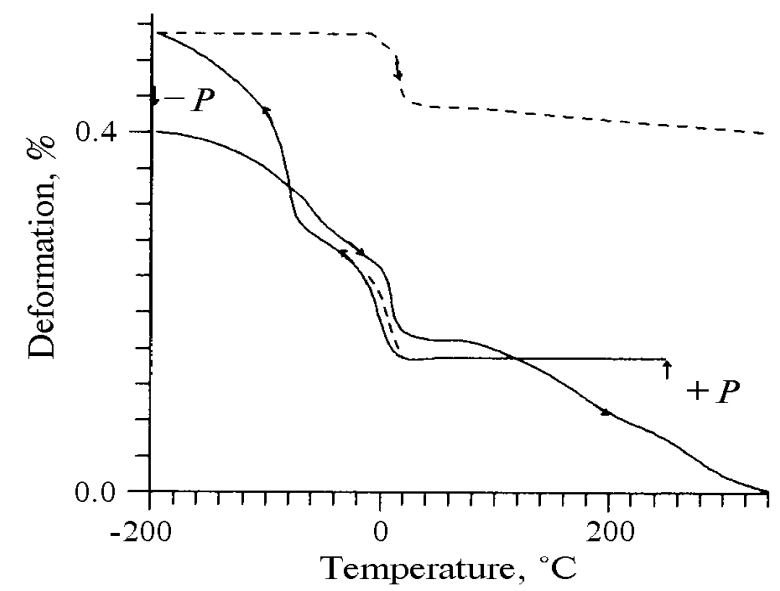

Figure 49. SME behaviour at the 90th thermal cycle (solid line-sample was unloaded before reverse MT, dashed line-shape recovery under external load), $P=150 \mathrm{MPa}$. 
prevent it from the irreversible plastic deformation by slip during SME. Introduction of dislocations influences on SME characteristics in the same way (see [51] for example). Apparently, in the case of thermal cycling of $\mathrm{ZrCu}$ alloy diffusional processes play an important role (unlike the TiNi alloy [50]) because of the wide temperature range of the thermal cycling $\left(-196-400^{\circ}\right.$ C). It confirms indirectly by dividing of the MT into two stages during thermal cycling (Figs. 46, 47, 49) and directly by the metallographic and electron microscopic studies when the precipitation of the second phase on the grain boundaries were found.

\section{NON-MARTENSITIC SHAPE MEMORY EFFECT DRIVEN BY AGEING PROCESSES}

The first report about the non-martensitic shape memory effect called 'length memory effect' were published in [52]. Then, the authors of [53] studied the structural, phase composition and long time strength at 1173-1373 $\mathrm{K}$ of directionally solidified Ni-base eutectic COTAC-744 [54] with $\gamma / \gamma^{\prime}-\mathrm{MeC}$ structure [53]. It was shown that the quenching from the temperature of full dissolution of the $\gamma^{\prime}$-phase and ageing at $1173 \mathrm{~K}$ for $108 \mathrm{ksec}$ provide the optimal size and morphology of $\gamma^{\prime}$-phase that is responsible for the increase of the long time strength at $1173-1373 \mathrm{~K}$ in this material. Repeated thermal treatment (RTT) consisted in annealing at $1473 \mathrm{~K}$ during $3.6-9 \mathrm{ksec}$ of the specimens subjected previously to creep tests on $1.5-1.8 \%$ results in general restoration of a) $\gamma^{\prime}$-phase size and morphology, b) defect structure, c) mechanical properties, and d) geometrical dimensions (this could be the reason for the appearance of the 'length memory effect' term) similar to [52]. The authors of [53] described the retained elastic stresses in $\gamma / \gamma^{\prime}$-matrix and single crystal $\mathrm{MeC}$ ( $\mathrm{Me}-\mathrm{Nb}, \mathrm{Ta}$ ) monocarbide fibres as the driving force of the effect mentioned above. These fibres are elongated elastically up to $1.5-1.8 \%$ of creep test deformation. At the same time, the matrix undergoing plastic deformation. After the creep test the fibres are deformed elastically by the elongation stresses and as a result the fibres applying the compression stresses on a matrix. After the RTT these compression stresses cause the restoration of the matrix shape and elastic unloading of the fibres. At the creep test deformations higher than $1.8 \%$ the relaxation of the retained stresses by the fibres fragmentation takes place that causes to the disappearance of the so-called 'length memory effect' [53].

So, it is clearly seen that the existence of the MT in material is enough for the SME but not necessary. The general necessary condition for the SME is the existence of the structural or microstructural reversibility caused by the non-relaxed (elastic) internal stresses appeared under the process of the accumulation of the deformation during the structural transformation.

Bublei, Koval, and Pasko [55] have examined shape recovery during heating in $\mathrm{Cu}-\mathrm{Al}-\mathrm{Mn}$ alloys after dynamic ageing in a state of strain. 
They used ones containing 11-12 mass.\% Al and from 2 to 6 mass.\% $\mathrm{Mn}$; they were melted in an induction furnace in argon and were then homogenized in the $\beta$-phase stability region (at $850^{\circ} \mathrm{C}$ ) for $20 \mathrm{~h}$. The compositions were determined by X-ray spectral means. The specimens were quenched in water from $900^{\circ} \mathrm{C}$. The heat treatment (ageing up to $400^{\circ} \mathrm{C}$ ) was in a salt bath.

The martensite transformation temperature ranges and the shape recovery characteristics (temperature dependence and degree of recovery) were determined according to [22]. The phase compositions were monitored by XRD with $\mathrm{Cu} K_{\alpha}$ radiation.

The $30 \times 2 \times 0.4 \mathrm{~mm}$ plates with the composition $\mathrm{Cu}+11.4$ mass. $\% \mathrm{Al}++$ 3.4 mass. \% Mn were given to dynamic ageing after quenching: they were bent in a cylindrical mount $20 \mathrm{~mm}$ in diameter to $2 \%$ strain and in that state were aged between 250 and $400^{\circ} \mathrm{C}$.

In the quenched state, the specimens showed shape memory related to the martensite transformation (Fig. 50a); on ageing a specimen that had not undergone preliminary dynamic ageing, there were no marked changes in the temperature range and shape recovery on ageing for up to $30 \mathrm{~min}$ at $250-400^{\circ} \mathrm{C}$. Similar results have been obtained $[56,57]$ for $\mathrm{Cu}-\mathrm{Al}-\mathrm{Mn}$ alloys similar in composition.

The shape memory effect in dynamically aged specimens was different from that in quenched ones. Figure $50 \mathrm{~b}$ shows the bending change on

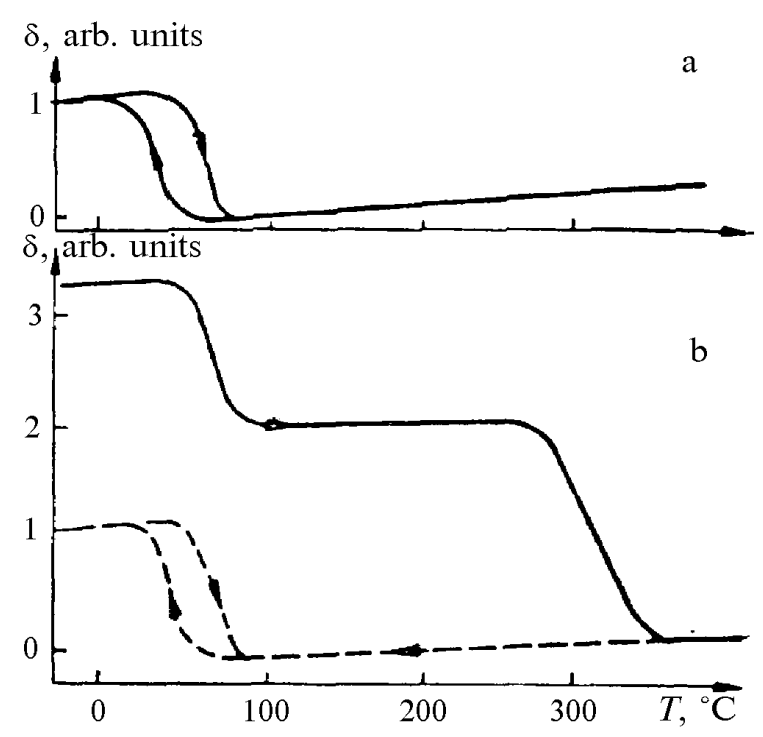

Figure 50. Variation in deflection $\delta$ (arbitrary units) on heating of quenched alloy (a) and an alloy dynamically aged at $250^{\circ} \mathrm{C}$ for $5 \mathrm{~min}$ (b), composition $\mathrm{Cu}+11.4$ mass.\% $\mathrm{Al}+3.4$ mass.\% $\mathrm{Mn}$. 
heating for $\mathrm{Cu}+11.4$ mass. \% $\mathrm{Al}+3.4$ mass. \% Mn dynamically aged for 5 $\min$ at $250^{\circ} \mathrm{C}$. The shape recovery is splitting in two stages: the first stage coincides with the temperature range for the reverse martensite transformation, while the second stage begins at $300-400^{\circ} \mathrm{C}$. During subsequent cooling and heating in a dynamically aged specimen, there was no shape recovery at high temperatures (second stage). The shape recovery curve did not differ from that for the variation in bending on heating and cooling for the quenched alloy. The resistivity during martensite transformation was examined as a function of temperature, which showed no fall in the shape recovery temperature range $300-400^{\circ} \mathrm{C}$, which shows that the high temperature recovery is not of martensitic type.

Ageing at $300-400^{\circ} \mathrm{C}$ for deformed specimens had different effect on the two stages. The low-temperature stage is unaffected with or without dynamic ageing. The shape recovery at high temperatures is reduced from $100 \%$ on ageing for $1 \mathrm{~min}$ at $250^{\circ} \mathrm{C}$ to $20 \%$ with $1 \mathrm{~min}$ at $400^{\circ} \mathrm{C}$ (Fig. 51). The range in which the high-temperature recovery occurs shifts upwards.

The quenched specimens were given various sequences of strain and ageing at $250^{\circ} \mathrm{C}$; ones previously aged for $1 \mathrm{~min}$ at $250^{\circ} \mathrm{C}$ and then strained in the mount at room temperature showed no shape recovery at high temperatures. The high-temperature effect can occur only on dynamic ageing for slightly decomposed $\beta_{1}$ phase.

XRD was applied to the changes on dynamic ageing; the phase diagrams for these alloys show that the $\beta_{1}$ phase at $410^{\circ} \mathrm{C}$ contains $\mathrm{Cu}+12$ mass. $\% \mathrm{Al}$ +7.5 mass. $\% \mathrm{Mn}$ and decomposes by a eutectoid mechanism with the formation of stable $\alpha, \gamma_{2}$ and $\mathrm{Cu}_{3} \mathrm{Mn}_{2} \mathrm{Al}$ phases. The XRD did not indicate any changes in structure in those phases in alloys after dynamic ageing. The quenched and dynamically aged specimens gave lines from the $\alpha, \gamma_{2}$ and $\beta_{1}$ phases, and the last, as in other $\mathrm{Cu}-\mathrm{Al}$ alloys, showed $\mathrm{B1}+D 0_{3}$ ordering. The lattice parameter for the $\beta_{1}$ phase for quenched $\mathrm{Cu}+11.4$ mass. $\% \mathrm{Al}+$ 3.4 mass. \% Mn was $a=0.288 \mathrm{~nm}$. Ageing at $250^{\circ} \mathrm{C}$ for up to $60 \mathrm{~min}$ increased monotonously to $0.292 \mathrm{~nm}$, where there was some broadening for the $\beta_{1}$ lines, which may be due to isostructural decomposition of the $\beta_{1}$ phase with the deposition of $\mathrm{Cu}_{2} \mathrm{MnAl}$ particles in the $\mathrm{Cu}_{3} \mathrm{Al}$ matrix [58]. The amounts of the $\alpha$ - and $\gamma_{2}$-phases were only $10-15 \%$ in the quenched and dynamically aged specimens that showed the high-temperature shape memory effect. The $\gamma_{2}$ phase has an f.c.c. lattice of $\gamma_{2}$ brass type and corresponds to $\mathrm{Cu}_{9} \mathrm{Al}_{4}$ in binary alloys, while the $\alpha$-phase is a solid solution of manganese and aluminium in copper.

Increasing the dynamic-ageing time or raising the ageing temperature increases the amounts of $\alpha$ and $\gamma_{2}$ phases segregating; at the same time, there is a reduction in the deflection on shape recovery at $250-350^{\circ} \mathrm{C}$, with the range in which the effect occurs shifting to higher temperatures (Fig. 52).

The quenched and dynamically aged specimens had the same phase composition, so the high-temperature effect may be due to the initial 


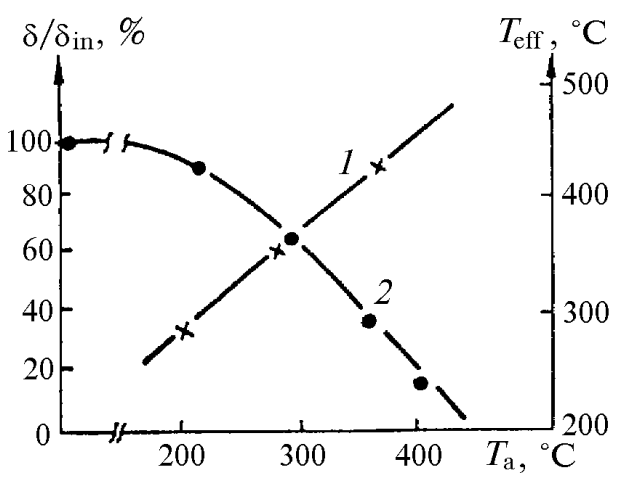

Figure 51. Temperature for the high temperature shape memory effect $\left(T_{\text {ef }}\right)$ (1) and shape recovery ratio $\delta / \delta_{\text {in }}$ in \% (2) as a function of dynamic ageing temperature $\left(T_{\mathrm{a}}\right)(t-1 \mathrm{~min})$.

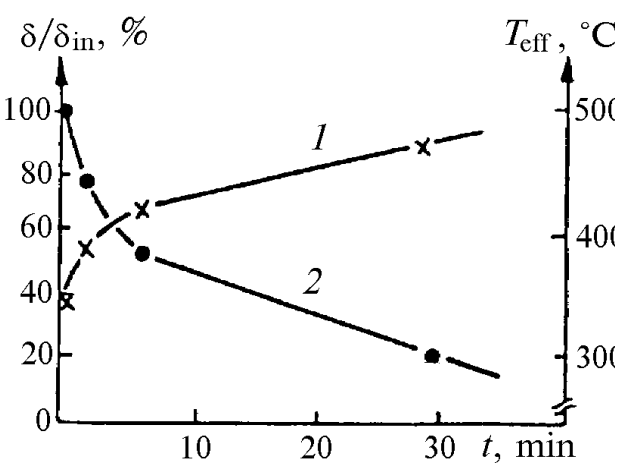

Figure 52. Temperature for the high temperature shape memory effect $\left(T_{\text {ef }}\right)$ (1) and shape recovery ratio $\delta / \delta_{\text {in }}$ in \% (2) as a function of dynamic ageing time $(t)\left(T_{\mathrm{a}}-350^{\circ} \mathrm{C}\right)$

stages of eutectoid decomposition in the $\beta_{1}$ phase, where the amounts of the segregating stable phases do not exceed $10 \%$, namely one gets $\alpha$ and $\gamma_{2}$ particles coherent with the $\beta_{1}$ matrix. Coherency is lost at a size $D_{\mathrm{cr}}$ and then the high-temperature shape memory effect weakens. At that time, which one can identify from hardness increase in the $\beta_{1}$ phase [59], there is no high-temperature shape memory effect.

Two-stage shape memory has been observed in $\mathrm{Cu}-\mathrm{Al}-\mathrm{Mn}$ alloys given dynamic ageing in the strained state after quenching; the first stage involves a martensite mechanism, while the second is not of martensite type. The range and extent of the recovery for the latter are dependent on the ageing temperature. That stage may be related to the initial steps in the eutectoid decomposition of the $\beta_{1}$ phase on ageing.

Another example of the similar behaviour can be found in [60]. The SME in Ti-52 at.\% Ni alloy was found in bending conditions at 773$973 \mathrm{~K}$. The authors of this paper attributed this effect to the precipitationdissolution processes of the $\mathrm{Ti}_{3} \mathrm{Ni}_{4}$ coherent particles. They also explained the process of the accumulation of the deformation in the terms of anisotropic mismatch between matrix and particles in addition to the preferential formation of the differently oriented particles variants in compressed and elongated sides of the specimens under constraint ageing in bending. Unfortunately, they did not show any structural result confirming their model.

Koval, Monastyrski and Firstov have studied the precipitation processes in Fe-Ni-Co-Ti system and obtained the same effect in the same temperature range [61].

The alloy studied in this investigation had the following composition: Fe- 


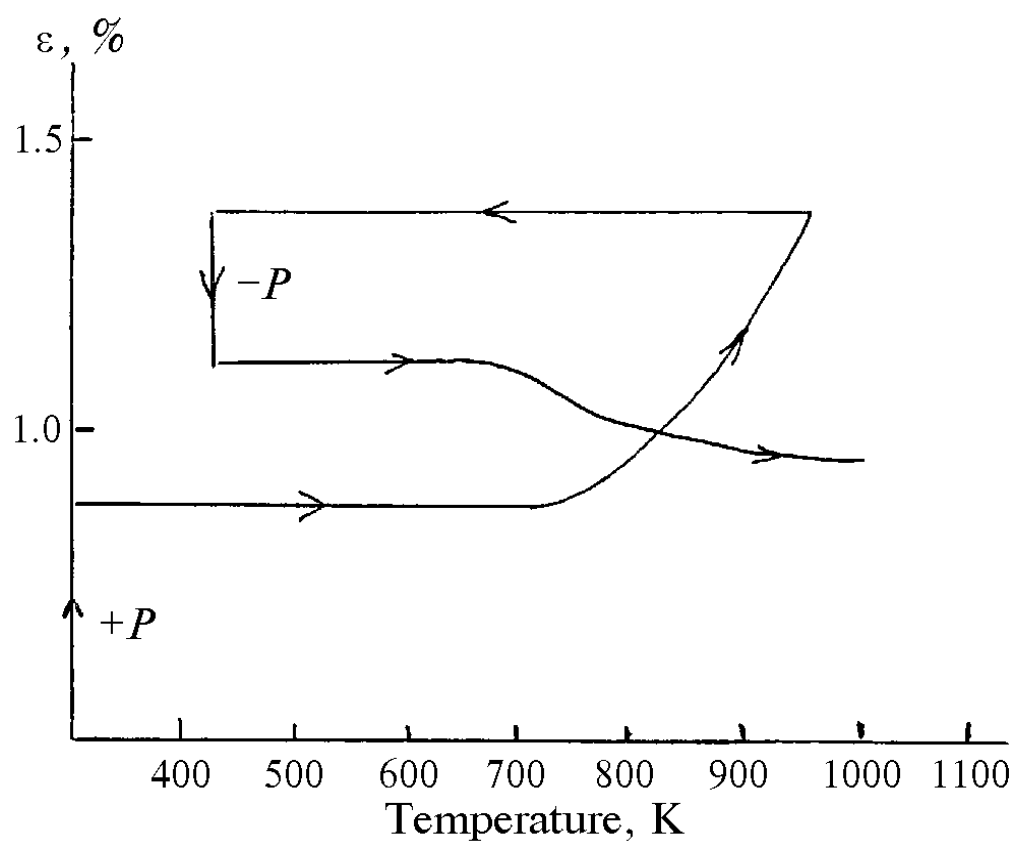

Figure 53. Shape memory effect in Fe-34.9 at.\% Ni-13.8 at.\% Co-4.4 at.\% $\mathrm{Ti}$ alloy after preliminary quenching from $1473 \mathrm{~K}\left(K_{\mathrm{SME}}=30-40 \%\right)$.

34.9 at.\% Ni-13.8 at.\% Co-4.4 at.\% Ti. The specimens quenched from $1473 \mathrm{~K}$ into water were tested using bending technique [22] in the temperature range $300-1100 \mathrm{~K}$ under the static load with the $1-2 \mathrm{~K} / \mathrm{sec}$ heating rate. After the loading at room temperature and heating the shape change was not observed up to $700 \mathrm{~K}$ (Fig. 53). The subsequent heating was accompanied by the bending of the specimens. Then, at $1000 \mathrm{~K}$ the specimens were quickly cooled (50-100 K/sec) and released from the static load. Repeated heating exhibited the shape recovery in the 700-900 K temperature range. The shape recovery ratio in this case was equal to $30-40 \%$. It was suggested that this effect caused by the precipitation processes of $\gamma^{\prime}$-phase $\left(\mathrm{Ni}_{3} \mathrm{Ti}\right)$ that takes place in the same temperature range.

Electron microscopic investigation of the quenched specimen subjected to the first heating under static load confirmed our suggestion (Fig. 54). In the bright (Fig. 54a) and dark fields (Fig. 54b) the fine particles (5 $\mathrm{nm}$ ) of the $\gamma^{\prime}$-phase preferentially formed on the dislocation nets are clearly seen.

The dislocations density in deformed specimens was higher than in quenched ones. So, it was concluded that the incomplete shape recovery (Fig. 53) was caused by plastic deformation processes. That is why we have studied the hardening of the matrix by means of $\gamma^{\prime}$-phase precipita- 


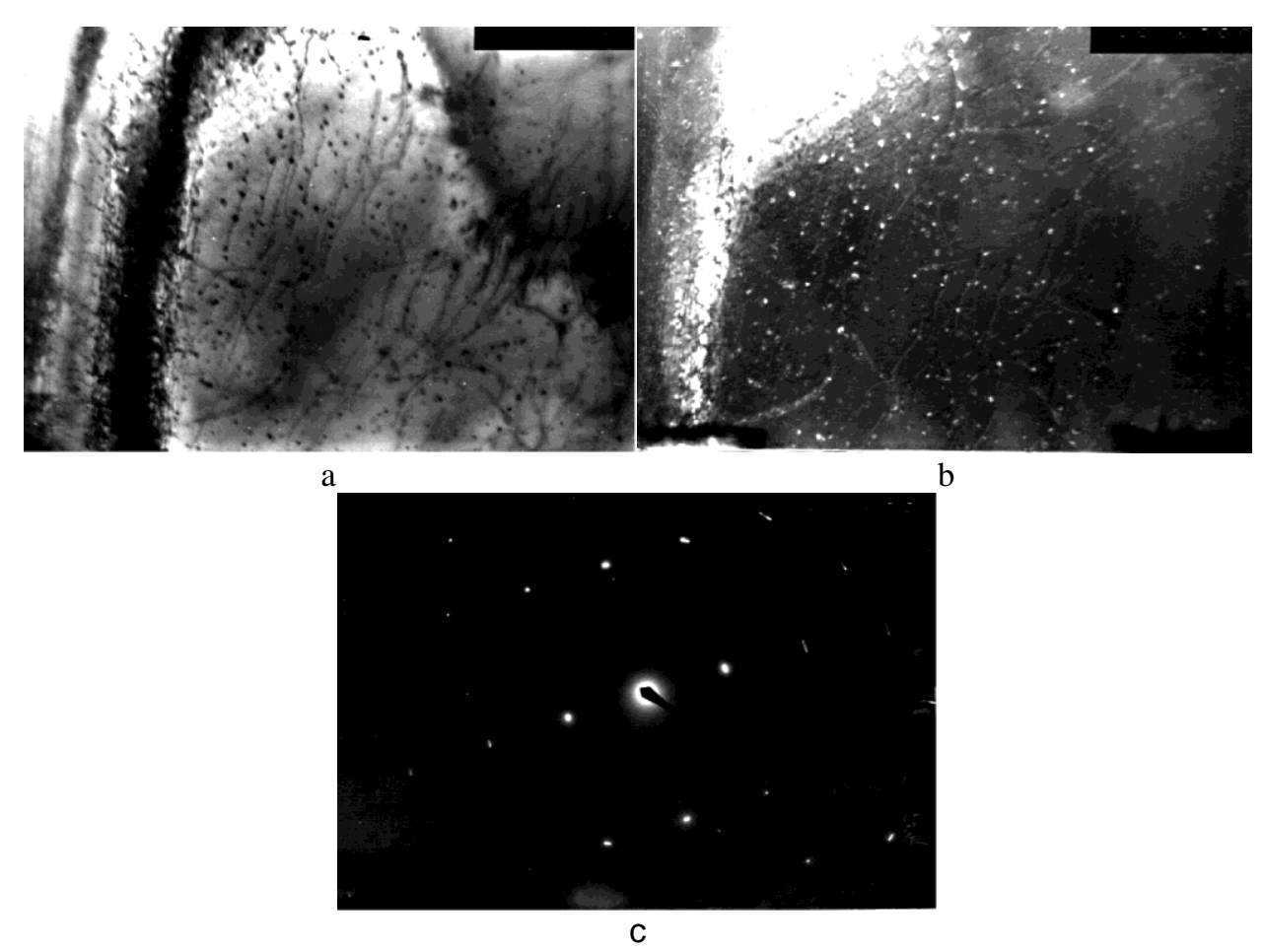

Figure 54. Structure of the Fe-34.9 at.\% Ni-13.8 at.\% Co-4.4 at.\% Ti alloy after preliminary quenching from $1473 \mathrm{~K}$ (elongated region of the specimen accumulated deformation during heating in bending): bright field (a), dark field taken in (001) superstructural reflection (b), diffraction pattern, zone axis [211] (c).

tion during ageing at $973 \mathrm{~K}$. The results of microhardness measurements are shown in Fig. 55. The significant increase of hardness is seen at the nucleation and growth stage. Then, hardness passes through a maximum at $400-500$ seconds of ageing and increases up to $\sim 1500 \mathrm{MPa}$ at $1 \mathrm{~h}$ of ageing. Such strengthening of the matrix is quite enough for suppressing of plastic deformation. Therefore, this time of ageing was chosen for the improving of the incomplete SME shown in Fig. 53.

The SME behaviour of the preliminary aged samples is shown in Fig. 56 . In this case the nearly complete shape recovery was found. The subsequent cycling did not change the shape recovery ratio but the temperature range of bending and shape recovery processes was shifted to higher temperatures.

Electron microscopic investigations of the preliminary aged samples after bending were performed on specimens cut from the both sides (elongated (Fig. 57) and compressed (Fig. 58)). The drastic difference in the dimensions of the particles can be seen. In elongated region the diameter of particles is $\sim 20 \mathrm{~nm}$ and in compressed $\sim 10 \mathrm{~nm}$. No visible at- 


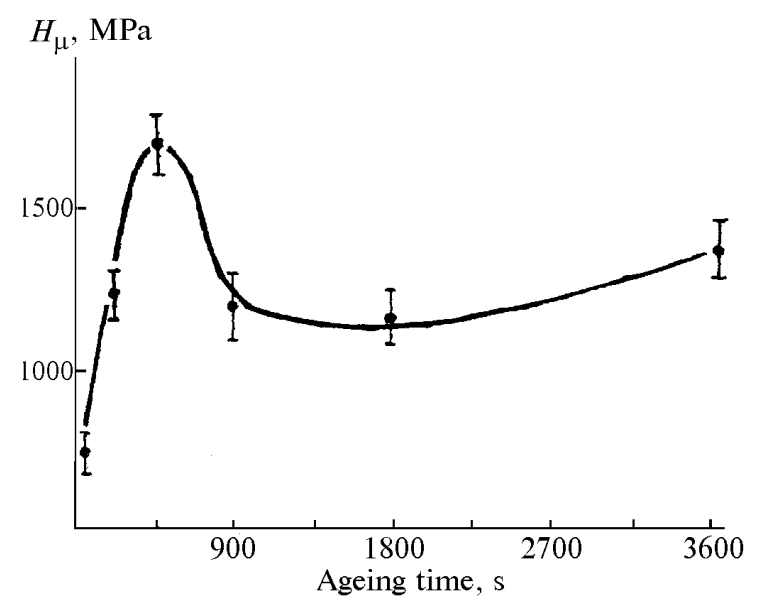

Figure 55. Microhardness changes vs ageing time at $973 \mathrm{~K}$ for $\mathrm{Fe}-34.9$ at. $\% \mathrm{Ni}-$ 13.8 at.\% Co-4.4 at.\% Ti alloy after preliminary quenching from $1473 \mathrm{~K}$.

tributes of plastic deformation processes can be seen. After the restoration of the original shape the size of the particles on both sides equalizes and becomes equal to $\sim 5 \mathrm{~nm}$ (Fig. 59).

It can thus be supposed that in the case of the non-martensitic SME in ausaged $\mathrm{Fe}-34.9$ at.\% Ni-13.8 at.\% Co-4.4 at.\% Ti alloy the difference in size of the spherical $\gamma^{\prime}$-phase particles on the different sides of the bent specimens is the origin of the high temperature deformation. Equalizing of

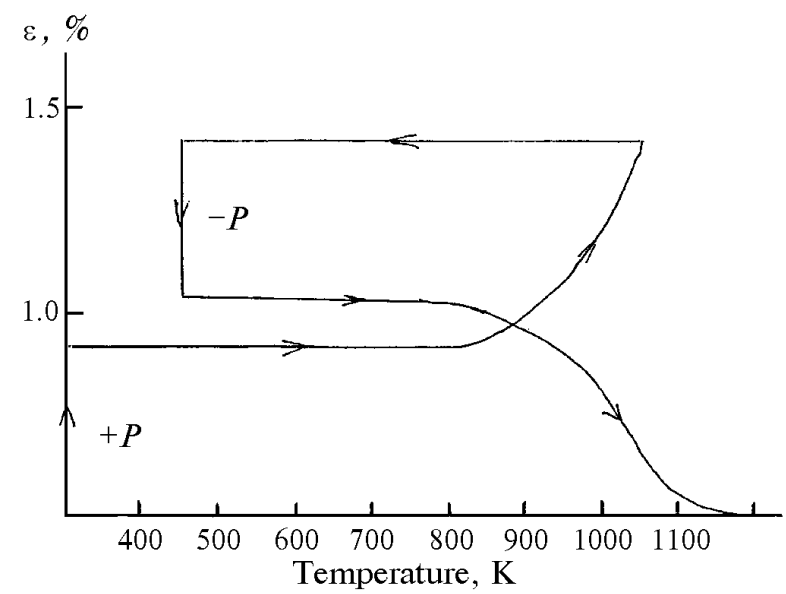

Figure 56. Shape memory effect in Fe-34.9 at.\% Ni-13.8 at.\% Co-4.4 at.\% Ti alloy after preliminary quenching from $1473 \mathrm{~K}$ and subsequent ageing at $973 \mathrm{~K}$ during $1 \mathrm{~h}\left(K_{\mathrm{SME}}=90-100 \%\right)$. 


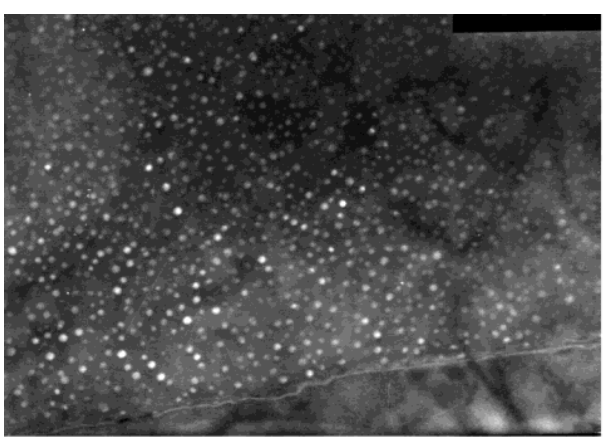

a

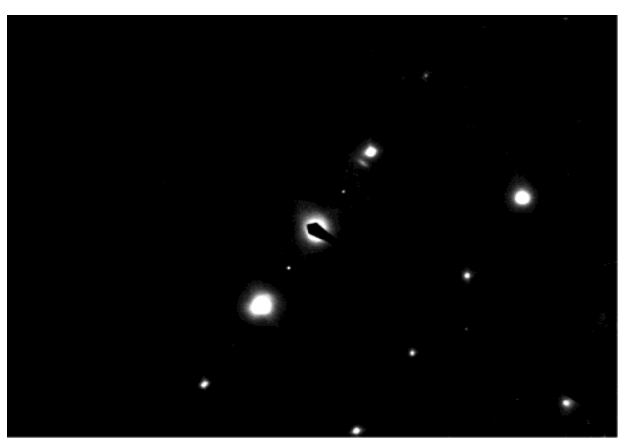

b

Figure 57. Structure of the Fe-34.9 at.\% Ni-13.8 at.\% Co-4.4 at.\% Ti alloy after preliminary quenching from $1473 \mathrm{~K}$ and subsequent ageing at $973 \mathrm{~K}$ during $1 \mathrm{~h}$ (elongated region of the specimen accumulated deformation during heating in bending): dark field taken in (001) superstructural reflection (a), diffraction pattern, zone axis [310] (b).

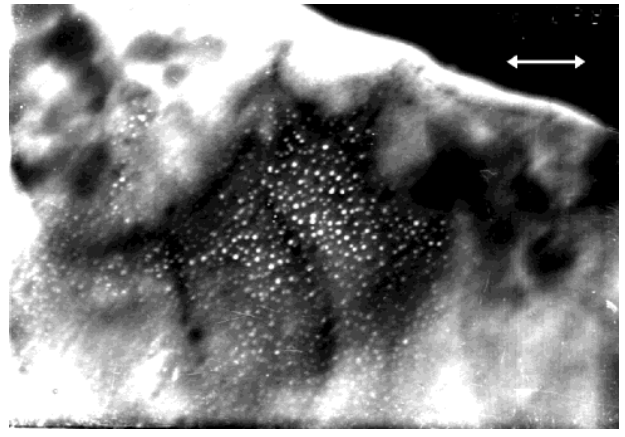

a

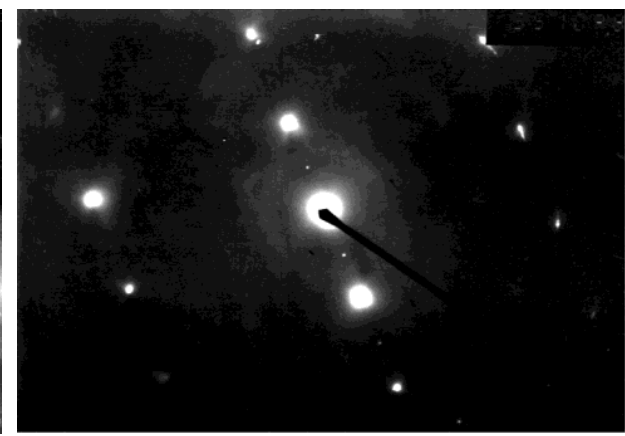

b

Figure 58. Structure of the Fe-34.9 at.\% Ni-13.8 at.\% Co-4.4 at.\% Ti alloy after preliminary quenching from $1473 \mathrm{~K}$ and subsequent ageing at $973 \mathrm{~K}$ during $1 \mathrm{~h}$ (compressed region of the specimen accumulated deformation during heating in bending): dark field taken in (001) superstructural reflection (a), diffraction pattern, zone axis [210] (b).

that sizes after the nearly complete shape recovery confirms this supposition and leads us to agree with the conclusions made in Ref. [55].

Really, in our case also the precipitation-dissolution processes of the second phase play the major role in the non-martensitic SME. As for the process of accumulation of the deformation, we can not completely agree with the authors of [55] because they exploit the plate-like shape of the particles in their model. In our case the particles are spherical but the result is the same. Anyway, it is too early to give the definite answer on the mechanism of this process. 


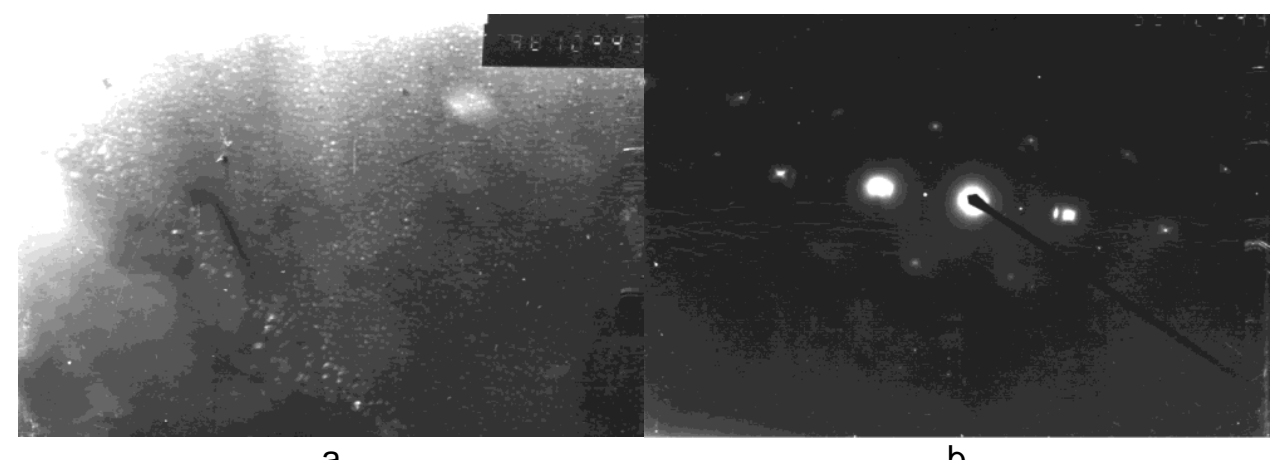

a

b

Figure 59. Structure of the Fe-34.9 at.\% Ni-13.8 at.\% Co-4.4 at.\% Ti alloy after preliminary quenching from $1473 \mathrm{~K}$ and subsequent ageing at $973 \mathrm{~K}$ during $1 \mathrm{~h}$ (after the shape recovery; both sides of the specimen have the same structural state): dark field taken in (001) superstructural reflection (a), diffraction pattern, zone axis [110] (b).

Additional quantitative measurements of the size, density and distribution of the particles in different constraint conditions will help us in better understanding of the mechanism of the non-martensitic SME.

Naturally, this effect is far from the industrial application now but the high temperatures of the precipitation for some materials still leave us the possibility to use it in one-way shape memory thermal sensitive elements when the other SMA are out of use.

\section{CONCLUSIONS}

High-temperature $B 2$ phase of $\mathrm{Zr}$-based equiatomic intermetallics transforms martensitically on cooling mostly into two monotonic martensites.

Interaction between the thin plates of these two types of martensite results in the in the wide temperature hysteresis, prolonged temperature intervals of forward and reverse MT's and large amount of energy dissipated during full cycle of $\mathrm{MT}$ in $\mathrm{Zr}$-based equiatomic intermetallics in contrast to materials undergoing MT of thermoelastic type. MT in $B 2 \mathrm{com}-$ pounds of $Z r$ is accompanied by the perfect SME even at high temperatures in spite of wide temperature hysteresis. Good shape memory properties, high oxidation resistance up to $800 \mathrm{~K}$ and comparative cheapness (excluding ZrRh and Zrlr) make the quasi-binary intermetallics of Zr competitive with existing SMA's in the possible high-temperature applications.

Non-martensitic SME driven by the precipitation-dissolution processes of second phase in constrained conditions is far from the industrial application now but the high temperatures of the precipitation for some materials still leave us the possibility to use it in one-way shape memory thermal sensitive elements when the other SMA's are out of use. 


\section{REFERENCES}

1. E. M. Carvalho and I. R. Harris, J. Less-Common Met., 106: 129 (1985).

2. Yu. N. Koval, G. S. Firstov, and A. V. Kotko, Scripta Met. Mat., 27: 1611 (1992).

3. V. V. Nemoshkalenko, A. V. Zhalko-Titarenko, Yu. N. Koval et al., Metallofiz. Noveishie Technol., 15, No. 1: 12 (1993) (in Russian).

4. F. E. Wang, J. Appl. Phys., 38: 822 (1967).

5. F. E. Wang and W. Ernst, J. Appl. Phys., 39: 2192 (1968).

6. I. R. Harris, D. Hossain, and K. G. Barraclough, Scripta Met., 4: 305 (1970).

7. D. Hossain, I. R. Harris, and K. G. Barraclough, J. Less-Common Met., 37: 35 (1974).

8. C. Lall, M. H. Loretto, and I. R. Harris, Acta Metall., 26: 1631 (1978).

9. E. M. Carvalho and I. R. Harris, J. Less-Common Met., 106: 117 (1985).

10. E. M. Carvalho and I. R. Harris, J. Less-Common Met., 106: 143 (1985).

11. E. M. Carvalho and I. R. Harris, J. Mat. Sci., 15: 1224 (1980).

12. I. Z. Jorda, T. Graf, and L. Schellenberg, J. Less-Common Met., 136, No. 1: 313 (1988).

13. E. L. Semenova and Yu. V. Kudryavtsev, J. Alloys and Compounds, 203: 165 (1994).

14. Yu. N. Koval, G. S. Firstov, L. Delaey, and J. Van Humbeeck, Scripta Met. et Mat., 31, No. 7: 799 (1994).

15. W. Y. Jang, J. Van Humbeeck, L. Delaey et al., 'The Influence of Ti and Ni Additions and Thermal Cycling on the Martensitic Transformation in CuZr Alloys' (Proc. of the Advanced Materials'93, B: Shape Memory Materials and Hydrides) (Eds. K. Otsuka et al.), Trans. Mat. Res. Soc. Jpn., 18B (Elsevier: 1994), p. 1009.

16. A. V. Zhalko-Titarenko, M. L. Yevlashina, V. N. Antonov et al., Phys. Stat. Sol. (b), 184: 121 (1994).

17. Yu. N. Koval and G. S. Firstov, 'Crystal Structure of the $\mathrm{ZrCu}$ Intermetallic Compound' (Proc. of XVIth Conference on Applied Crystallography) (Cieszyn, Poland, 22-26 August, 1994) (Eds. H. Morawiec and D. Stróz) (Singapore: World Scientific: 1995), p. 310.

18. W. Bührer, R. Gotthardt, A. Kulik et al., J. Phys. F: Met. Phys., 13: L77 (1983).

19. Y. Kudoh, M. Tokonami, S. Miyazaki, and K. Otsuka, Acta Metall., 33, No. 11: 2049 (1985).

20. R. M. Waterstrat, L. A. Bendersky, and R. Kuentzler, 'Deformation Twins and Martensite in Ductile B2 Alloys of the Zr(RuPd) System' (Proc. of the ICOMAT-92) (Monterey, USA, 20-24 July, 1992) (Ed. J. Perkins) (Monterey Institute for Advanced Studies: 1993), p. 545.

21. I. Groma, J. Lendvai, A. Cziráki et al., Scripta Met. et Mat., 26: 255 (1992).

22. V. V. Martynov and L. G. Khandros, Fiz. Met. Metalloved., 39, No. 5: 1037 (1975) (in Russian).

23. D. B. Wiles and R. A. Young, J. Appl. Cryst., 14: 149 (1981).

24. D. Schryvers, G. S. Firstov, J. W. Seo et al., Scripta Mat., 36: 1119 (1997).

25. K. Shimizu and K. Otsuka, Shape Memory Effects in Alloys (Ed. J. Perkins) (New York: Plenum Press: 1975), p. 59-83.

26. J. Ortin and A. Planes, Acta Metall., 36, No. 8: 1873 (1988).

27. A. Cornelis and C. M. Wayman, Scripta Met., 10: 359 (1976).

28. D. S. Lieberman, M. A. Schmerling, and R. S. Karz, Shape Memory Effects in A/loys (Ed. J. Perkins) (New York: Plenum Press: 1975), p. 203-226. 
29. B. Predel and W. Schwerman, Z. Naturforschg., 22a: 1499 (1967).

30. G. Airoldi, B. Rivolta, and C. Turco, 'Heats of Transformations as a Function of Thermal Cycling in NiTi Alloys' (Proc. of the ICOMAT-86) (Nara, Japan, 26-30 August, 1986) (Sendai: The Japan Institute of Metals: 1987), p. 691-696.

31. Y. C. Lo, S. K. Wu, and C. M. Wayman, Scripta Met. et Mat., 24: 1571 (1990).

32. Yu. N. Koval, G. S. Firstov, J. Van Humbeeck et al., 'B2 Intermetallic Compounds of Zr. New Class of the Shape Memory Alloys' (Proc. of the ICOMAT-95) (Lausanne,Switzerland, 20-25 August, 1995) (Eds. R. Gotthardt and J. Van Humbeeck), J. Physique IV, C8, 5 (Les Editions de Physique, 1995), p. 1103-1108.

33. G. V. Kurdjumov and L. G. Khandros, Dokl. Akad. Nauk SSSR, 66: 211 (1949) (in Russian).

34. G. S. Firstov, Yu. N. Koval, and J. Van Humbeeck (unpublished results).

35. R. A. Young and A. Sakthivel, Program DBWS-9006PC for Rietveld Analysis of XRay and Neutron Powder Diffraction Patterns (release of 1991).

36. R. J. Hill and C. J. Howard, J. Appl. Cryst., 20: 467 (1987).

37. G. S. Firstov, Yu. N. Koval, and J. Van Humbeeck, 'Irreversible Processes During Martensitic Transformation in Zr-Based Shape Memory Alloys' (Proc. of the ESOMAT'97) (Enschede, The Netherlands, 1-5 July, 1997) (Eds. J. Beyer, А. Вц ttger, and J. H. Mulder), J. Physique IV, C5, 7: 549 (1997).

38. G. S. Firstov, Yu. N. Koval, and J. Van Humbeeck, 'Shape Memory Behaviour in Quasi-Binary ZrCu-Based Intermetallic Compounds' (Proc. of the SMST'99) (Antwerp Zoo, Belgium, 5-9 September, 1999) (to be published).

39. G. Roebben, B. Bollen, A. Brebels et al., Rev. Sci. Instrum., 68: 4511 (1997).

40. A. S. Nowick and B. S. Berry, in Anelastic Relaxation in Crystalline Solids (New York: Academic Press: 1972).

41. D. B. Wiles and R. A. Young, J. Appl. Cryst., 14: 149 (1981).

42. J. W. Seo and D. Schryvers, Acta mater., 46, No. 4: 1165 (1998).

43. S. A. Shabalovskaya, Solid State Com., 70, No. 1: 23 (1989).

44. V. V. Kokorin, I. A. Osipenko, and T. V. Shirina, Fiz. Met. Metalloved., 67, No. 3 : 601 (1989) (in Russian).

45. S. A. Shabalovskaya, 'Factors Determining B2 Phase Stability in Ti-Based Compounds' (Proc. of the ICOMAT-92) (Monterey, USA, 20-24 July, 1992) (Eds. C. M. Wayman and J. Perkins) (Monterey Institute for Advanced Studies: 1993), p. 123.

46. A. M. Kostyshin and G. A. Takzey, 'Dynamic Magnetic Susceptibility of Spin Glasses' (Kiev: 1985) (Prepr./Academy of Sciences of the Ukr.SSR. Institute for Metal Physics. 4.85).

47. V. N. German, A. A. Bakanova, L. A. Tarasova, and Yu. N. Sumulov, Soviet Physics-Solid State (Translated from Fizika Tverdogo Tela), 12, No. 2: 490 (1970).

48. $\quad$ E. C. Stoner, Proc. R. Soc. London, Ser. A, 154: 656 (1936).

49. A. N. Das and B. Ghosh, J. Phys. C: Solid State Phys., 16: 1799 (1983).

50. S. Miyazaki, Y. Igo, and K. Otsuka, Acta Met., 34, No. 10: 2045 (1986).

51. Yu. N. Koval, A. P. Kozlov, and G. E. Monastyrski, Scripta Met., 23, No. 10: 1731 (1989).

52. T. Khan, G. F. Stohr, and H. Bibring, On Optimized DS Composite for Turbine Blades (Proc. of the Fourth International Symposium on Superalloys) (ASM: 1980), p. 531-540.

53. S. T. Kishkin, I. L. Svetlov, L. P. Sorokina et al., Fiz. Met. Metalloved., 55, No. 4: 754 (1983) (in Russian).

54. H. Bibring, T. Khan, M. Rabinovich, and G. F. Stohr, Development and Evaluation of New Industrial DS Monocarbide Reinforced Composites for Turbine Blades 
(Proc. of the Third International Symposium on Superalloys) (Seven Springs, Pennsylvania, USA: 1976), p. 331-345.

55. I. R. Bublei, Yu. N. Koval, and A. Yu. Pasko, Phys. Metals, 10, No. 5: 902 (1991).

56. L. G. Khandros and I. A. Arbuzova, Metally, Ehlektrony, Reshyotka (Metals, Electrons, and Lattice) (Kiev: Naukova Dumka: 1975), p. 109-143 (in Russian).

57. T. L. Dobrovol'skaya, P. V. Titov, and L. G. Khandros, Martensitic Transformation in Cu-Al-Mn Alloys After Partial Decomposition of the $\beta_{1}$ Phase (Proc. of the ICOMAT-77) (Kiev, USSR, 16-20 May, 1977) (Eds. V. N. Gridnev and L. G. Khandros); Martensitnyye Prevrashcheniya v Metallakh i Splavakh (Martensitic Transformations in Metals and Alloys) (Kiev: Naukova Dumka: 1979), p. 155-157 (in Russian).

58. M. Bouchard and G. Thomas, Acta Met., 23, No. 12: 1485 (1975).

59. A. Kelly and R. Nicholson, Dispersion Hardening (Moscow: Mir: 1968) (Russian translation).

60. R. Kainuma and M. Matsumoto, Scripta Met., 22: 475 (1988).

61. Yu. N. Koval, G. E. Monastyrski, and G. S. Firstov, Method of Fabrication of the Thermal Sensitive Element-Temperature Transducer (Inventor's Certificate of the USSR No. 1469901), Byulleten' Izobretenij i Otkrytij (Bulletin of the Inventions and Discoveries), No. 12, p. 244 (1989). 